\title{
Biodegradable Inorganic Upconversion Nanocrystals for In Vivo Applications
}

Pengfei Peng, ${ }^{\dagger,} \mathrm{Na} \mathrm{Wu},{ }^{\perp}$ Lixiang Ye, ${ }^{\#}$ Feilong Jiang, ${ }^{\dagger}$ Wei Feng, ${ }^{\perp}$ Fuyou Li, ${ }^{\perp}$ Yongsheng Liu, ${ }^{*},+, \neq$ and Maochun Hong ${ }^{*}, \dot{t}, \hat{t}$

${ }^{\dagger}$ State Key Laboratory of Structural Chemistry, Fujian Institute of Research on the Structure of Matter, Chinese Academy of Sciences, Fuzhou, Fujian 350002, China

${ }^{\perp}$ Department of Chemistry \& State Key Laboratory of Molecular Engineering of Polymers, Fudan University, Shanghai 200433, China

${ }^{\#}$ Fujian Center for Safety Evaluation of New Drug, Fujian Medical University, Fuzhou, Fujian 350122, China

tUniversity of the Chinese Academy of Sciences, Beijing, 100049, China

${ }^{\S}$ School of Physical Science and Technology, ShanghaiTech University, Shanghai 201210, China

\section{Contents}

$\begin{array}{ll}\text { I. Materials and Methods } & \text { S2 }\end{array}$

$\begin{array}{ll}\text { II. Figures S1-S30 S10 } & \text { S10 }\end{array}$

$\begin{array}{ll}\text { III. Tables S1-S6 } & \text { S40 }\end{array}$

$\begin{array}{ll}\text { IV. References } & \text { S44 }\end{array}$ 


\section{Materials and Methods}

Reagents. $\mathrm{KOH}(99.99 \%), \mathrm{NaOH}(96 \%)$ and $\mathrm{NH}_{4} \mathrm{~F}$ (98\%) were purchased from Aladdin (China). Zirconium (IV) acetylacetonate (97\%), $\mathrm{Yb}\left(\mathrm{CH}_{3} \mathrm{CO}_{2}\right)_{3} .4 \mathrm{H}_{2} \mathrm{O}(99.95 \%) \mathrm{Er}\left(\mathrm{CH}_{3} \mathrm{CO}_{2}\right)_{3} .4 \mathrm{H}_{2} \mathrm{O}(99.9 \%)$, $\mathrm{Y}\left(\mathrm{CH}_{3} \mathrm{CO}_{2}\right)_{3} .4 \mathrm{H}_{2} \mathrm{O}(99.99 \%), 1$-octadecene (90\%, ODE), oleic acid (90\%, OA) and peanut oil were purchased from Sigma-Aldrich. Tris-HCl buffer solution ( $\mathrm{pH} 8.8$ ), Hanks' Balanced Salt Solution (HBSS), Phosphate buffer solution (PBS), NaAc-HAc buffer solution (pH 5.2), and 0.9\% sodium chloride injection were purchased from Beyotime. Cyclohexane, methanol, and ethanol were purchased from Sinopharm Chemical Reagent Co., China. All chemicals were used as received without further purification.

Material Characterization. Powder X-ray diffraction (XRD) measurements were performed on a powder diffractometer (MiniFlex2, Rigaku) with a graphite-monochro-matized $\mathrm{CuK} \alpha$ radiation $\left(1.5419 \AA\right.$ ) from $10^{\circ}$ to $70^{\circ}$ at a scanning rate of $7^{\circ} \cdot \mathrm{min}^{-1}$. Infrared spectra were recorded on a Magna 750 Fourier transform infrared spectrometer (FT-IR). Both the transmission electron microscopy (TEM) and high-resolution TEM measurements were conducted on a transmission electron microscope (TEM, TECNAI G2F20) equipped with an energy dispersive X-ray spectroscope (EDS). Elemental analyses for the degradation products of lanthanide-doped $\mathrm{K}_{3} \mathrm{ZrF}_{7}$ and $\beta-\mathrm{NaYF}_{4}$ upconversion nanocrystals (UCNCs) both in vitro and in vivo were carried out by inductively coupled plasma mass spectrometry (ICP-MS, Thermo Scientific XSERIES 2) and inductively coupled plasma-optical emission spectrometry (ICP-OES, Thermo Scientific iCAP 7400). Upconversion luminescence (UCL) spectra were measured on a spectrometer equipped with both continuous (450 W) xenon, pulsed flash lamps and a 980-nn diode laser (FLS980, Edinburgh Instrument). UCL bioimaging images in nude mice were taken by Andor CCD camera with an external 0-3 W adjustable CW semiconductor laser at $980 \mathrm{~nm}$ (Shanghai Hi-Tech Optoelectronic Co., China). Red UCL digital photographs were taken with a Canon EOS 5D Mark IV camera without using any filter. Histopathological examinations of rats were performed by using tissue processor (Excelsior ES, Thermo Scientific), embedding workstation (HistoStar, Thermo Scientific), automatic microtome (Finese ME+, Thermo Scientific) and microscope (ECLIPSE 80i, Nikon).

General Procedure for the Synthesis of $\mathrm{K}_{3} \mathrm{ZrF}_{7}: \mathrm{Yb} / \mathrm{Er}(20 / 2 \mathrm{~mol} \%)$ UCNCs with an Average

Size of $13.8 \pm 1.2 \mathbf{~ n m}$. In brief, $0.39 \mathrm{mmol}$ of zirconium acetylacetonate, $0.1 \mathrm{mmol}$ of 
$\mathrm{Yb}\left(\mathrm{CH}_{3} \mathrm{CO}_{2}\right)_{3} \cdot 4 \mathrm{H}_{2} \mathrm{O}$ and $0.01 \mathrm{mmol}$ of $\mathrm{Er}\left(\mathrm{CH}_{3} \mathrm{CO}_{2}\right)_{3} \cdot 4 \mathrm{H}_{2} \mathrm{O}$ were mixed with $8.5 \mathrm{~mL}$ of $\mathrm{OA}$ and 17 $\mathrm{mL}$ of ODE in a $100-\mathrm{mL}$ three-neck round-bottom flask. The mixture solution was heated to $130{ }^{\circ} \mathrm{C}$ under $\mathrm{N}_{2}$ flow with constant stirring for $30 \mathrm{~min}$ to form a clear solution, and then cooled down to room temperature naturally. Thereafter, $9 \mathrm{~mL}$ of methanol solution containing $\mathrm{NH}_{4} \mathrm{~F}(3.5 \mathrm{mmol})$ and $3 \mathrm{~mL}$ of methanol solution containing $\mathrm{KOH}(3 \mathrm{mmol})$ was added in turn, and the resultant solution was stirred at $50{ }^{\circ} \mathrm{C}$ for $30 \mathrm{~min}$. After the methanol was evaporated, the solution was heated to $305^{\circ} \mathrm{C}$ under $\mathrm{N}_{2}$ flow with vigorous stirring for $40 \mathrm{~min}$, and then cooled down to room temperature. The resulting $\mathrm{K}_{3} \mathrm{ZrF}_{7}: \mathrm{Yb} / \mathrm{Er} \mathrm{NCs}$ were precipitated by addition of ethanol, collected by centrifugation at $8000 \mathrm{rpm}$ for $8 \mathrm{~min}$, washed with ethanol for one time, and finally re-dispersed in cyclohexane.

\section{General Procedure for the Synthesis of $\mathrm{K}_{3} \mathrm{ZrF}_{7}: \mathrm{Yb} / \mathrm{Er}(20 / 2 \mathrm{~mol} \%)$ UCNCs with an Average}

Size of $8.1 \pm 0.7 \mathbf{~ n m}$. In brief, $0.39 \mathrm{mmol}$ of zirconium acetylacetonate, $0.1 \mathrm{mmol}$ of $\mathrm{Yb}\left(\mathrm{CH}_{3} \mathrm{CO}_{2}\right)_{3} \cdot 4 \mathrm{H}_{2} \mathrm{O}$ and $0.01 \mathrm{mmol}$ of $\mathrm{Er}\left(\mathrm{CH}_{3} \mathrm{CO}_{2}\right)_{3} \cdot 4 \mathrm{H}_{2} \mathrm{O}$ were mixed with $8.5 \mathrm{~mL}$ of $\mathrm{OA}$ and 17 $\mathrm{mL}$ of ODE in a $100 \mathrm{~mL}$ three-neck round-bottom flask. The solution was heated to $130{ }^{\circ} \mathrm{C}$ under $\mathrm{N}_{2}$ flow with constant stirring for $30 \mathrm{~min}$ to form a clear solution, and then cooled down to room temperature. Thereafter, $9 \mathrm{~mL}$ of methanol solution containing $\mathrm{NH}_{4} \mathrm{~F}(3.5 \mathrm{mmol})$ and $6 \mathrm{~mL}$ of methanol solution containing $\mathrm{KOH}(6 \mathrm{mmol})$ was added in turn, and the resultant solution was stirred at $50{ }^{\circ} \mathrm{C}$ for $30 \mathrm{~min}$. After the methanol was evaporated, the solution was heated to $305^{\circ} \mathrm{C}$ under $\mathrm{N}_{2}$ flow with vigorous stirring for $40 \mathrm{~min}$, and then cooled down to room temperature naturally. The resulting $\mathrm{K}_{3} \mathrm{ZrF}_{7}$ : $\mathrm{Yb} / \mathrm{Er} \mathrm{NCs}$ were precipitated by addition of ethanol, collected by centrifugation at $8000 \mathrm{rpm}$ for $8 \mathrm{~min}$, washed with ethanol for one time, and finally re-dispersed in cyclohexane.

General Procedure for the Synthesis of $\beta$-NaYF 4 Yb/Er (20/2 mol\%) UCNCs. In a typical procedure of the synthesis of $\beta-\mathrm{NaYF}_{4}: \mathrm{Yb} / \mathrm{Er} \mathrm{UCNCs}, 0.39 \mathrm{mmol}$ of $\mathrm{Y}\left(\mathrm{CH}_{3} \mathrm{CO}_{2}\right)_{3} \cdot 4 \mathrm{H}_{2} \mathrm{O}, 0.1 \mathrm{mmol}$ of $\mathrm{Yb}\left(\mathrm{CH}_{3} \mathrm{CO}_{2}\right)_{3} \cdot 4 \mathrm{H}_{2} \mathrm{O}$ and $0.01 \mathrm{mmol}$ of $\mathrm{Er}\left(\mathrm{CH}_{3} \mathrm{CO}_{2}\right)_{3} \cdot 4 \mathrm{H}_{2} \mathrm{O}$ were mixed with $5 \mathrm{~mL}$ of $\mathrm{OA}$ and 16 $\mathrm{mL}$ of ODE in a $100 \mathrm{~mL}$ three-neck round-bottom flask. The solution was heated to $150{ }^{\circ} \mathrm{C}$ under $\mathrm{N}_{2}$ flow with constant stirring for $60 \mathrm{~min}$ to form a clear solution, and then cooled down to room temperature. Thereafter, $10 \mathrm{~mL}$ of methanol solution containing $1.25 \mathrm{mmol}$ of $\mathrm{NaOH}$ and $2 \mathrm{mmol}$ of $\mathrm{NH}_{4} \mathrm{~F}$ was added, and the resultant solution was stirred at $50{ }^{\circ} \mathrm{C}$ for $30 \mathrm{~min}$. After the methanol was evaporated, the solution was heated to $300^{\circ} \mathrm{C}$ under $\mathrm{N}_{2}$ flow with vigorous stirring for $60 \mathrm{~min}$, and then cooled down to room temperature. The resulting $\beta$-NaYF4:Yb/Er UCNCs were precipitated by 
addition of ethanol, collected by centrifugation, washed with ethanol for several times, and finally redispersed in cyclohexane.

Preparation of Ligand-Free $\boldsymbol{\beta}-\mathrm{NaYF}_{4}: \mathrm{Yb} / \mathbf{E r}$ UCNCs. The as-prepared OA-capped $\mathrm{NaYF}_{4}: \mathrm{Yb} / \mathrm{Er}$ UCNCs $(30 \mathrm{mg}$ ) were dispersed in $15 \mathrm{~mL}$ acidic ethanol solution (prepared by adding $112 \mu \mathrm{L}$ concentrated hydrochloric acid to $15 \mathrm{~mL}$ absolute ethanol) and ultrasonicated for $15 \mathrm{~min}$ to remove the surface ligands. After the reaction, the ligand-free $\mathrm{NaYF}_{4}: \mathrm{Yb} / \mathrm{Er} \mathrm{UCNCs}$ were collected via centrifugation at $14000 \mathrm{rpm}$ for $10 \mathrm{~min}$, and further purified by adding an acidic ethanol solution (pH 4). The resulting products were washed with ethanol and deionized water several times, and then redispersed in deionized water for the following use.

\section{Cell Culture and In Vitro Biotoxicity of the As-Synthesized $\mathrm{K}_{3} \mathrm{ZrF}_{7}: \mathrm{Yb} / \mathrm{Er}(20 / 2 \mathrm{~mol} \%) \mathrm{UCNCs}$.}

The in vitro biotoxicity of the as-synthesized $\mathrm{K}_{3} \mathrm{ZrF}_{7}: \mathrm{Yb} / \mathrm{Er}$ UCNCs was tested by using a standard methyl thiazolyl tetrazolium (MTT) assay on human embryonic lung fibroblasts (HELF) cells. In brief, HELF cells were seeded into a 96-well cell culture plate at $1 \times 10^{4} /$ well and cultured in DMEM medium with $10 \% \mathrm{FBS}$ and $1 \%$ penicillin-streptomycin $\left(37{ }^{\circ} \mathrm{C}, 5 \% \mathrm{CO}_{2}\right)$ for $24 \mathrm{~h}$. Thereafter, different concentrations of $\mathrm{K}_{3} \mathrm{ZrF}_{7}: \mathrm{Yb} / \mathrm{Er} \operatorname{UCNCs}(0,15.6,31.3,62.5,125,250$ and $500 \mu \mathrm{g} / \mathrm{mL}$, diluted in DMSO) with four parallel tests were added to the wells. After incubating with the UCNCs at $37{ }^{\circ} \mathrm{C}$ under $5 \% \mathrm{CO}_{2}$ for $24 \mathrm{~h}$, the MTT solution $(5 \mathrm{~mL}, 5 \mathrm{mg} / \mathrm{mL})$ was added to each well and the plate was incubated for an additional $4 \mathrm{~h}$ at $37^{\circ} \mathrm{C}$ under $5 \% \mathrm{CO}_{2}$. Following the addition of $10 \%$ SDS (50 $\mu \mathrm{L}$ per well), the assay plate was allowed to stand at room temperature for $12 \mathrm{~h}$. The optical density OD 570 value (Abs.) of each well, with background subtraction at $690 \mathrm{~nm}$, was measured on a multimodal microplate reader (Synergy 4, BioTek). The following formula was used to calculate the inhibition of cell growth: Cell viability $(\%)=($ mean of absorbance value of treatment groups/mean of absorbance value of controls) $\times 100 \%$.

Determining the Contents of the Liver Microsomal Proteins in the Livers of SPF Rats. Specific pathogen free (SPF) rats were chosen as the animal model to test the biochemical index of hepatic enzymes with and without intravenous injection of the dispersant of $\mathrm{K}_{3} \mathrm{ZrF}_{7}: \mathrm{Yb} / \mathrm{Er}(20 / 2 \mathrm{~mol} \%)$ UCNCs in sodium chloride injection $(0.9 \mathrm{wt} \%)$. Animal studies were approved by the Fujian Medical 
University of Ethical Committees on Experimental Animal Care and Use (No. 2019-0042) and were performed in accordance with institutional and national guidelines. The maximum dose method was used to investigate the toxicity of rat after intravenous injection. The negative control group (sodium chloride injection, $0.9 \mathrm{wt} \%, 0.5 \mathrm{~mL})$, the maximum dose group $\left(100 \mathrm{mg} \mathrm{kg}^{-1}\right)$, the middle dose group (50 $\left.\mathrm{mg} \mathrm{kg}^{-1}\right)$ and the low dose group $\left(10 \mathrm{mg} \mathrm{kg}^{-1}\right)$ were selected to investigate the relationship between the biochemical index of liver microsomal protein (hepatic enzymes) and dose after tail-vein injection for one time. Each group had ten rats containing 5 males and 5 females and were raised normally for 7 days. Hereafter, the injected SPF rats were sacrificed in a form of euthanasia with $\mathrm{CO}_{2}$, and the livers were removed immediately, perfused with cold $0.15 \mathrm{M} \mathrm{KCl}$ solution. Then, $0.1 \mathrm{~g}$ liver was weighed and homogenized in $0.9 \mathrm{~mL}$ of normal saline solution using a homogenizer. The homogenate was centrifuged, $1200 \times \mathrm{g}$ for $10 \mathrm{~min}$ at $4{ }^{\circ} \mathrm{C}$ in a refrigerated centrifuge. The liver microsomal proteins were collected by differential centrifugation as follows: (1) the supernatant $(0.5 \mathrm{~mL})$ of homogenate was centrifuged $300 \times \mathrm{g}$ for $30 \mathrm{~min}$ at $4{ }^{\circ} \mathrm{C}$ in a refrigerated centrifuge; (2) the supernatant $(0.4 \mathrm{~mL})$ of step 1 was centrifuged $700 \times \mathrm{g}$ for $30 \mathrm{~min}$ at $4{ }^{\circ} \mathrm{C}$; (3) the supernatant $(0.35 \mathrm{~mL})$ of step 2 was centrifuged $2200 \times \mathrm{g}$ for $30 \mathrm{~min}$ at $4{ }^{\circ} \mathrm{C}$; (4) the supernatant $(0.3 \mathrm{~mL})$ of step 3 was centrifuged $700 \times \mathrm{g}$ for $30 \mathrm{~min}$ at $4{ }^{\circ} \mathrm{C}$; (5) the supernatant $(0.2 \mathrm{~mL})$ of step 4 was centrifuged $1200 \times \mathrm{g}$ for $30 \mathrm{~min}$ at $4{ }^{\circ} \mathrm{C}$. The resulting sediment was the liver microsomal proteins (stored in refrigerator at $-80{ }^{\circ} \mathrm{C}$ ). The content of liver microsomal protein was determined by using a coomassie brilliant blue (G-250) kit. The principle was that under acidic conditions, the coomassie brilliant blue (G-250) combined with the protein to form a blue complex. The complex had a maximum absorption peak at $595 \mathrm{~nm}$, and its color was proportional to the protein concentration. The following formula was applied to calculate the content of the hepatic enzymes in the liver of SPF rat: Content of microsomal protein $(\mathrm{g} / \mathrm{L})=($ the optical density of sample - baseline value of optical density)/(standard values of optical density baseline value of optical density) * Dilution factor of the sample. 


\section{Supplementary Figures}

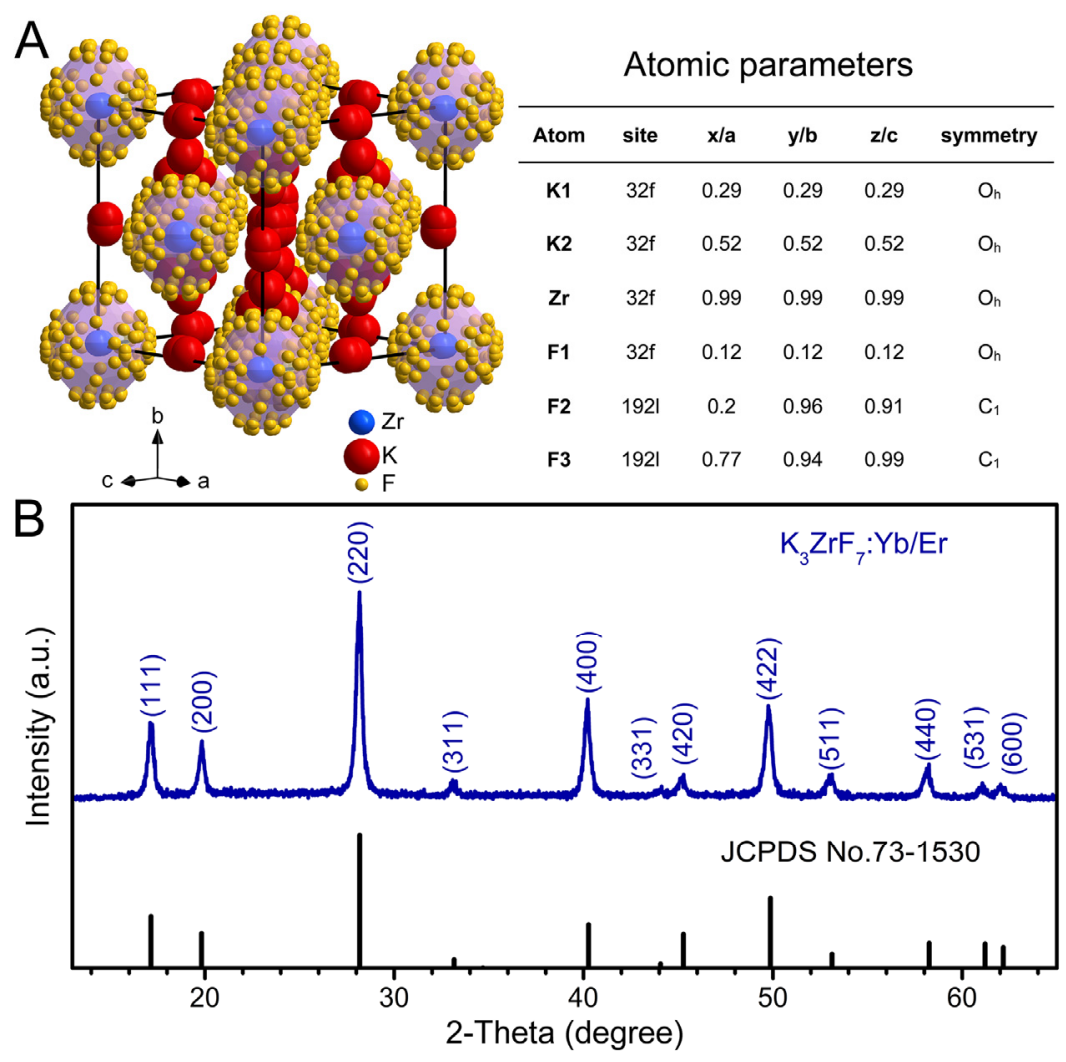

Figure S1. (A) Schematic presentation and crystallographic data of cubic-phase $\mathrm{K}_{3} \mathrm{ZrF}_{7}$ crystal structure. (B) XRD pattern for the as-synthesized $\mathrm{K}_{3} \mathrm{ZrF}_{7}: \mathrm{Yb} / \mathrm{Er}(20 / 2 \mathrm{~mol} \%)$ UCNCs, showing the formation of highly crystalline cubic-phase $\mathrm{K}_{3} \mathrm{ZrF}_{7}: \mathrm{Yb} / \mathrm{Er} \mathrm{UCNCs}$. Cubic-phase $\mathrm{K}_{3} \mathrm{ZrF}_{7}$ crystal has a face-centered cubic lattice with a space group of $F \mathrm{~m} \overline{3} \mathrm{~m}(\mathrm{a}=\mathrm{b}=\mathrm{c}=8.951 \AA, \mathrm{Z}=4){ }^{2-4}$ In cubic-phase $\mathrm{K}_{3} \mathrm{ZrF}_{7}$ crystal, each tetravalent zirconium $\left(\mathrm{Zr}^{4+}\right)$ is coordinated with seven $\mathrm{F}^{-}$anions occupying 104 dynamically equivalent positions, forming a distorted pentagonal-bipyramidal cluster of $\left[\mathrm{ZrF}_{7}\right]^{3-}$ with a high site-symmetry $\left(O_{\mathrm{h}}\right)$ of $\mathrm{Zr}^{4+}$ that can readily dissolve in water. As for the other water-soluble component of $\mathrm{K}^{+}$cation, it also occupies four dynamically equivalent positions with a $O_{\mathrm{h}}$ sitesymmetry in cubic-phase $\mathrm{K}_{3} \mathrm{ZrF}_{7}$ crystal. Benefiting from this dynamically "soft" host lattice containing water-soluble components of $\left[\mathrm{ZrF}_{7}\right]^{3-}$ cluster and $\mathrm{K}^{+}$cation, both the as-synthesized pure $\mathrm{K}_{3} \mathrm{ZrF}_{7}$ and $\mathrm{K}_{3} \mathrm{ZrF}_{7}: \mathrm{Yb} / \mathrm{Er}$ nanocrystals can degrade into systemically clearable products when exposed to water. Besides, similar to the cases of other inorganic fluorides such as hexagonal-phase $\mathrm{NaYF}_{4}$, cubic-phase $\mathrm{K}_{3} \mathrm{ZrF}_{7}$ crystal has also the intrinsic feature of low lattice phonon energies less than $500 \mathrm{~cm}^{-1} .5$ As a result, upon exciting by using a $980-\mathrm{nm}$ diode laser, intense red UCL of $\mathrm{Er}^{3+}$ can be generated after the substituted $\mathrm{Yb} / \mathrm{Er}$ doping into the high-symmetry crystal lattice of cubic-phase $\mathrm{K}_{3} \mathrm{ZrF}_{7}$ crystal as previously reported ${ }^{1}$. 

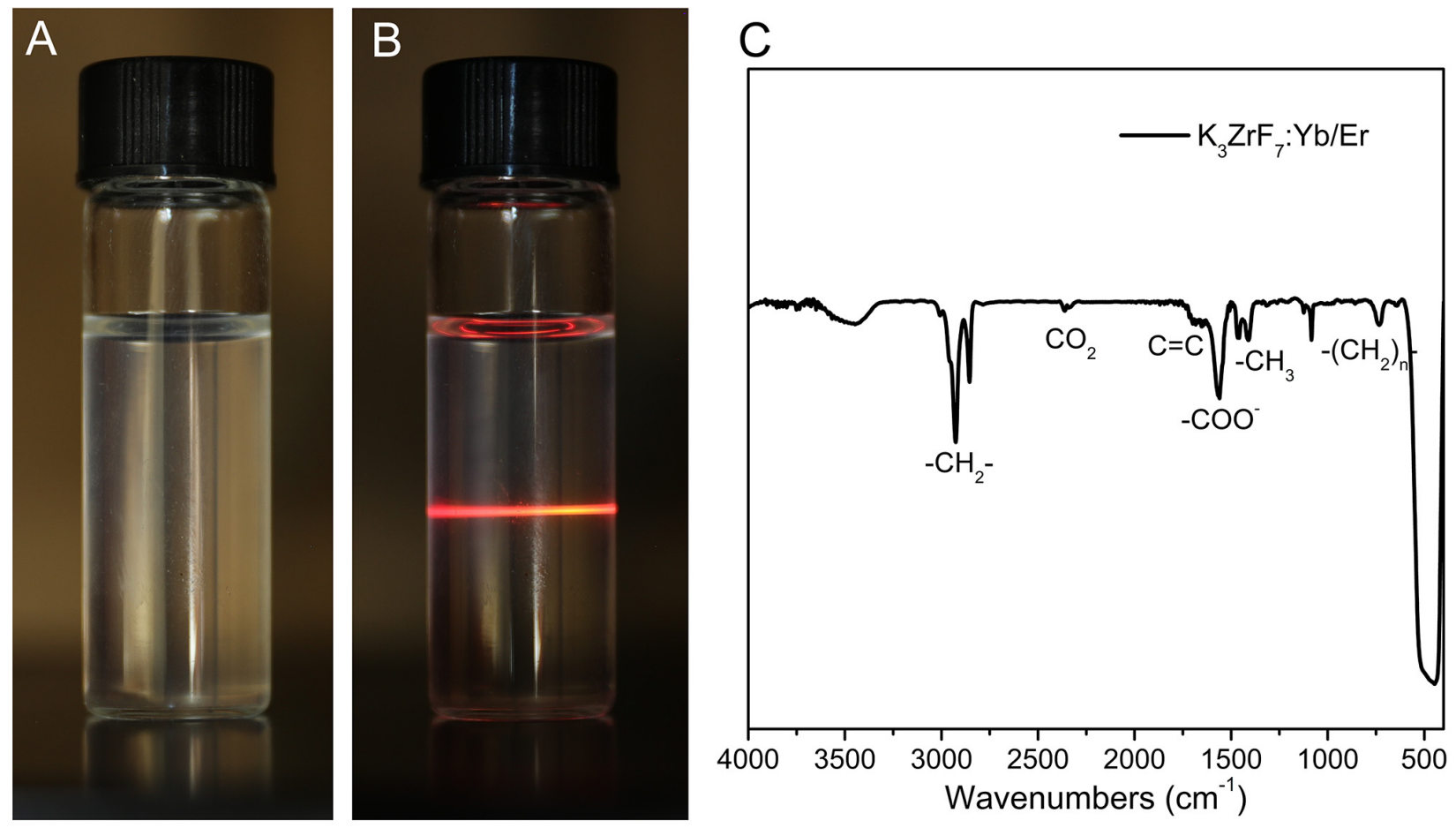

Figure S2. Photographs of the as-synthesized $\mathrm{K}_{3} \mathrm{ZrF}_{7}: \mathrm{Yb} / \mathrm{Er} \mathrm{UCNCs}$ when dispersed in cyclohexane taken (A) in daylight and (B) upon excitation with a 980-nm diode laser at a power density of $\sim 10 \mathrm{~W}$ $\mathrm{cm}^{-2}$, and $(\mathbf{C})$ the FT-IR spectrum for the as-synthesized OA-capped $\mathrm{K}_{3} \mathrm{ZrF}_{7}: \mathrm{Yb} / \mathrm{Er} \mathrm{UCNCs}$, showing the hydrophobic nature of them. All the as-synthesized $\mathrm{K}_{3} \mathrm{ZrF}_{7}: \mathrm{Yb} / \mathrm{Er} \mathrm{UCNCs}$ exhibit a hydrophobic nature owing to their surface-capped OA ligands, as evidenced by their corresponding FT-IR spectrum (Figure S2, C), where all the FT-IR peaks can be easily assigned to the typical vibrational peaks of OA, and thus can be readily dispersed in nonpolar organic solvents such as cyclohexane (Figure S2, A-B), as previously reported literature regrading lanthanide-doped inorganic UCNCs based on different host matrix..$^{6-7}$ 

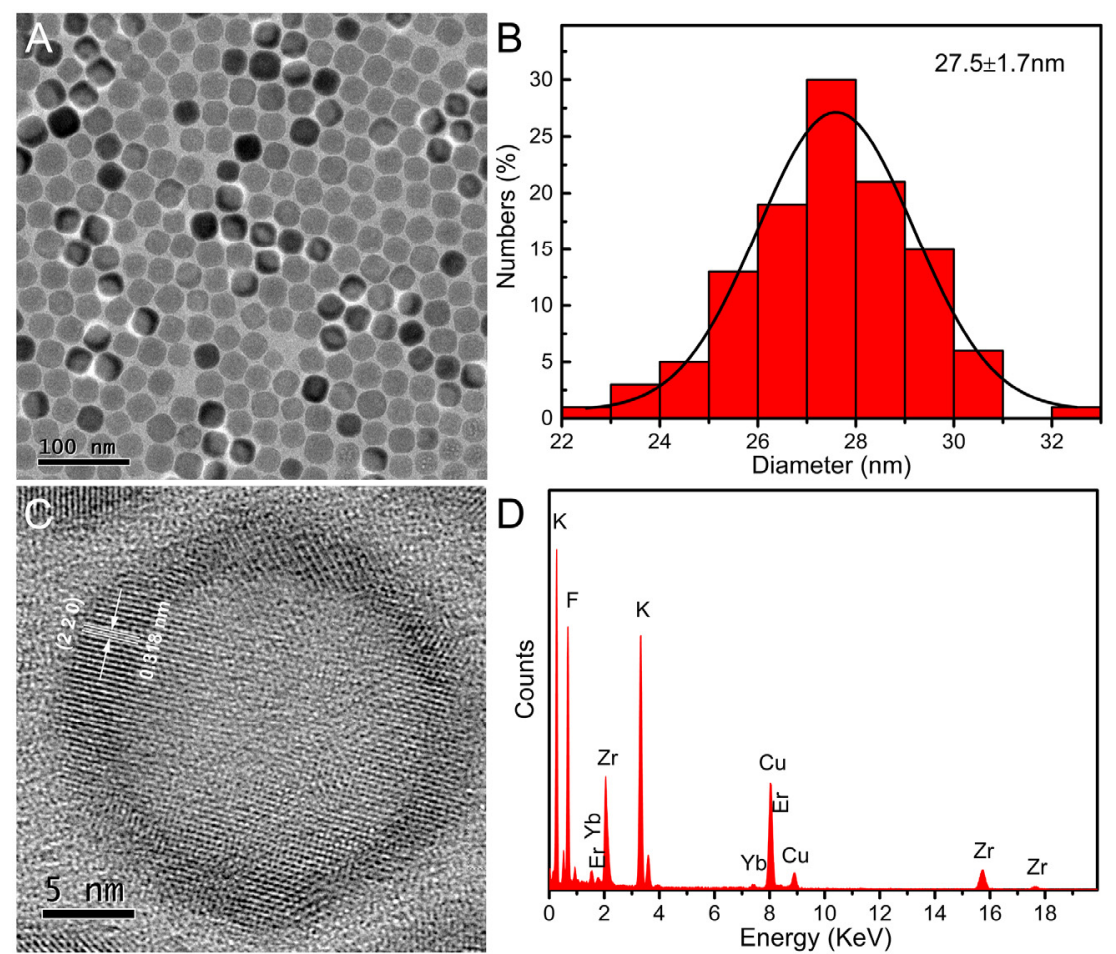

Figure S3. (A) Representative TEM image for the as-synthesized $\mathrm{K}_{3} \mathrm{ZrF}_{7}: \mathrm{Yb} / \mathrm{Er} \mathrm{UCNCs}$, and (B) their corresponding size distribution obtained from TEM images of 300 UCNCs. (C) High-resolution TEM image of a randomly selected $\mathrm{K}_{3} \mathrm{ZrF}_{7}: \mathrm{Yb} / \mathrm{Er} \mathrm{UCNC}$, showing the high crystallinity for the assynthesized $\mathrm{K}_{3} \mathrm{ZrF}_{7}: \mathrm{Yb} / \mathrm{Er} \mathrm{UCNCs}$ we prepared. (D) EDS pattern for some randomly selected UCNCs, confirming the presence of all expected elements including K, Zr, F, Yb, and Er. All the as-synthesized $\mathrm{K}_{3} \mathrm{ZrF}_{7}: \mathrm{Yb} / \mathrm{Er} \mathrm{UCNCs}$ were first investigated by using TEM to characterize their morphology and size distribution. As indicated in Figure S3, A-B, the as-synthesized $\mathrm{K}_{3} \mathrm{ZrF}_{7}: \mathrm{Yb} / \mathrm{Er}$ UCNCs are approximately spherical with a mean diameter of $27.5 \pm 1.7 \mathrm{~nm}$. Their corresponding high-resolution TEM image shows clear lattice fringes with a d-spacing of $0.318 \mathrm{~nm}$ (Figure S3, C), in agreement with the lattice spacing of the (220) plane of cubic-phase $\mathrm{K}_{3} \mathrm{ZrF}_{7}$ crystal (JCPDS, No. 73-1530), and thus demonstrating the formation of highly crystalline $\mathrm{K}_{3} \mathrm{ZrF}_{7}: \mathrm{Yb} / \mathrm{Er} \mathrm{UCNCs}$. The EDS spectrum, collected over a large illumination area covering some UCNCs, confirms the presence of all expected elements of K, Zr, F, Yb and $\mathrm{Er}$ in the as-synthesized $\mathrm{K}_{3} \mathrm{ZrF}_{7}: \mathrm{Yb} / \mathrm{Er} \mathrm{UCNCs}$ (Figure S3, D), and thus turns out that the $\mathrm{Yb}$ and $\mathrm{Er}$ ions can be successfully doped into the host matrix of $\mathrm{K}_{3} \mathrm{ZrF}_{7}: \mathrm{Yb} / \mathrm{Er}$ UCNCs, regardless of their discrepancy in the valence state and ionic radius $\left(0.84 \AA\right.$ for $\mathrm{Zr}^{4+}, 0.99 \AA$ for $\mathrm{Yb}^{3+}$ and $1.00 \AA$ for $\mathrm{Er}^{3+}$ with a coordination number of eight). ${ }^{1}$ Most likely, the $\mathrm{Yb}^{3+}$ or $\mathrm{Er}^{3+}$ ion should occupy a substituted $\mathrm{Zr}^{4+}$ site in the lattice of cubic-phase $\mathrm{K}_{3} \mathrm{ZrF}_{7}$ matrix, as we previously observed in cubic-phase $\mathrm{Na}_{3} \mathrm{ZrF}_{7}: \mathrm{Yb} / \mathrm{Er}$ UCNCs. ${ }^{1}$ 

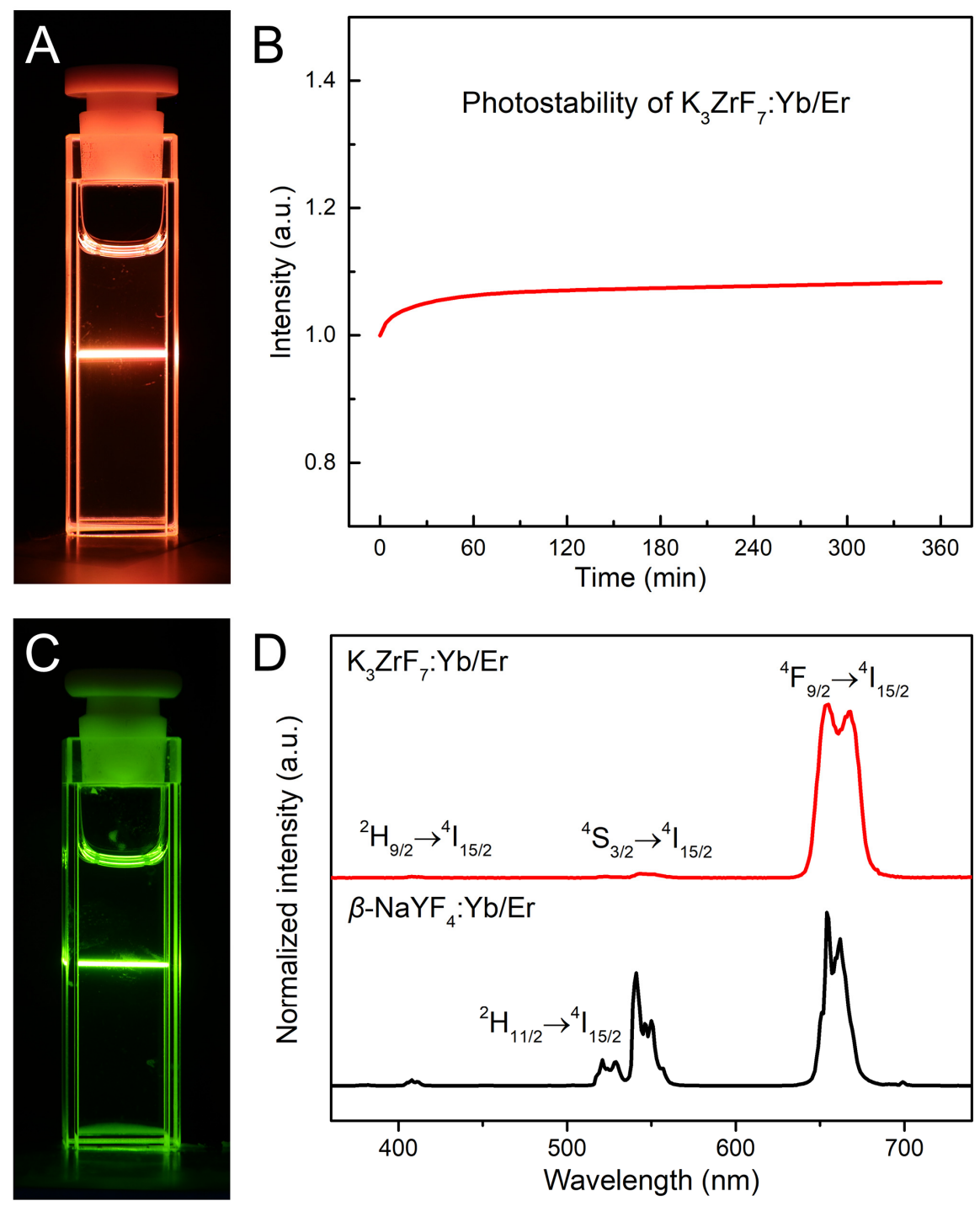

Figure S4. (A) Red UCL photograph of the as-synthesized $\mathrm{K}_{3} \mathrm{ZrF}_{7}: \mathrm{Yb} / \mathrm{Er}(20 / 2 \mathrm{~mol} \%)$ UCNCs in cyclohexane (CYH) upon 980-nm NIR diode laser excitation, and (B) their corresponding integrated red UCL intensity as a function of time upon continuous 980-nm NIR diode laser excitation at a power density of $\sim 100 \mathrm{~W} \mathrm{~cm}^{-2}$, demonstrating their excellent photostability over time. (C) Olive UCL photograph for $\mathrm{Yb}^{3+} / \mathrm{Er}^{3+}(20 / 2 \mathrm{~mol} \%)$-doped $\beta$-NaYF 4 UCNCs and their corresponding UCL spectrum in CYH solution (0.5 wt\%) upon 980-nm NIR diode laser excitation, showing their comparable red and green emission bands. As shown in Figure S4, B, the overall UCL intensity for the as-synthesized $\mathrm{K}_{3} \mathrm{ZrF}_{7}: \mathrm{Yb} / \mathrm{Er}$ UCNCs were observed to rise first and then remain almost unchanged when excited at the power density as high as $\sim 100 \mathrm{~W} \mathrm{~cm}^{-2}$, which strongly supports that the as-synthesized $\mathrm{K}_{3} \mathrm{ZrF}_{7}: \mathrm{Yb} / \mathrm{Er}$ UCNCs have good photostability when excited by using a 980-nm diode laser. Besides, owing to the high-symmetry crystal lattice of $\mathrm{K}_{3} \mathrm{ZrF}_{7}$ host matrix for $\mathrm{Yb}^{3+} / \mathrm{Er}^{3+}$ doping, the whole UCL spectrum is dominated by a bright-red emission centered at $\sim 656 \mathrm{~nm}$ 
alongside of two negligible emission bands peaking in the blue $(\sim 408 \mathrm{~nm})$ and green $(\sim 543 \mathrm{~nm})$ spectral regions, in stark contrast to the typical olive UCL observed from the $\mathrm{Yb}^{3+} / \mathrm{Er}^{3+}(20 / 2 \mathrm{~mol} \%)$ doped $\beta$-NaYF 4 UCNCs (Figure S4, D) or previously reported $\mathrm{K}_{3} \mathrm{ZrF}_{7}: \mathrm{Yb} / \mathrm{Er} \mathrm{UCNCs}^{8}$ with comparable red and green emission bands. Based on our research experiences, we can reason that the comparable red and green emission bands of $\mathrm{Er}^{3+}$ from the previously reported $\mathrm{K}_{3} \mathrm{ZrF}_{7}: \mathrm{Yb} / \mathrm{Er} \mathrm{UCNCs}$ are primarily originated from the $\mathrm{Er}^{3+}$ ions located at the surfaces of $\mathrm{K}_{3} \mathrm{ZrF}_{7}: \mathrm{Yb} / \mathrm{Er} \mathrm{UCNCs}$.

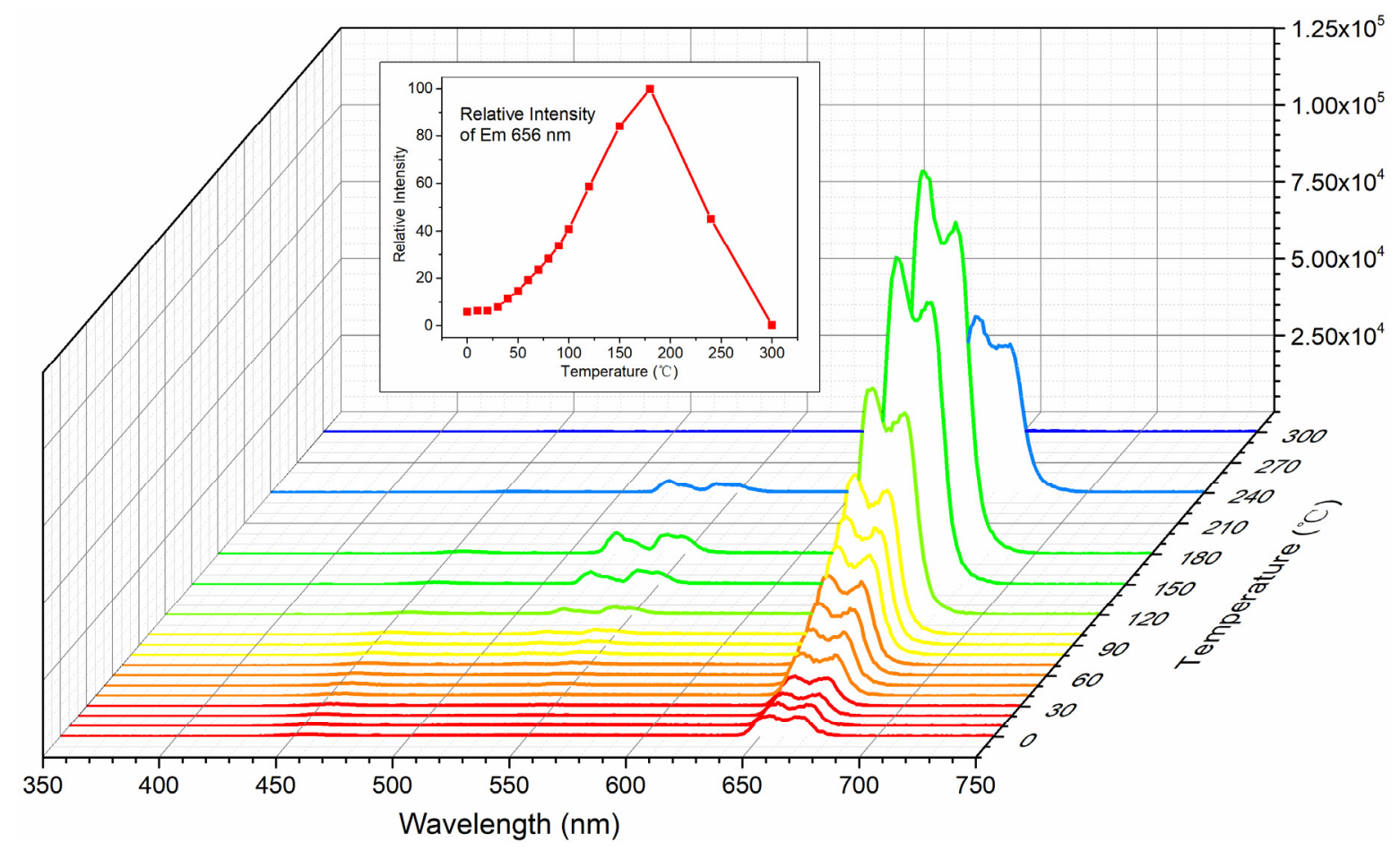

Figure S5. Temperature-dependent UCL spectra for the as-synthesized $\mathrm{K}_{3} \mathrm{ZrF}_{7}: \mathrm{Yb} / \mathrm{Er} \mathrm{UCNCs}$ in the form of solid state upon NIR 980-nm diode laser excitation, and the inset shows the intensity ratio for the red UCL brightness of the as-synthesized $\mathrm{K}_{3} \mathrm{ZrF}_{7}: \mathrm{Yb} / \mathrm{Er} \mathrm{UCNCs}$ at indicated temperature versus that measured at $0{ }^{\circ} \mathrm{C}$. As shown in Figure S5, the overall intensity for the red UCL of $\mathrm{Er}^{3+}$ in the as-synthesized $\mathrm{K}_{3} \mathrm{ZrF}_{7}: \mathrm{Yb} / \mathrm{Er} \mathrm{UCNCs}$ was detected to gradually increase with temperature from 0 to $180{ }^{\circ} \mathrm{C}$, which clearly demonstrates that the as-synthesized $\mathrm{K}_{3} \mathrm{ZrF}_{7}: \mathrm{Yb} / \mathrm{Er}$ UCNCs are thermally stable below $180{ }^{\circ} \mathrm{C}$ for diverse in vivo applications. Besides, we noted that the drastically decrease in the red UCL intensity above $180{ }^{\circ} \mathrm{C}$ was associated with the burning of oleic acids capped on the surfaces of the as-synthesized $\mathrm{K}_{3} \mathrm{ZrF}_{7}: \mathrm{Yb} / \mathrm{Er} \mathrm{UCNCs}$. 


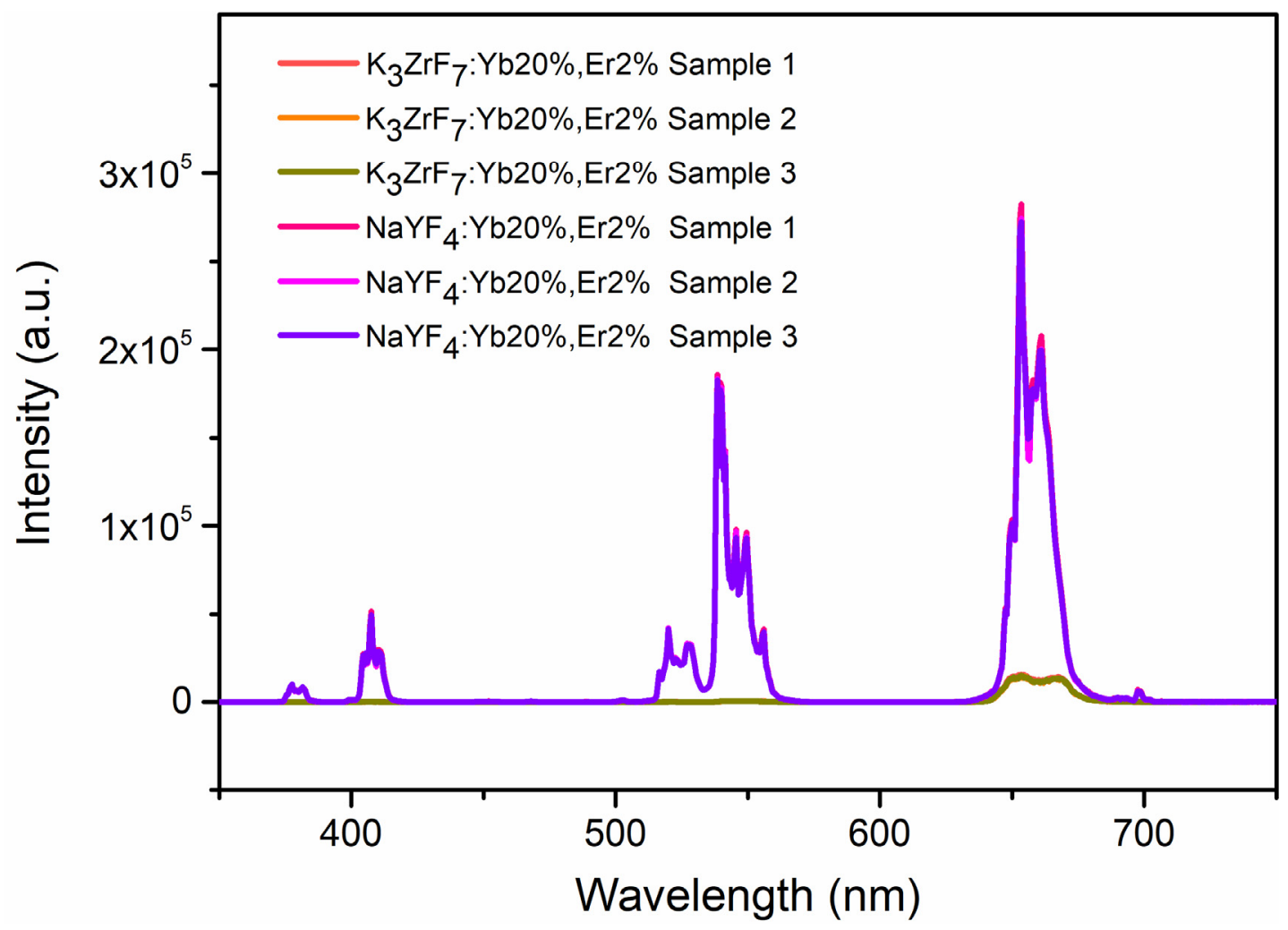

Figure S6. Comparison of UCL spectra for the as-synthesized $\mathrm{K}_{3} \mathrm{ZrF}_{7}: \mathrm{Yb} / \mathrm{Er}$ and $\beta$-NaYF $4: \mathrm{Yb} / \mathrm{Er}$ UCNCs with a nearly identical nanocrystal size of $\sim 28 \mathrm{~nm}$. All the UCL spectra were measured under otherwise identical experimental conditions upon a 980-nm diode laser excitation with a power density of $\sim 10 \mathrm{~W} \mathrm{~cm}^{-2}$. The integrated UCL intensities for all the as-synthesized $\mathrm{K}_{3} \mathrm{ZrF}_{7}: \mathrm{Yb} / \mathrm{Er}$ UCNCs (three parallel samples) were determined to be about one fifteenth of that of their $\beta$ $\mathrm{NaYF}_{4}: \mathrm{Yb} / \mathrm{Er}$ counterparts. The much weaker UCL brightness for the red-emitting $\mathrm{K}_{3} \mathrm{ZrF}_{7}: \mathrm{Yb} / \mathrm{Er}$ UCNCs relative to their $\beta$-NaYF4:Yb/Er counterparts was primarily owing to the high symmetry of cubic lattice of $\mathrm{K}_{3} \mathrm{ZrF}_{7}$ for $\mathrm{Yb} / \mathrm{Er}$ doping, which, in most cases, represents a low radiative probability of intra- $4 f$ transitions of lanthanide ion than in low site symmetry and thus low luminescence efficiency of upconversion. 


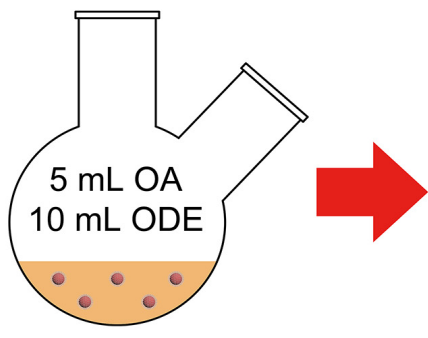

$6 \mathrm{~K}: 1 \mathrm{Zr}: 7 \mathrm{~F}$
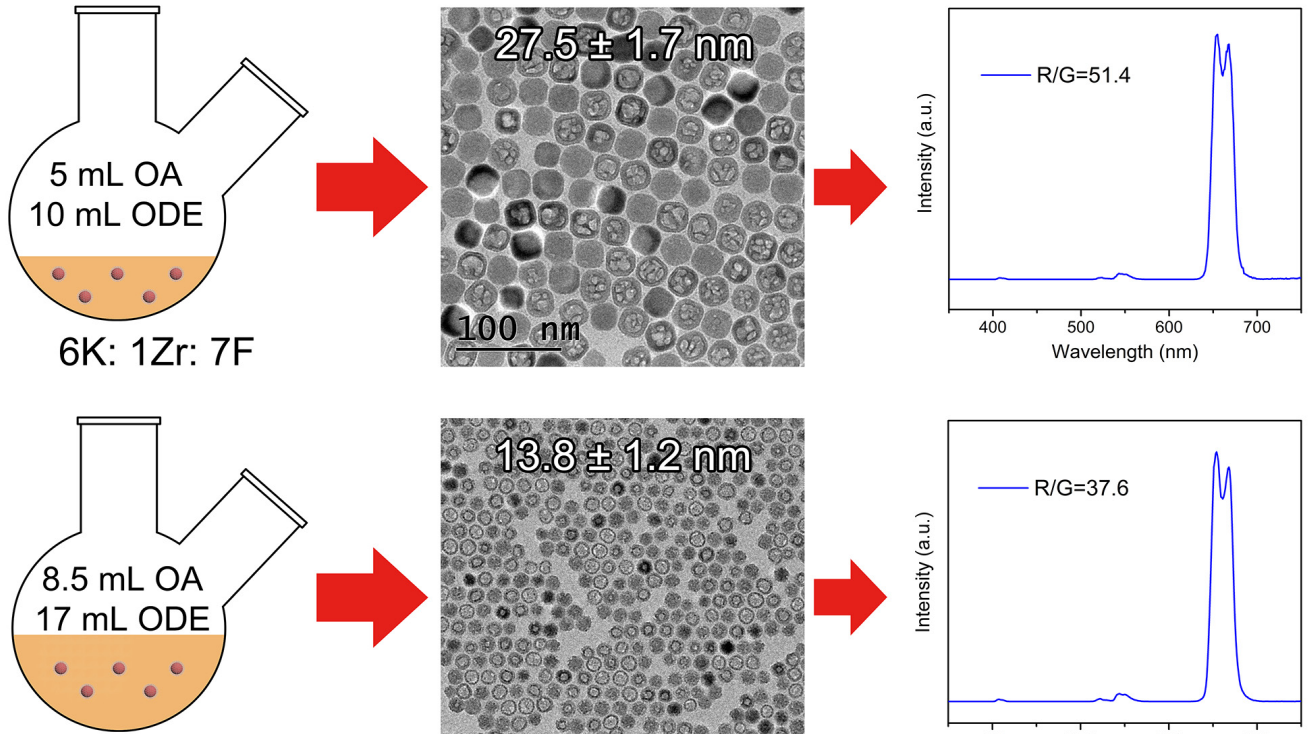

6K: 1Zr: 7F
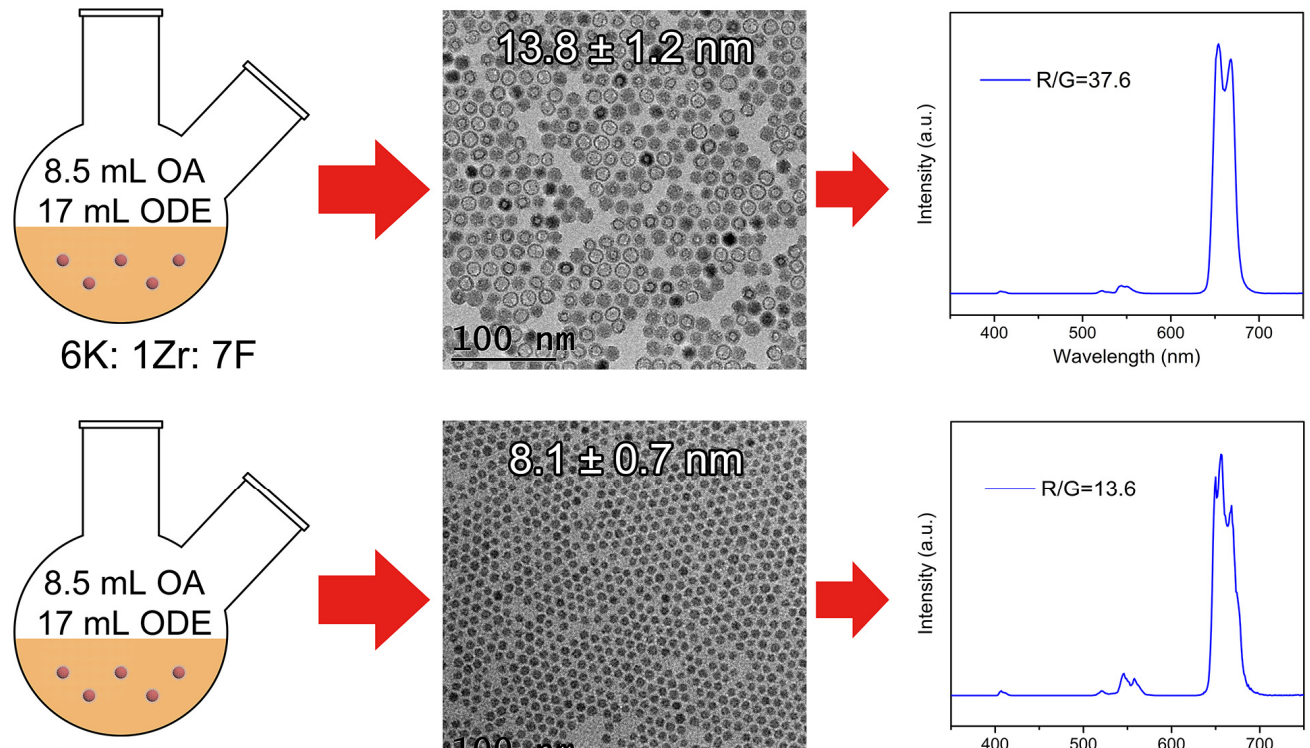

12K: $1 \mathrm{Zr}: 7 \mathrm{~F}$
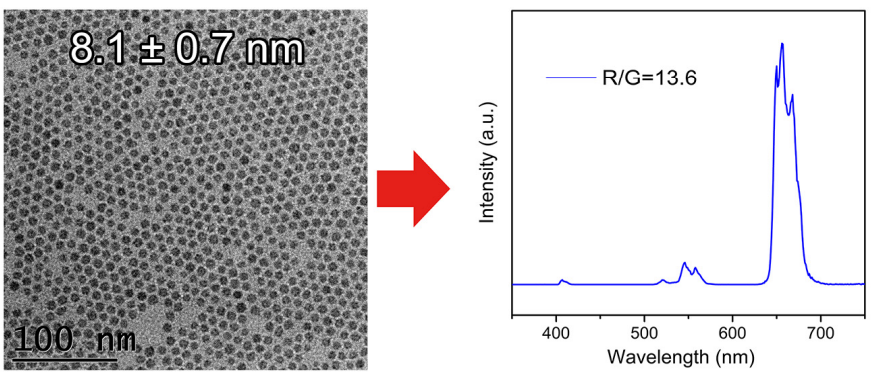

Figure S7. Schematic illustration showing the high red-to-green $(R / G)$ UCL intensity ratio for the assynthesized $\mathrm{K}_{3} \mathrm{ZrF}_{7}: \mathrm{Yb} / \mathrm{Er} \mathrm{UCNCs}$ as a function of nanocrystal size. Noted that the $\mathrm{K}_{3} \mathrm{ZrF}_{7}: \mathrm{Yb} / \mathrm{Er}$ UCNCs with different nanocrystal sizes were synthesized by changing the experimental variables including the volume ratio of $\mathrm{OA}$ and $\mathrm{ODE}$, and the molar ratio of $\mathrm{Zr}, \mathrm{K}$ and $\mathrm{F}$ precursors. All the UCL spectra were measured under identical experimental conditions upon a 980-nm diode laser excitation with a power density of $10 \mathrm{~W} \mathrm{~cm}^{-2}$. It can be seen clearly that the UCL spectra for the assynthesized $\mathrm{K}_{3} \mathrm{ZrF}_{7}: \mathrm{Yb} / \mathrm{Er} \mathrm{UCNCs}$ with different nanocrystal sizes are characterized by a dominant red emission band centered at $\sim 656 \mathrm{~nm}$ associated with the ${ }^{4} \mathrm{~F}_{9 / 2} \rightarrow{ }^{4} \mathrm{I}_{15 / 2}$ transition of $\mathrm{Er}^{3+}$, and their corresponding UCL R/G intensity ratios for the UCNCs with a varied nanocrystal sizes of $27.5 \pm 1.7$, $13.8 \pm 1.2$ and $8.1 \pm 0.7 \mathrm{~nm}$ were determined to be $51.4,37.6$ and 13.6 , respectively. These results unambiguously demonstrate the remarkable red UCL performance for the as-synthesized $\mathrm{K}_{3} \mathrm{ZrF}_{7}: \mathrm{Yb} / \mathrm{Er} \mathrm{UCNCs}$ irrespective of their varied nanocrystal sizes. 


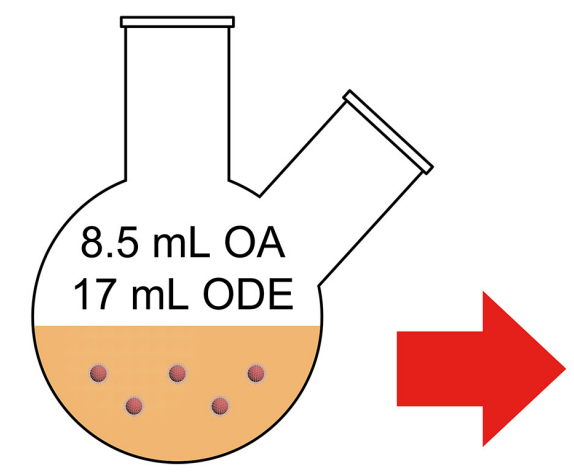

6K: 1(Zr\&RE): 7F

$\mathrm{RE}=\mathrm{Ybx} \% \mathrm{Er} 2 \%$

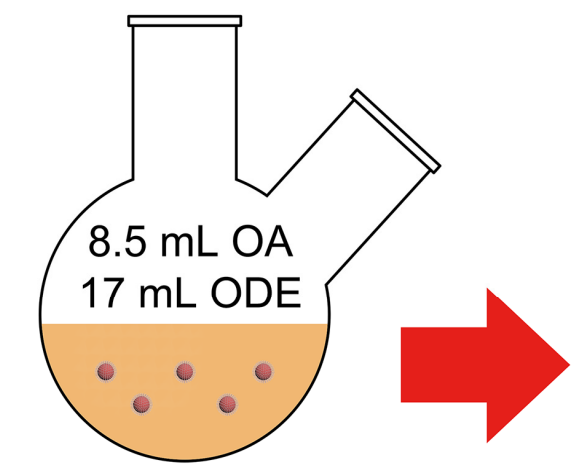

6K: 1(Zr\&RE): 7F

$\mathrm{RE}=\mathrm{Yb} 20 \% \mathrm{Erx} \%$
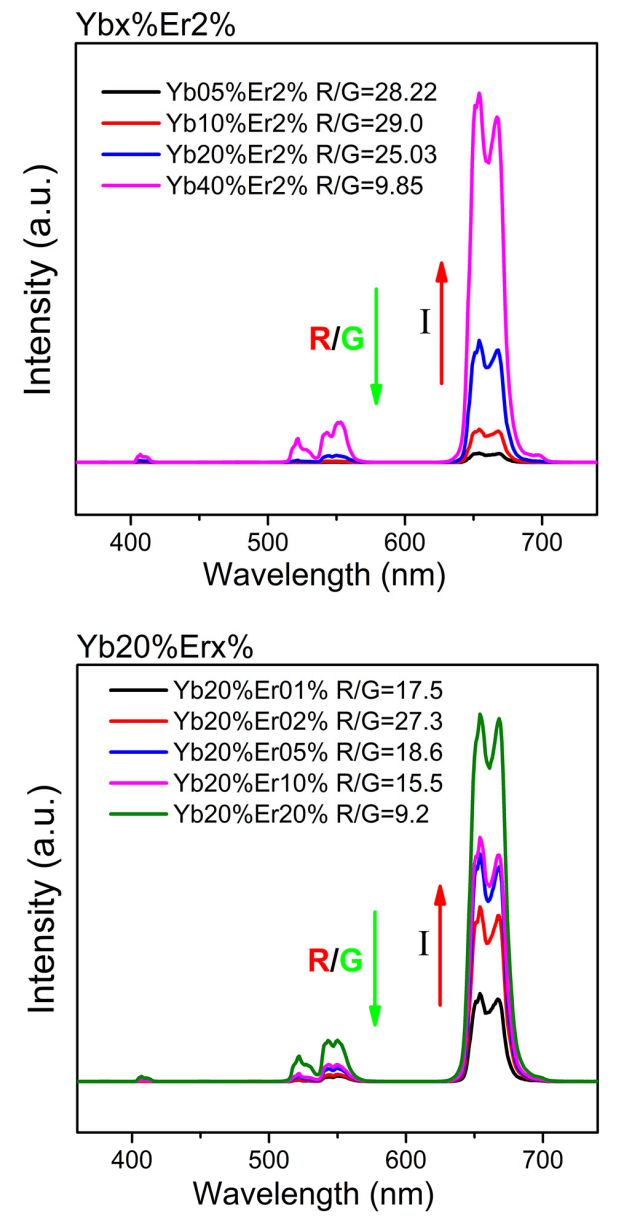

Figure S8. Comparison of UCL spectra for a series of $\mathrm{K}_{3} \mathrm{ZrF} 7: \mathrm{Yb} / \mathrm{Er} \mathrm{UCNCs}$ as a function of different $\mathrm{Yb}$ and Er doping contents. All the UCL spectra were measured under identical experimental conditions upon a 980-nm diode laser excitation with a power density of $10 \mathrm{~W} \mathrm{~cm}^{-2}$. As shown in Figure S8, the UCL R/G intensity ratios for all the $\mathrm{K}_{3} \mathrm{ZrF} 7: \mathrm{Yb} / \mathrm{Er}$ UCNCs were calculate to be higher than 9.2, further confirming the excellent red UCL performance of $\mathrm{K}_{3} \mathrm{ZrF} 7: \mathrm{Yb} / \mathrm{Er}$ UCNCs we prepared, irrespective of the different doping contents of $\mathrm{Yb}$ and Er ions. 

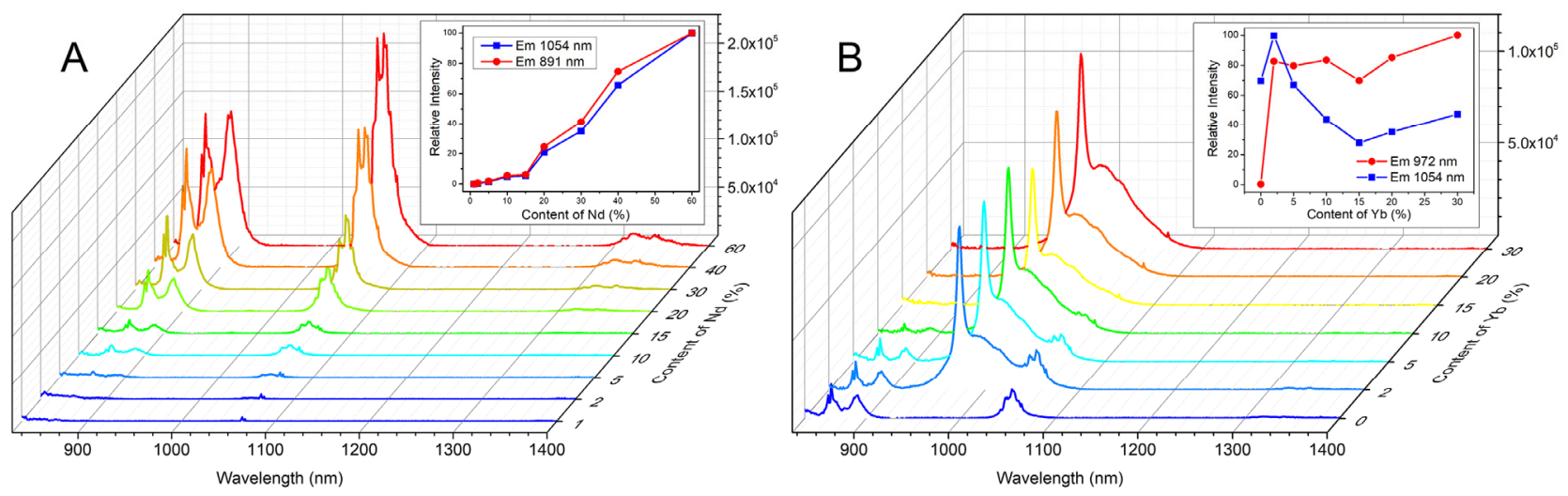

Figure S9. Room temperature NIR luminescence for (A) $\mathrm{Nd}^{3+}$ doped and (B) $\mathrm{Nd}^{3+} / \mathrm{Yb}^{3+}$ co-doped $\mathrm{K}_{3} \mathrm{ZrF}_{7}: \mathrm{Yb} / \mathrm{Er}$ nanocrystals as a function of $\mathrm{Nd}^{3+}$ and $\mathrm{Nd}^{3+} / \mathrm{Yb}^{3+}$ doping contents under 808 -nm laser excitation. As shown in Figure S9, desirable NIR luminescence ranging from 850 to $1100 \mathrm{~nm}$ can be readily realized in $\mathrm{Nd}^{3+}$ doped and $\mathrm{Nd}^{3+} / \mathrm{Yb}^{3+}$ co-doped $\mathrm{K}_{3} \mathrm{ZrF}_{7}: \mathrm{Yb} / \mathrm{Er}$ nanocrystals upon 808-nm excitation after changing the $\mathrm{Yb}^{3+} / \mathrm{Er}^{3+}$ dopants to $\mathrm{Yb}^{3+} / \mathrm{Nd}^{3+}$, showing that the $\mathrm{Nd}^{3+}$ doped and $\mathrm{Nd}^{3+} / \mathrm{Yb}^{3+}$ co-doped $\mathrm{K}_{3} \mathrm{ZrF}_{7}$ nanocrystals we prepared hold great promise for the in vivo fluorescence imaging in the NIR spectral region. 


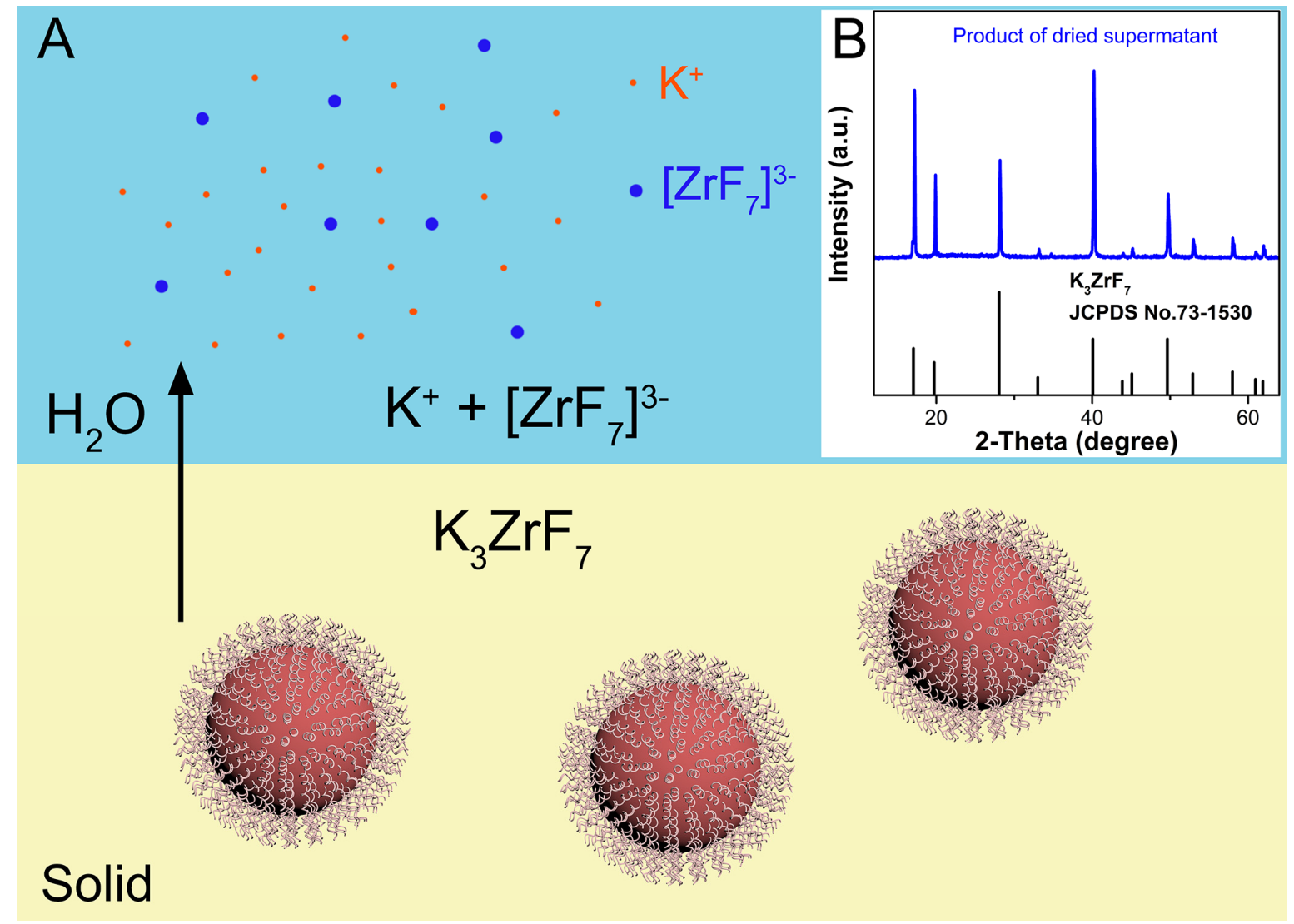

Figure S10. (A) Schematic diagram depicting the water degradation process for the pure OA-capped $\mathrm{K}_{3} \mathrm{ZrF}_{7}$ nanocrystals when directly immersed into water. (B) XRD pattern for the dried supernatant after water degradation of pure $\mathrm{OA}$-capped $\mathrm{K}_{3} \mathrm{ZrF}_{7}$ nanocrystals, revealing the formation of aqueous solution of $\left[\mathrm{ZrF}_{7}\right]^{3-}$ cluster (and/or its hydrated derivatives) and $\mathrm{K}^{+}$cation after degradation. As indicated in Figure S10, A, pure water ( $\mathrm{pH}$ 7) can trigger the dissolving of water-soluble component (i.e., $\left[\mathrm{ZrF}_{7}\right]^{3-}$ cluster) from the host matrix of pure cubic-phase $\mathrm{K}_{3} \mathrm{ZrF}_{7}$ nanocrystals, forming weakly acidic aqueous solution of $\left[\mathrm{ZrF}_{7}\right]^{3-}$ cluster (and/or its hydrated derivatives) and $\mathrm{K}^{+}$cation $(\mathrm{pH} \sim 5.7$, Supplementary Table S2). This can be well-established by their corresponding XRD pattern for the dried supernatant after water degradation of the pure OA-capped $\mathrm{K}_{3} \mathrm{ZrF}_{7}$ nanocrystals, where all the XRD peaks are well consistent with cubic-phase $\mathrm{K}_{3} \mathrm{ZrF}_{7}$ crystal (JCPDs, No. 73-1530) (Figure S10, B). 


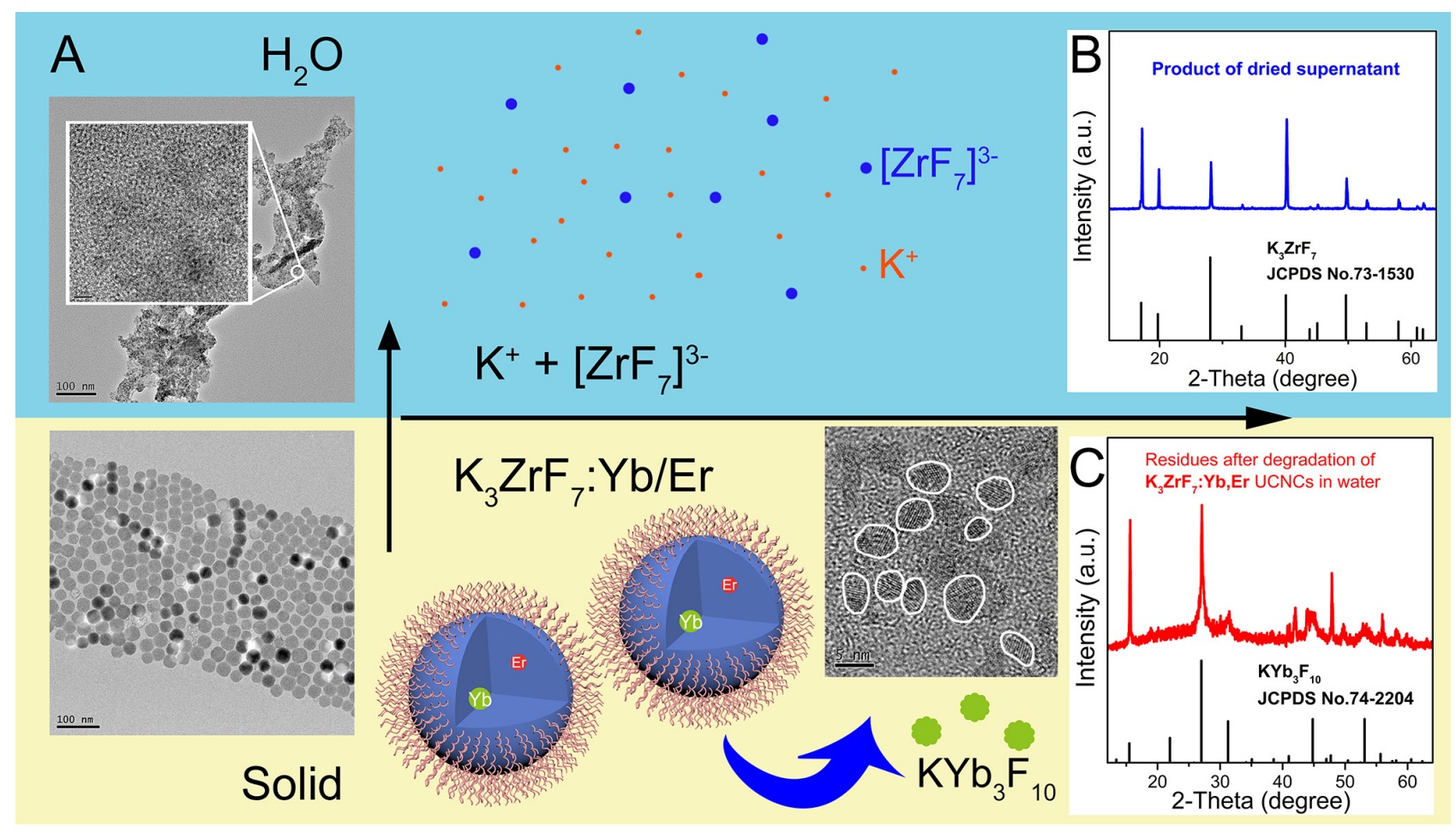

Figure S11. (A) Schematic diagram showing the water degradation process for the as-synthesized $\mathrm{K}_{3} \mathrm{ZrF}_{7}: \mathrm{Yb} / \mathrm{Er} \mathrm{UCNCs}$ when directly immersed into water. The insets of (A) exhibit the TEM images before and after water degradation for the as-synthesized $\mathrm{K}_{3} \mathrm{ZrF}_{7}: \mathrm{Yb} / \mathrm{Er} \mathrm{UCNCs}$, (B-C) XRD patterns for the dried supernatant and solid residues after water degradation of the as-synthesized $\mathrm{K}_{3} \mathrm{ZrF}_{7}: \mathrm{Yb} / \mathrm{Er} \mathrm{UCNCs}$. During the degradation process as indicated in Figure S11, A, pure water (pH 7) can trigger the dissolving of water-soluble component (i.e., $\left[\mathrm{ZrF}_{7}\right]^{3-}$ cluster) from the host matrix of pure cubic-phase $\mathrm{K}_{3} \mathrm{ZrF}_{7}$ nanocrystals, forming weakly acidic aqueous solution of [ $\left.\mathrm{ZrF}_{7}\right]^{3-}$ cluster (and/or its hydrated derivatives) and $\mathrm{K}^{+}$cation ( $\mathrm{pH} \sim 5.6$, Supplementary Table S2), as clearly evidenced by the XRD pattern for the dried supernatant showing that all XRD peaks can be well indexed in accordance with cubic-phase $\mathrm{K}_{3} \mathrm{ZrF}_{7}$ crystal (JCPDs, No. 73-1530) (Figure S11, B). Meanwhile, the XRD pattern for the solid residues after water degradation of $\mathrm{K}_{3} \mathrm{ZrF}_{7}: \mathrm{Yb} / \mathrm{Er} \mathrm{UCNCs}$ is determined to be consistent with $\mathrm{KYb}_{3} \mathrm{~F}_{10}$ (JCPDS, No. 74-2204) (Figure S11, C). Taken together, these results unambiguously provide solid evidences to turn out that the as-synthesized $\mathrm{K}_{3} \mathrm{ZrF}_{7}: \mathrm{Yb} / \mathrm{Er}$ UCNCs are indeed degradable upon exposure to water. 

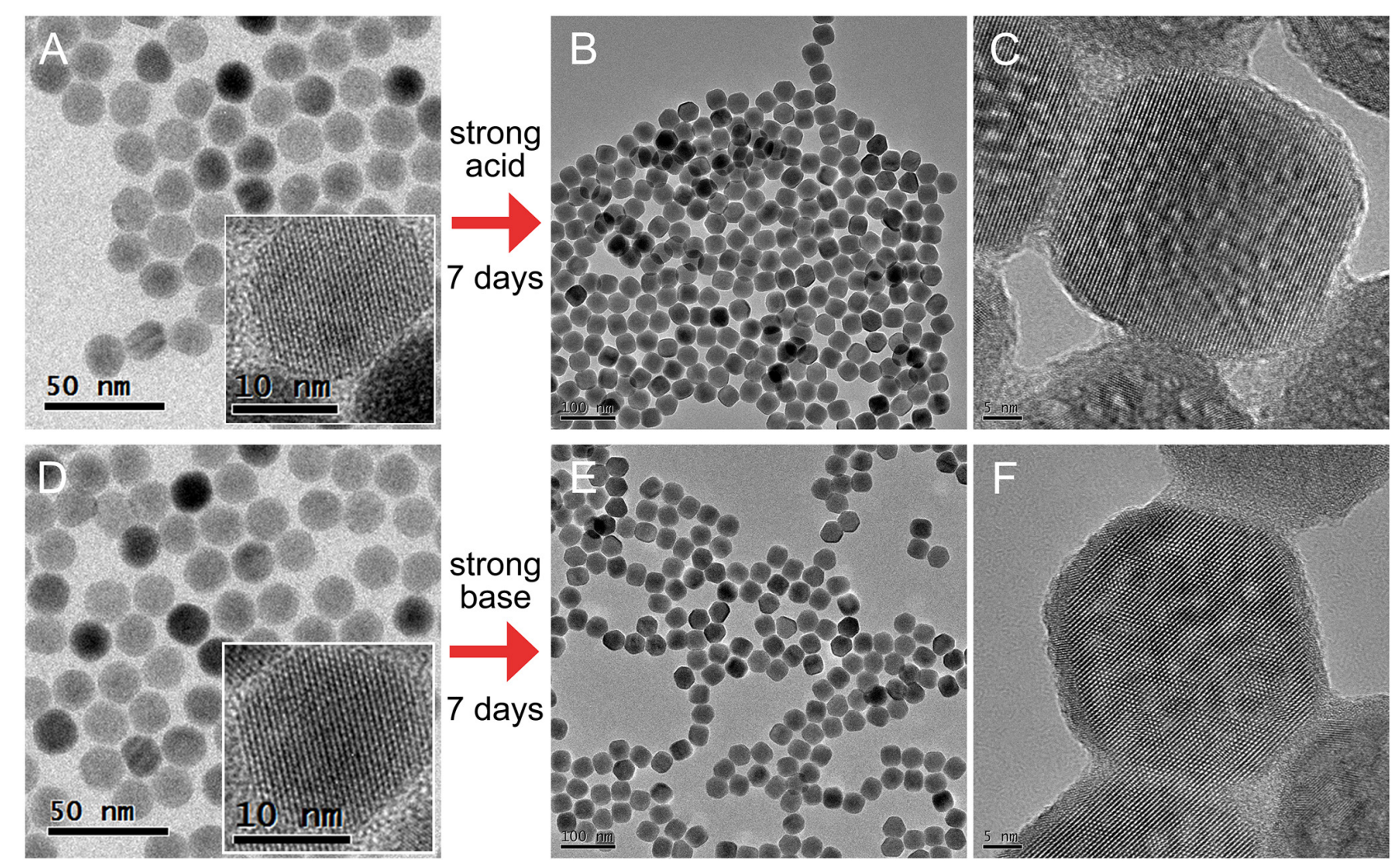

Figure S12. Representative TEM and high-resolution TEM images for $\beta$-NaYF4:Yb,Er UCNCs (A) before and (B-C) after treatment in strongly acidic and basic conditions for 7 days after undergoing severely supersonic treatment. As clearly shown in Figure S12, the nanocrystal morphology and crystallinity for the $\beta$-NaYF $4: \mathrm{Yb}, \mathrm{Er} \mathrm{UCNCs}$ can be well preserved before and after treatment under strongly acidic and basic conditions for 7 days, which supports that the crystal lattice of $\beta$-NaYF4 host is not degradable even under strongly acidic and basic conditions, totally different from the case of $\mathrm{K}_{3} \mathrm{ZrF}_{7}: \mathrm{Yb} / \mathrm{Er} \mathrm{UCNCs}$ we prepared (Figure S11). 

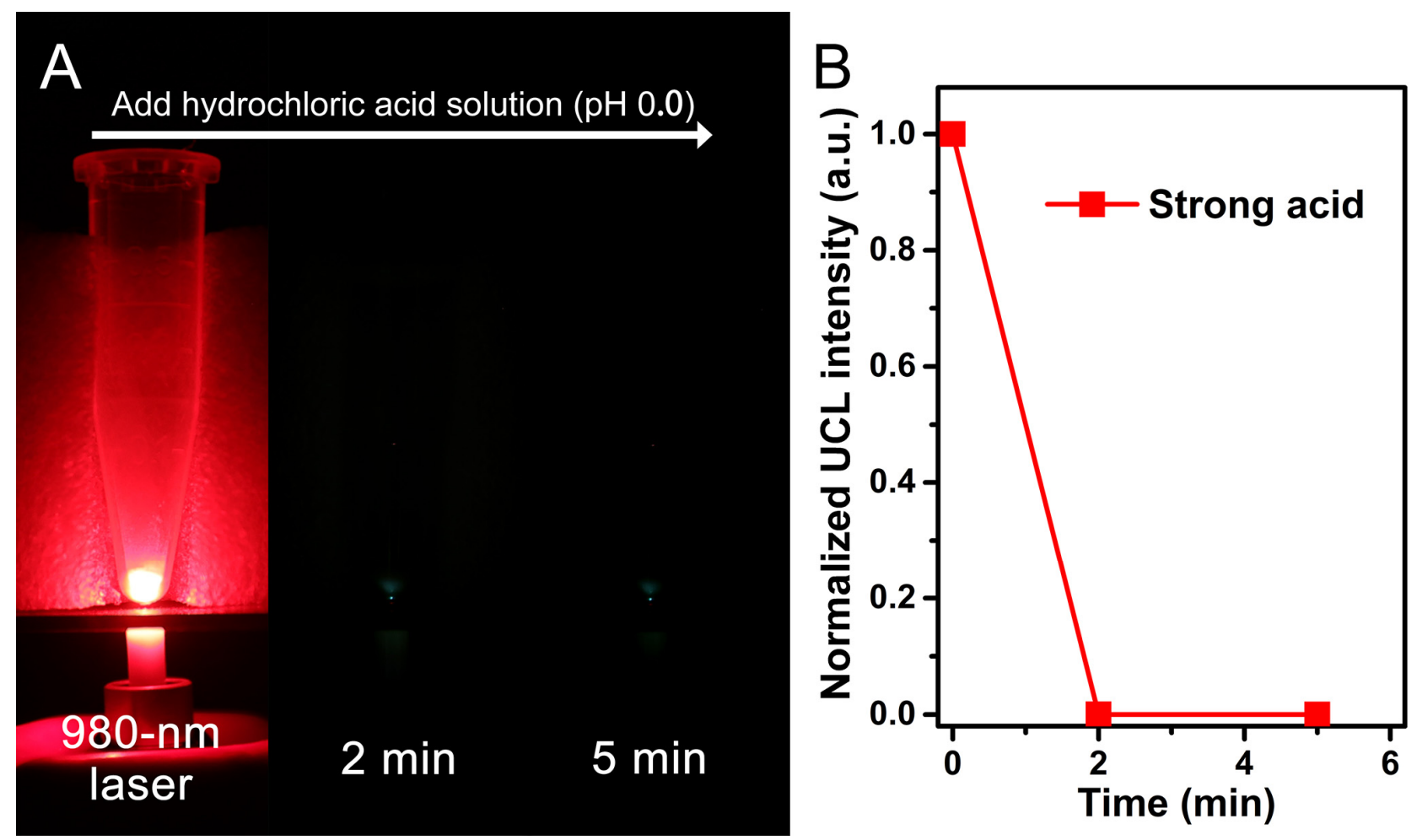

Figure S13. (A) UCL photographs for the red-emitting $\mathrm{K}_{3} \mathrm{ZrF}_{7}: \mathrm{Yb} / \mathrm{Er} \mathrm{UCNCs}$ in the form of solid state taken before and after immersing them into hydrochloric acid solution $(\mathrm{pH}=0)$ as a function of time, and (B) their corresponding overall red UCL intensity with time when excited by using a 980$\mathrm{nm}$ diode laser, showing the rapid water degradation rate of the red-emitting $\mathrm{K}_{3} \mathrm{ZrF}_{7}$ : $\mathrm{Yb} / \mathrm{Er} \mathrm{UCNCs}$ in strongly acidic aqueous solution. As shown in Figure S13, A-B, the red UCL of $\mathrm{Er}^{3+}$ from the solid $\mathrm{K}_{3} \mathrm{ZrF}_{7}: \mathrm{Yb} / \mathrm{Er} \mathrm{UCNCs}$ is hardly detectable after immersing into the hydrochloric acid solution for 2 min, which clearly reveals that the red-emitting $\mathrm{K}_{3} \mathrm{ZrF}_{7}: \mathrm{Yb} / \mathrm{Er} \mathrm{UCNCs}$ can rapidly degrade into nonluminescent (or weakly green-emitting) components upon exposure to hydrochloric acid solution ( $\mathrm{pH}$ $=0$ ). 

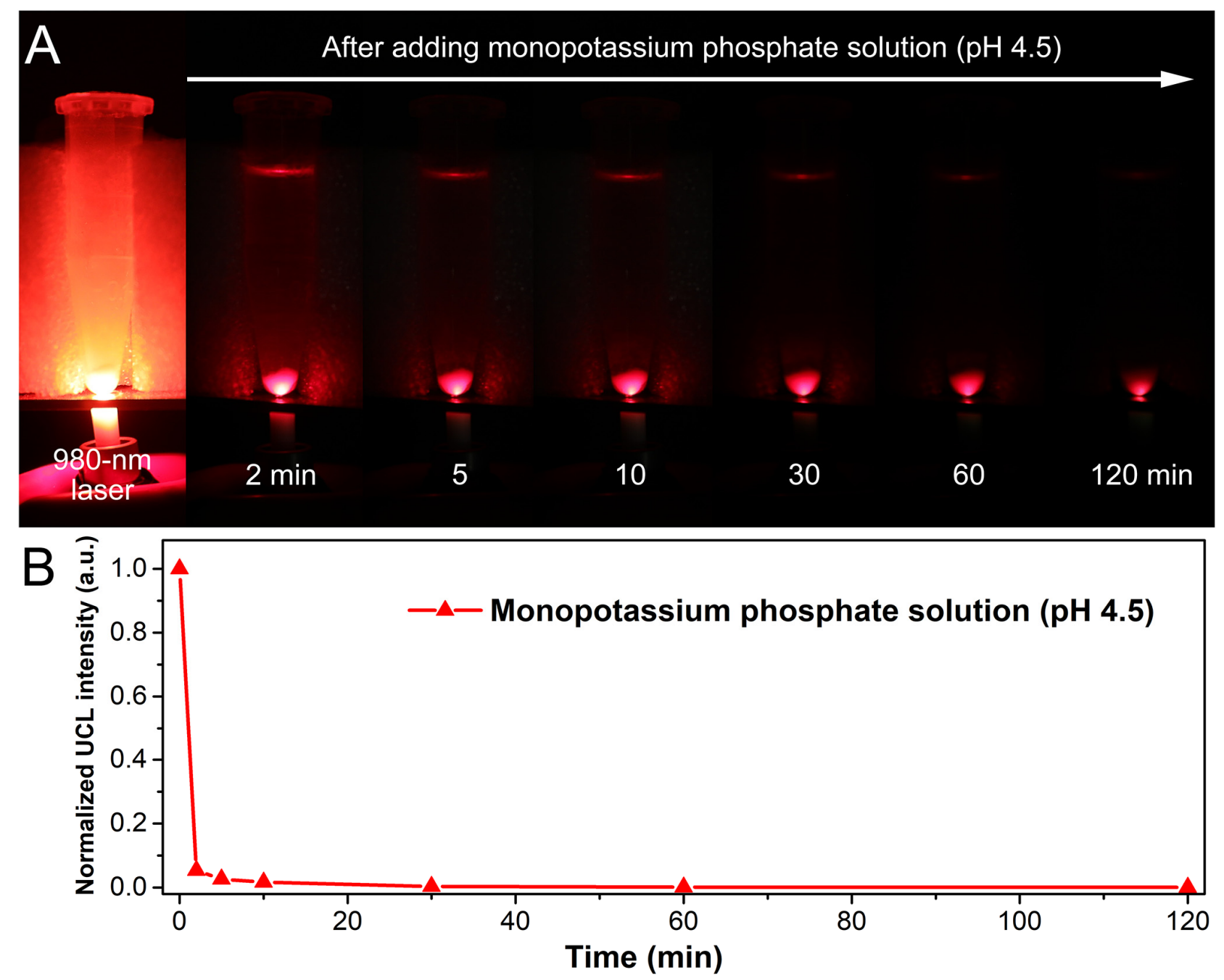

Figure S14. (A) UCL photographs for the red-emitting $\mathrm{K}_{3} \mathrm{ZrF}_{7}: \mathrm{Yb} / \mathrm{Er}$ UCNCs in the form of solid state taken before and after immersing them into monopotassium phosphate solution ( $\mathrm{pH} 4.5)$ as a function of time, and (B) their corresponding overall red UCL intensity with time when excited by using a 980-nm diode laser. After directly immersed into the monopotassium phosphate solution with a $\mathrm{pH}$ value of 4.5 , the overall red UCL intensity for the red-emitting $\mathrm{K}_{3} \mathrm{ZrF}_{7}: \mathrm{Yb} / \mathrm{Er} \mathrm{UCNCs}$ is found to drastically decrease to $\sim 0.1 \%$ of their initial intensity during a period of $\sim 10 \mathrm{~min}$, which suggests that the red-emitting $\mathrm{K}_{3} \mathrm{ZrF}_{7}: \mathrm{Yb} / \mathrm{Er} \mathrm{UCNCs}$ can rapidly degrade in the monopotassium phosphate solution with a $\mathrm{pH}$ value of 4.5 . 

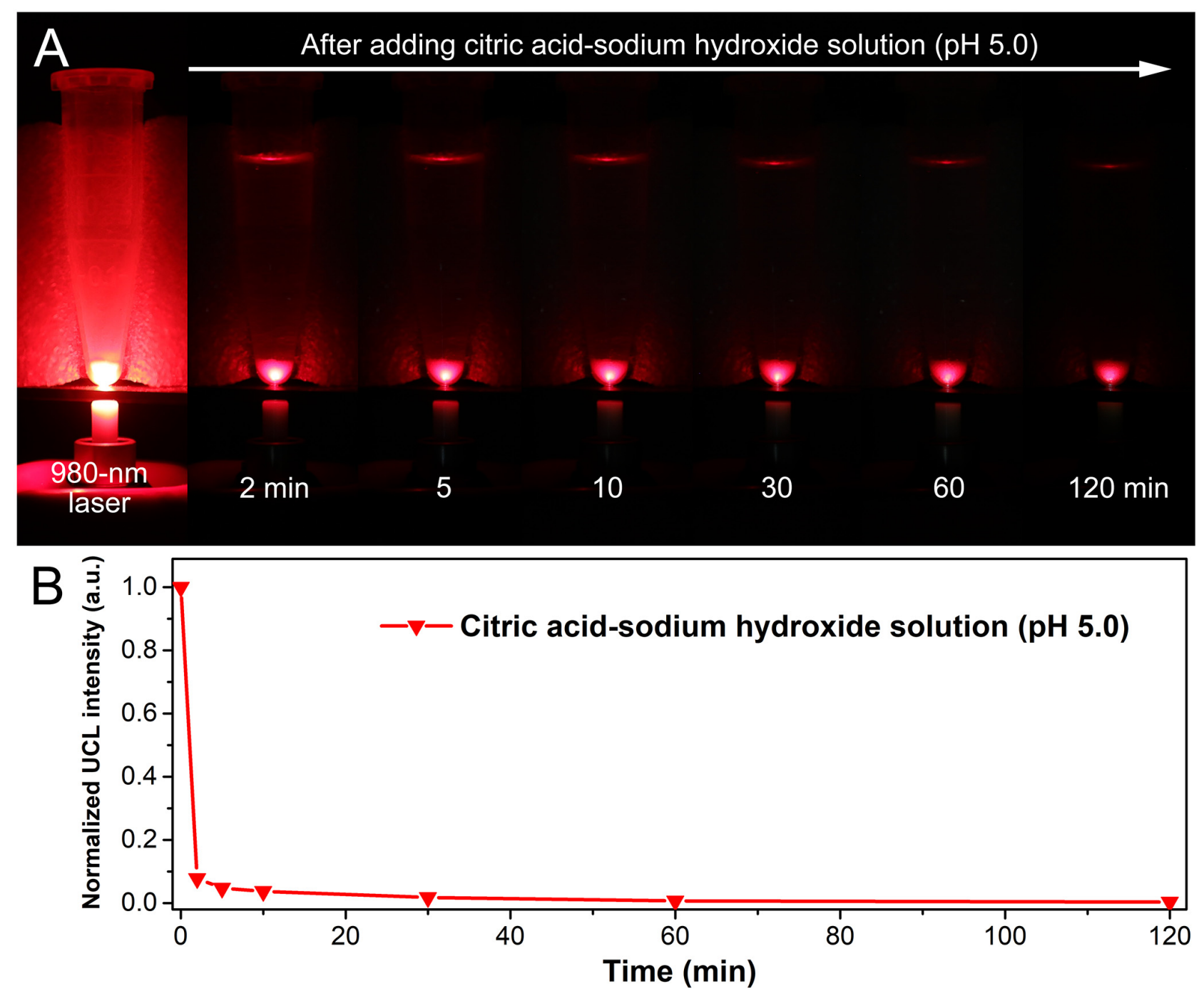

Figure S15. (A) UCL photographs for the red-emitting $\mathrm{K}_{3} \mathrm{ZrF}_{7}: \mathrm{Yb} / \mathrm{Er} \mathrm{UCNCs}$ in the form of solid state taken before and after immersing them into citric acid-sodium hydroxide solution ( $\mathrm{pH} 5.0)$ as a function of time, and (B) their corresponding overall red UCL intensity with time when excited by using a 980-nm diode laser. After directly immersed into the citric acid-sodium hydroxide solution with a $\mathrm{pH}$ value of 5.0, the overall red UCL intensity of the red-emitting $\mathrm{K}_{3} \mathrm{ZrF}_{7}$ : $\mathrm{Yb} / \mathrm{Er} \mathrm{UCNCs}$ is found to drastically decrease to $\sim 5 \%$ of their initial intensity during a period of $\sim 10 \mathrm{~min}$, which reveals that the red-emitting $\mathrm{K}_{3} \mathrm{ZrF}_{7}: \mathrm{Yb} / \mathrm{Er} \mathrm{UCNCs}$ can also degrade in the citric acid-sodium hydroxide solution with a $\mathrm{pH}$ value of $\sim 5.0$. 

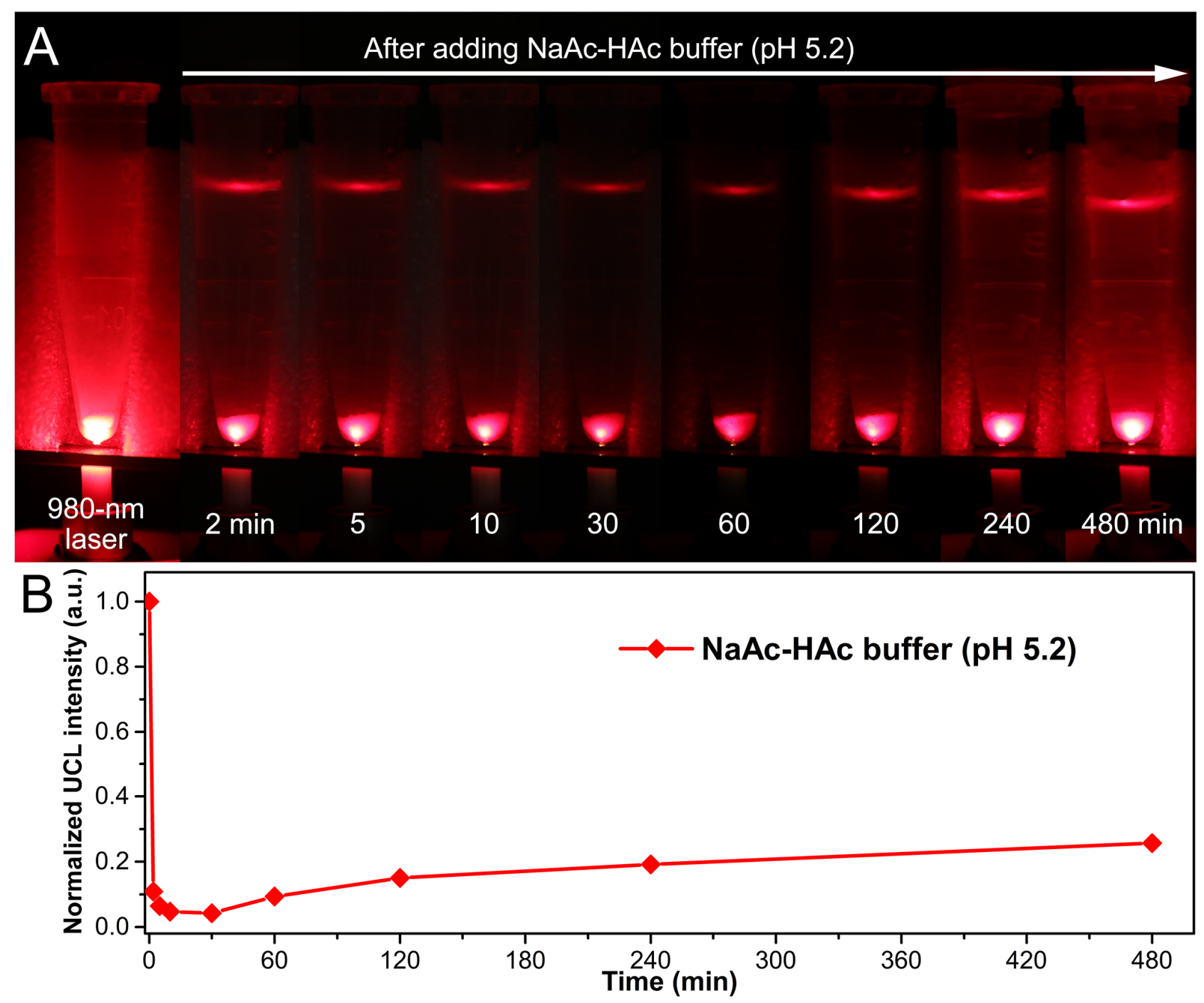

Figure S16. (A) UCL photographs for the red-emitting $\mathrm{K}_{3} \mathrm{ZrF}_{7}: \mathrm{Yb} / \mathrm{Er} \mathrm{UCNCs}$ in the form of solid state taken before and after immersing them into NaAc-HAc buffer ( $\mathrm{pH}$ 5.2), and (B) their corresponding overall red UCL intensity with time when excited by using a 980 -nm diode laser, showing the relatively slower water degradation rate of the red-emitting $\mathrm{K}_{3} \mathrm{ZrF}_{7}: \mathrm{Yb} / \mathrm{Er} \mathrm{UCNCs}$ in the NaAc-HAc buffer ( $\mathrm{pH}$ 5.2) when compared with the other scenarios aforementioned. After directly immersed into the NaAc-HAc buffer with a pH value of 5.2, the overall red UCL intensity of the redemitting $\mathrm{K}_{3} \mathrm{ZrF}_{7}: \mathrm{Yb} / \mathrm{Er} \mathrm{UCNCs}$ is found to decrease to $10-30 \%$ of their initial intensity during a period of $\sim 240 \mathrm{~min}$ and then remain nearly unchanged with time, which unambiguously suggests that the degradation rate of $\mathrm{K}_{3} \mathrm{ZrF}_{7}: \mathrm{Yb} / \mathrm{Er} \mathrm{UCNCs}$ is indeed slowed down in the NaAc-HAc buffer with a $\mathrm{pH}$ value of 5.2 relative to the other scenarios with a smaller $\mathrm{pH}$ value $(\leq 5)$. 

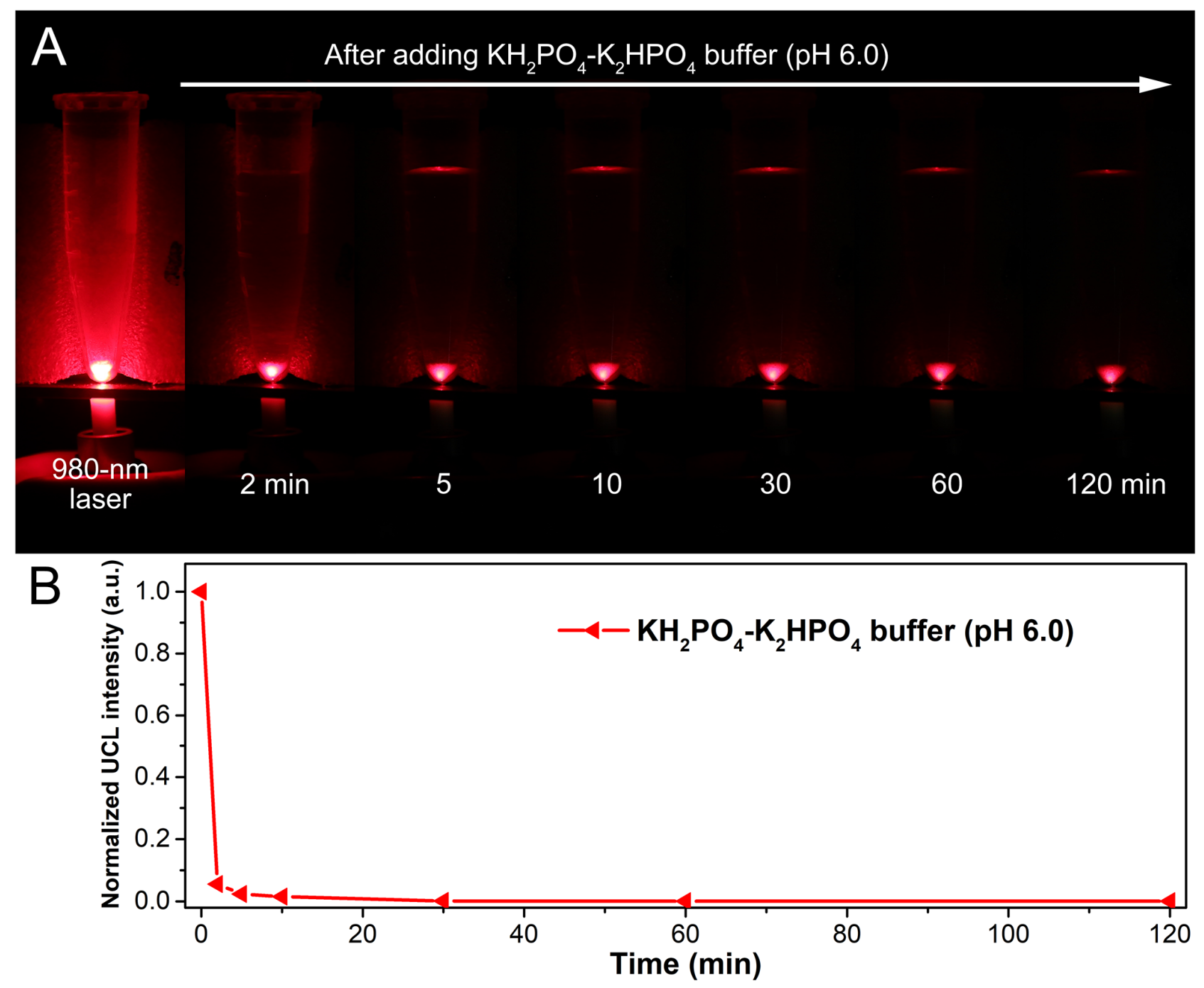

Figure S17. (A) UCL photographs for the red-emitting $\mathrm{K}_{3} \mathrm{ZrF}_{7}: \mathrm{Yb} / \mathrm{Er}$ UCNCs in the form of solid state taken before and after immersing them into $\mathrm{KH}_{2} \mathrm{PO}_{4}-\mathrm{K}_{2} \mathrm{HPO}_{4}$ buffer $(\mathrm{pH} 6.0)$ as a function of time, and (B) their corresponding overall red UCL intensity with time when excited by using a 980$\mathrm{nm}$ diode laser. After directly immersed into the $\mathrm{KH}_{2} \mathrm{PO}_{4}-\mathrm{K}_{2} \mathrm{HPO}_{4}$ buffer ( $\mathrm{pH} 6.0$ ) with a $\mathrm{pH}$ value of 6.0, the overall red UCL intensity of the red-emitting $\mathrm{K}_{3} \mathrm{ZrF}_{7}: \mathrm{Yb} / \mathrm{Er} \mathrm{UCNCs}$ is also found to drastically decrease to $\sim 5 \%$ of their initial intensity during a period of $\sim 10 \mathrm{~min}$ and then keep stable with time, which suggests that the red-emitting $\mathrm{K}_{3} \mathrm{ZrF}_{7}: \mathrm{Yb} / \mathrm{Er}$ UCNCs can also degrade in the $\mathrm{KH}_{2} \mathrm{PO}_{4}-\mathrm{K}_{2} \mathrm{HPO}_{4}$ buffer with a $\mathrm{pH}$ value of 6.0 . 

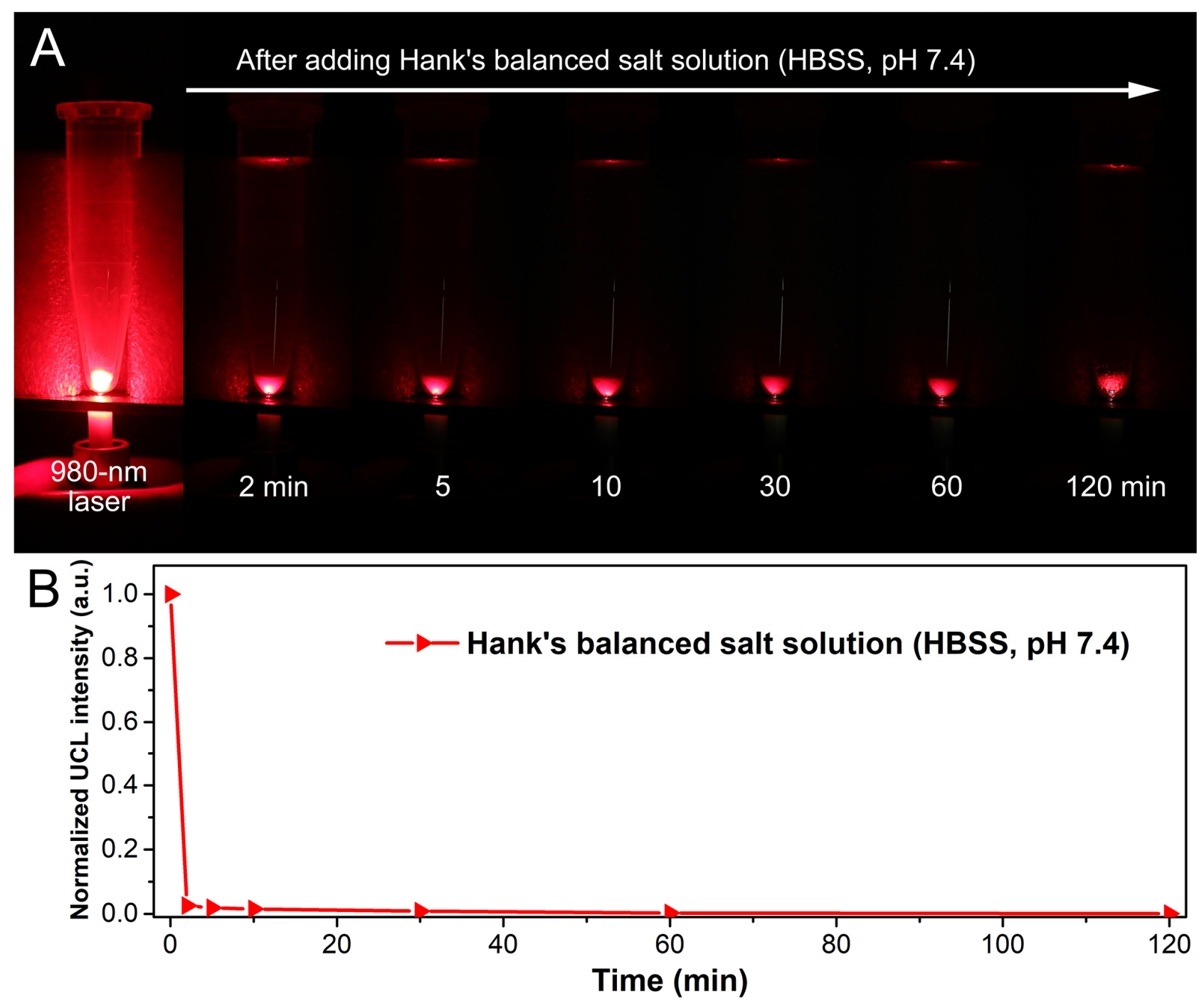

Figure S18. (A) UCL photographs for the red-emitting $\mathrm{K}_{3} \mathrm{ZrF}_{7}: \mathrm{Yb} / \mathrm{Er}$ UCNCs in the form of solid state taken before and after immersing them into Hank's balanced salt solution (HBSS, pH 7.4) as a function of time, and (B) their corresponding overall red UCL intensity with time when excited by using a 980-nm diode laser, showing the rapid water degradation rate of the red-emitting $\mathrm{K}_{3} \mathrm{ZrF}_{7}: \mathrm{Yb} / \mathrm{Er} \mathrm{UCNCs}$ in HBSS with a $\mathrm{pH}$ of 7.4. After directly immersed into in HBSS with a $\mathrm{pH}$ value of 7.4, the overall red UCL intensity of the red-emitting $\mathrm{K}_{3} \mathrm{ZrF}_{7}: \mathrm{Yb} / \mathrm{Er} \mathrm{UCNCs}$ is found to drastically decrease to $\sim 0.1 \%$ of their initial intensity during a period of $\sim 10 \mathrm{~min}$, which suggests that the red-emitting $\mathrm{K}_{3} \mathrm{ZrF}_{7}: \mathrm{Yb} / \mathrm{Er} \mathrm{UCNCs}$ can degrade rapidly in HBSS with a $\mathrm{pH}$ of 7.4. 


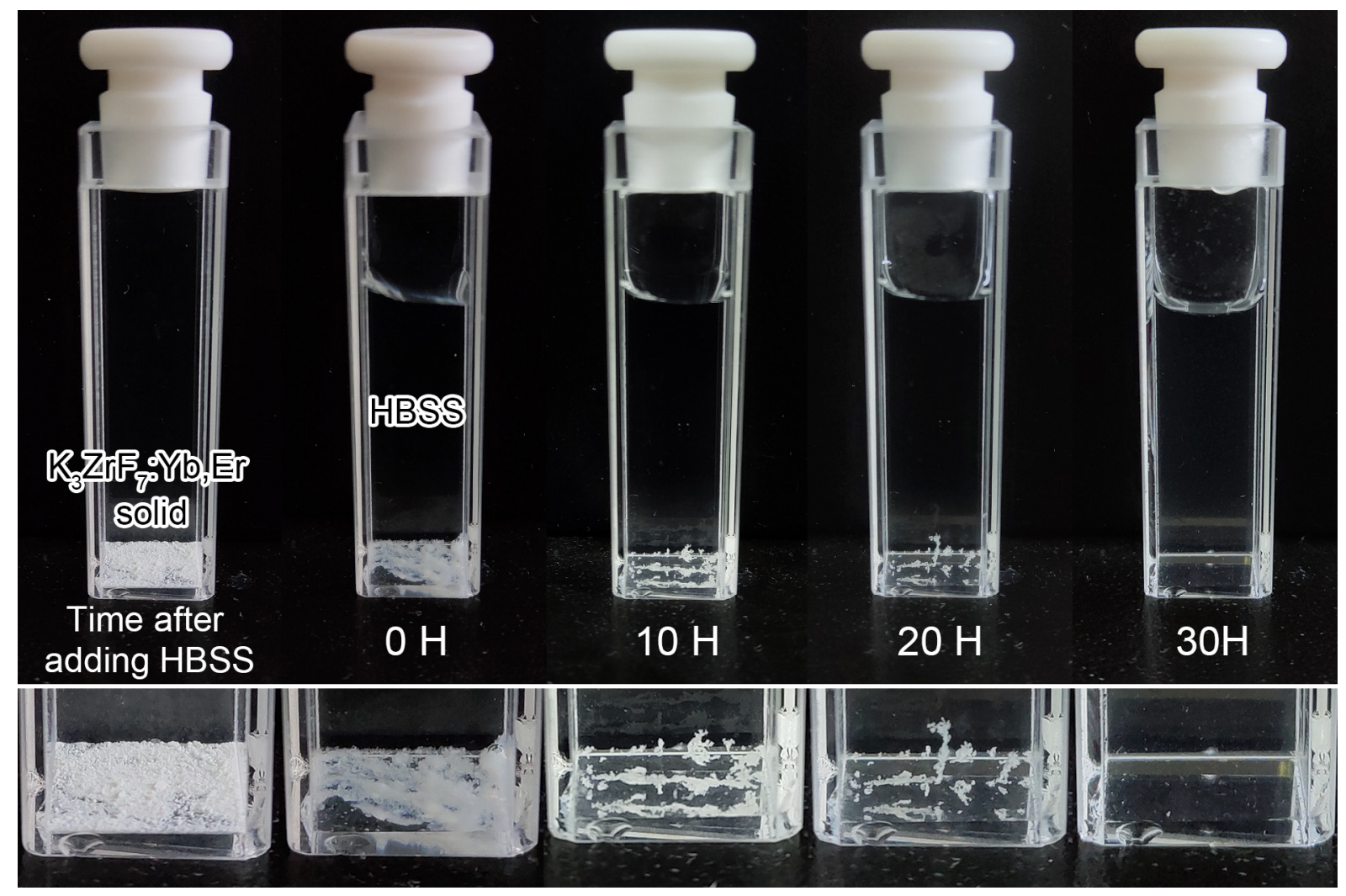

Figure S19. Photographs for the as-synthesized $\mathrm{K}_{3} \mathrm{ZrF}_{7}: \mathrm{Yb} / \mathrm{Er}(20 / 2 \mathrm{~mol} \%)$ UCNCs (solid) in a quartz cuvette as a function of time when being immersed into the HBSS solution ( $\mathrm{pH}$ 7.4), showing the complete water degradation of the as-synthesized $\mathrm{K}_{3} \mathrm{ZrF}_{7}: \mathrm{Yb} / \mathrm{Er}$ UCNCs even in their hydrophobic nature into water-soluble hydrolysates and then the formation of colorless transparent aqueous solution within $30 \mathrm{~h}$. 

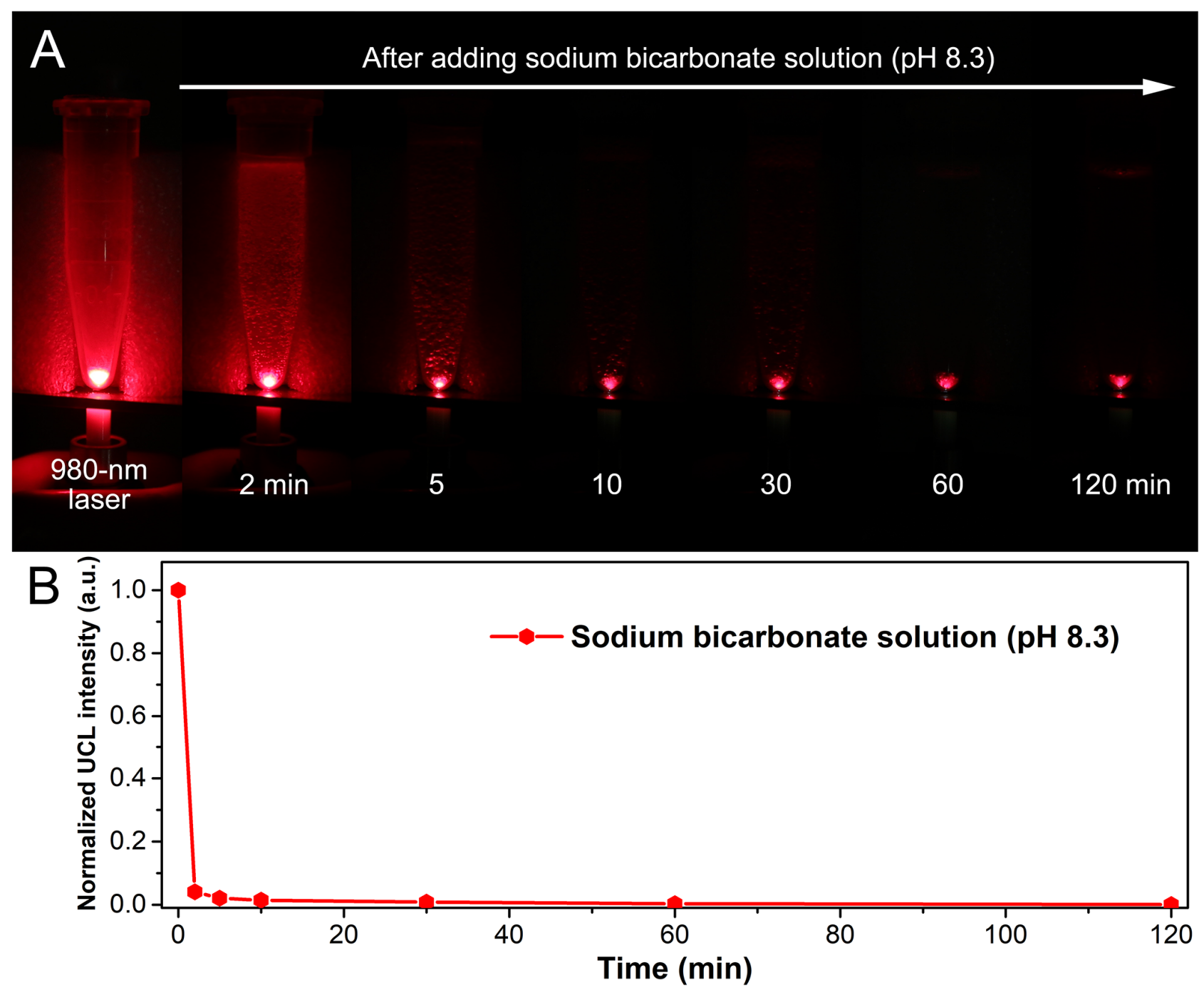

Figure S20. (A) UCL photographs for the red-emitting $\mathrm{K}_{3} \mathrm{ZrF}_{7}: \mathrm{Yb} / \mathrm{Er} \mathrm{UCNCs}$ in the form of solid state taken before and after immersing them into sodium bicarbonate solution ( $\mathrm{pH} 8.3$ ). as a function of time, and (B) their corresponding overall red UCL intensity with time when excited by using a 980-nm diode laser, showing the rapid water degradation rate of the red-emitting $\mathrm{K}_{3} \mathrm{ZrF}_{7}: \mathrm{Yb} / \mathrm{Er}$ UCNCs in sodium bicarbonate solution with a pH of 8.3. After directly immersed into in HBSS with a $\mathrm{pH}$ value of 8.3 , the overall red UCL intensity of the red-emitting $\mathrm{K}_{3} \mathrm{ZrF}_{7}: \mathrm{Yb} / \mathrm{Er} \mathrm{UCNCs}$ is found to drastically decrease to $\sim 0.1 \%$ of their initial intensity during a period of $\sim 5 \mathrm{~min}$, which strongly suggests that the red-emitting $\mathrm{K}_{3} \mathrm{ZrF}_{7}: \mathrm{Yb} / \mathrm{Er} \mathrm{UCNCs}$ can rapidly degrade into non-luminescent components upon exposure to sodium bicarbonate solution with a $\mathrm{pH}$ of 8.3. 

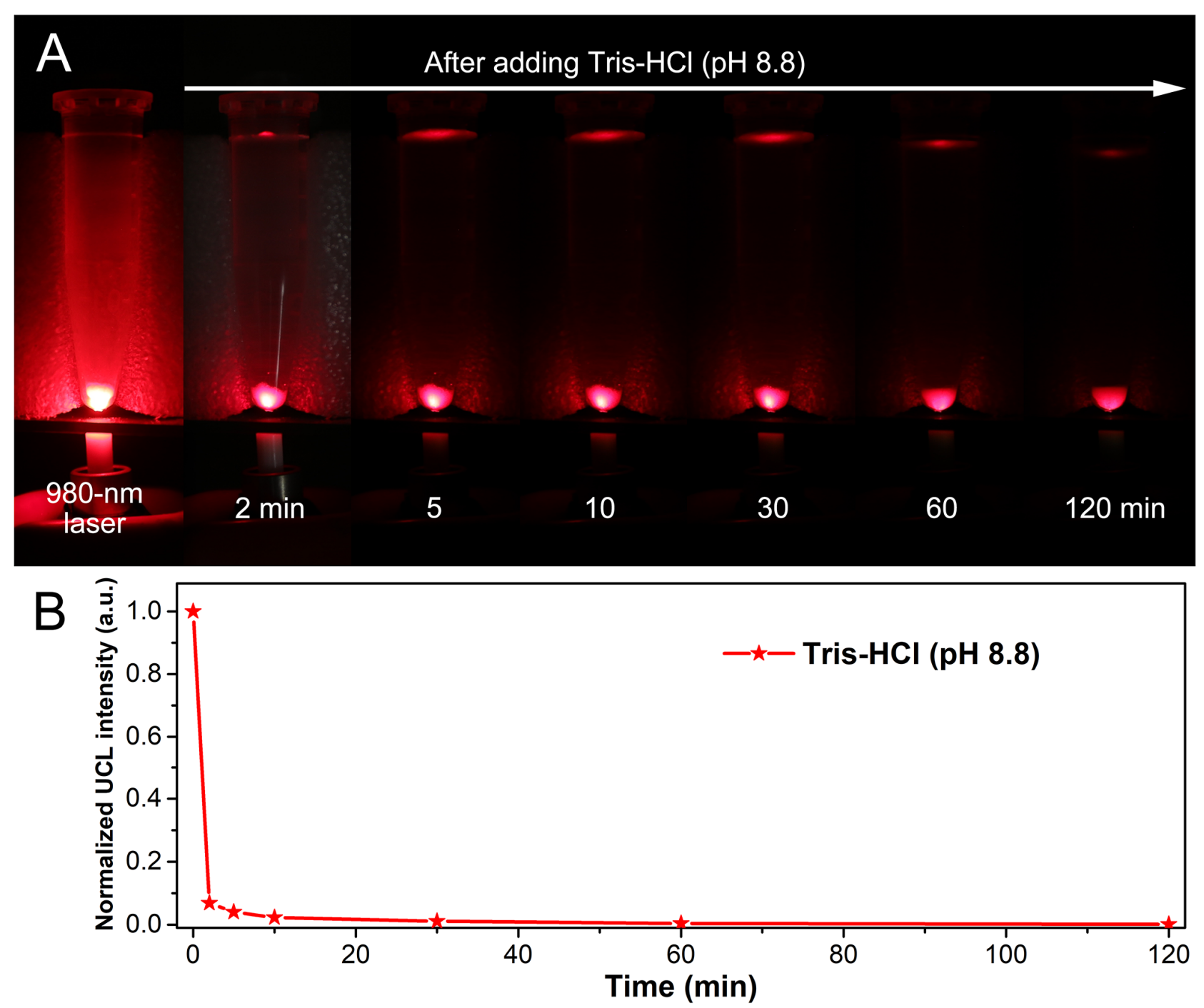

Figure S21. (A) UCL photographs for the red-emitting $\mathrm{K}_{3} \mathrm{ZrF}_{7}: \mathrm{Yb} / \mathrm{Er} \mathrm{UCNCs}$ in the form of solid state taken before and after immersing them into Tris- $\mathrm{HCl}(\mathrm{pH} \mathrm{8.8)}$ as a function of time, and (B) their corresponding overall red UCL intensity with time when excited by using a 980-nm diode laser, showing the rapid water degradation rate of the red-emitting $\mathrm{K}_{3} \mathrm{ZrF}_{7}: \mathrm{Yb} / \mathrm{Er} \mathrm{UCNCs}$ in Tris-HCl with a $\mathrm{pH}$ of 8.8. As shown in Figure S21, A-B, the overall red UCL intensity of the ed-emitting $\mathrm{K}_{3} \mathrm{ZrF}_{7}: \mathrm{Yb} / \mathrm{Er} \mathrm{UCNCs}$ is found to drastically decrease to $\sim 0.1 \%$ of their initial intensity during a period of $\sim 30 \mathrm{~min}$, which strongly suggests that the red-emitting $\mathrm{K}_{3} \mathrm{ZrF}_{7}: \mathrm{Yb} / \mathrm{Er} \mathrm{UCNCs}$ can rapidly degrade into non-luminescent components upon exposure to Tris- $\mathrm{HCl}$ with a $\mathrm{pH}$ of 8.8. 

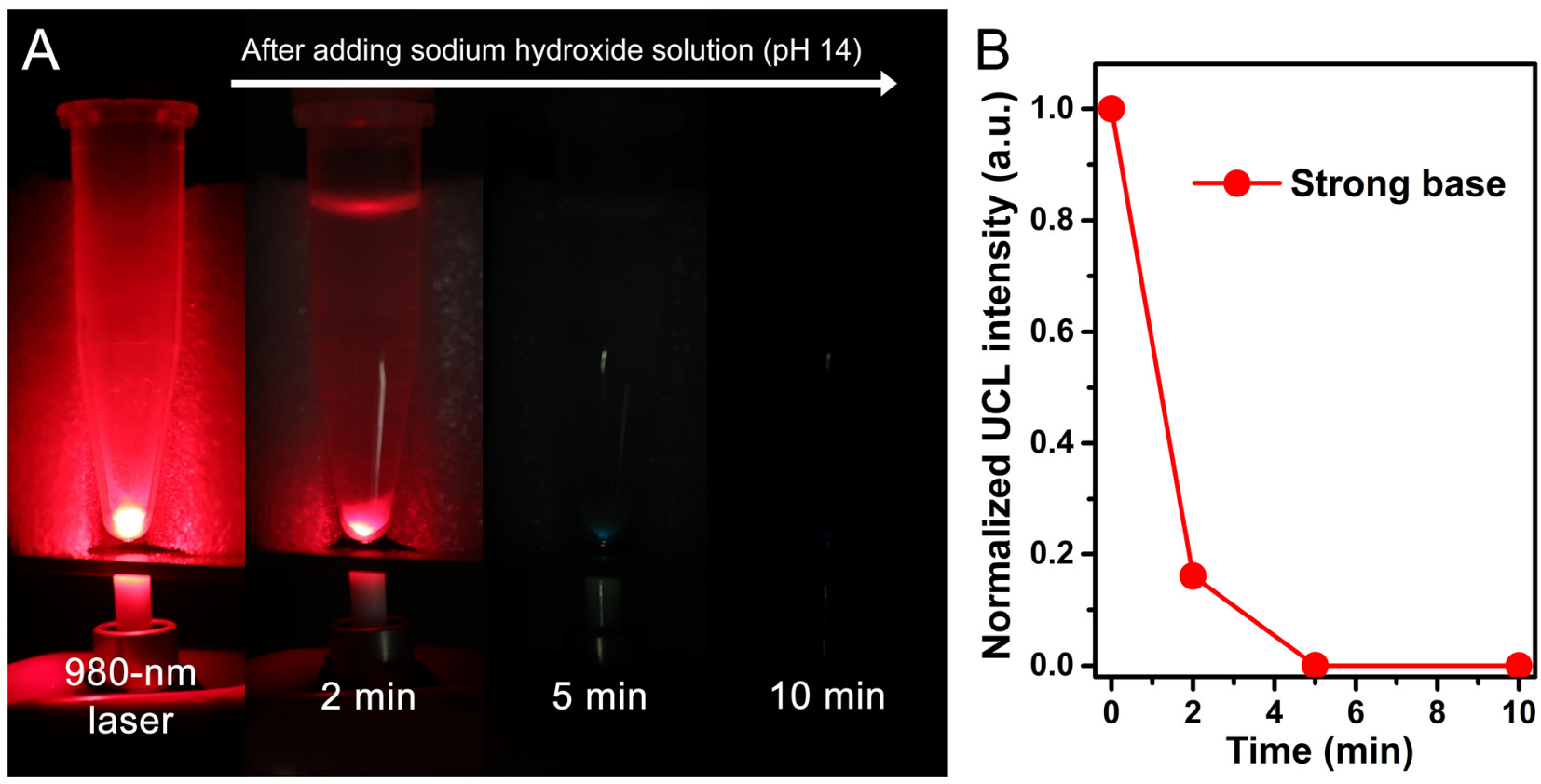

Figure S22. (A) UCL photographs for the red-emitting $\mathrm{K}_{3} \mathrm{ZrF}_{7}: \mathrm{Yb} / \mathrm{Er}$ UCNCs in the form of solid state taken before and after immersing them into sodium hydroxide solution $(\mathrm{pH} \mathrm{14)}$ as a function of time, and (B) their corresponding overall red UCL intensity with time when excited by using a 980$\mathrm{nm}$ diode laser, showing the rapid water degradation rate of the red-emitting $\mathrm{K}_{3} \mathrm{ZrF}_{7}: \mathrm{Yb} / \mathrm{Er} \mathrm{UCNCs}$ in strongly alkalinous environment. As shown in Figure S22, A-B, the red UCL of Er ${ }^{3+}$ from the solid $\mathrm{K}_{3} \mathrm{ZrF}_{7}: \mathrm{Yb} / \mathrm{Er} \mathrm{UCNCs}$ is hardly detectable after immersing into the sodium hydroxide solution ( $\mathrm{pH}$ 14) for $5 \mathrm{~min}$, which clearly verifies that the red-emitting $\mathrm{K}_{3} \mathrm{ZrF}_{7}: \mathrm{Yb} / \mathrm{Er}$ UCNCs can rapidly degrade into non-luminescent components upon exposure to sodium hydroxide solution with a $\mathrm{pH}$ of 14 . 

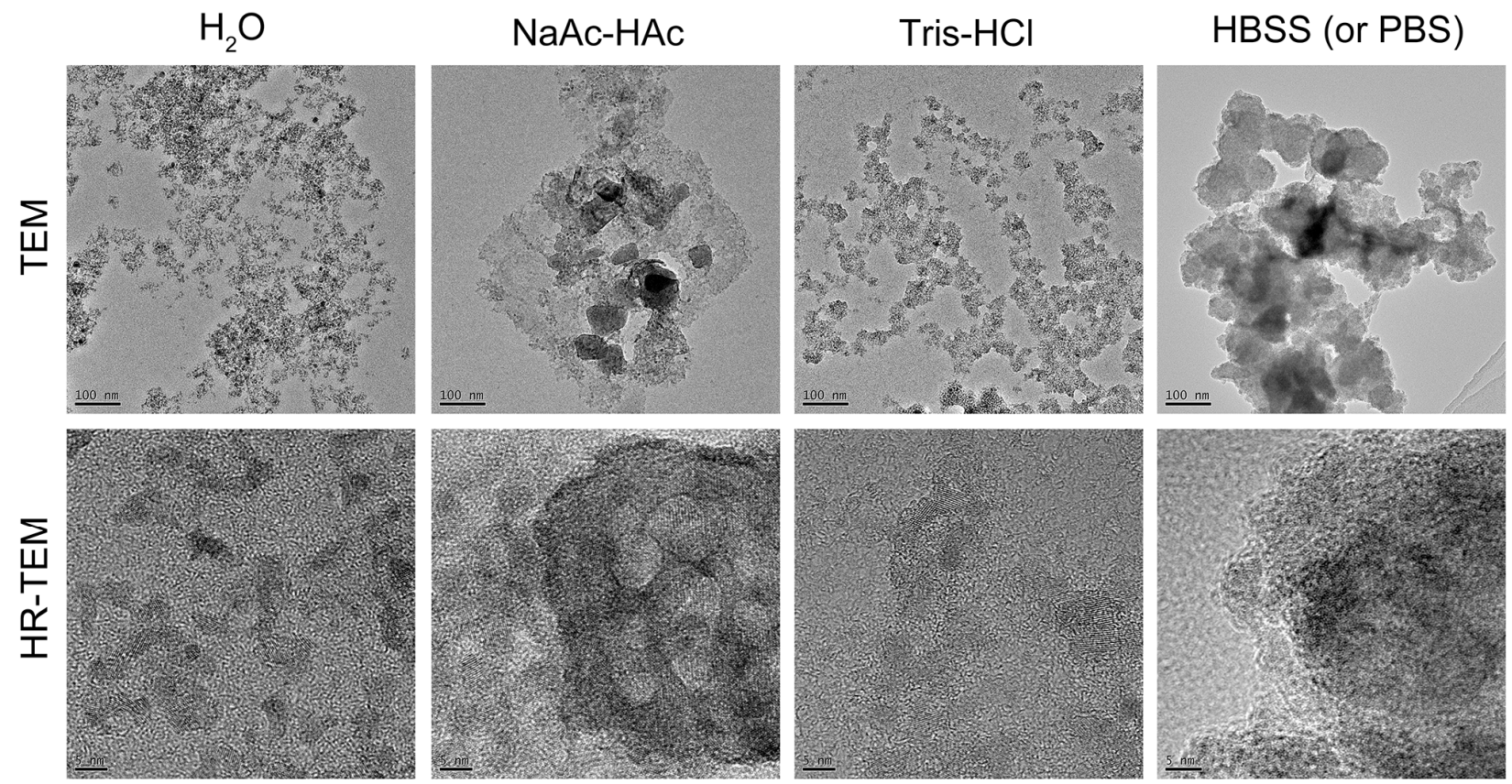

Figure S23. Representative TEM and high-resolution TEM (HRTEM) images for the as-synthesized red-emitting $\mathrm{K}_{3} \mathrm{ZrF}_{7}: \mathrm{Yb} / \mathrm{Er} \mathrm{UCNCs}$ before and after treatments with pure water $\left(\mathrm{H}_{2} \mathrm{O}\right)$, NaAc-HAc buffer (pH 5.2), Tris-HCl (pH 8.8) and Hank's balanced salt solution (HBSS, pH 7.4) for 24 h. Noted that the TEM images for the as-synthesized $\mathrm{K}_{3} \mathrm{ZrF}_{7}: \mathrm{Yb} / \mathrm{Er} \mathrm{UCNCs}$ in strongly acidic and alkalinous solutions cannot be obtained possibly due to their complete water degradation under these two conditions. As clearly indicated in Figure S23, all the red-emitting $\mathrm{K}_{3} \mathrm{ZrF}_{7}$ : $\mathrm{Yb} / \mathrm{Er}$ UCNCs with an average size of $\sim 28 \mathrm{~nm}$ can be completely transformed into small-sized $(\sim 5 \mathrm{~nm})$ residues when dispersed in pure water $\left(\mathrm{H}_{2} \mathrm{O}\right), \mathrm{NaAc}-\mathrm{HAc}$ buffer $(\mathrm{pH} 5.2)$, Tris- $\mathrm{HCl}(\mathrm{pH} 8.8)$ and Hank's balanced salt solution (HBSS, pH 7.4), indicative of their excellent water degradation performance in vitro . 

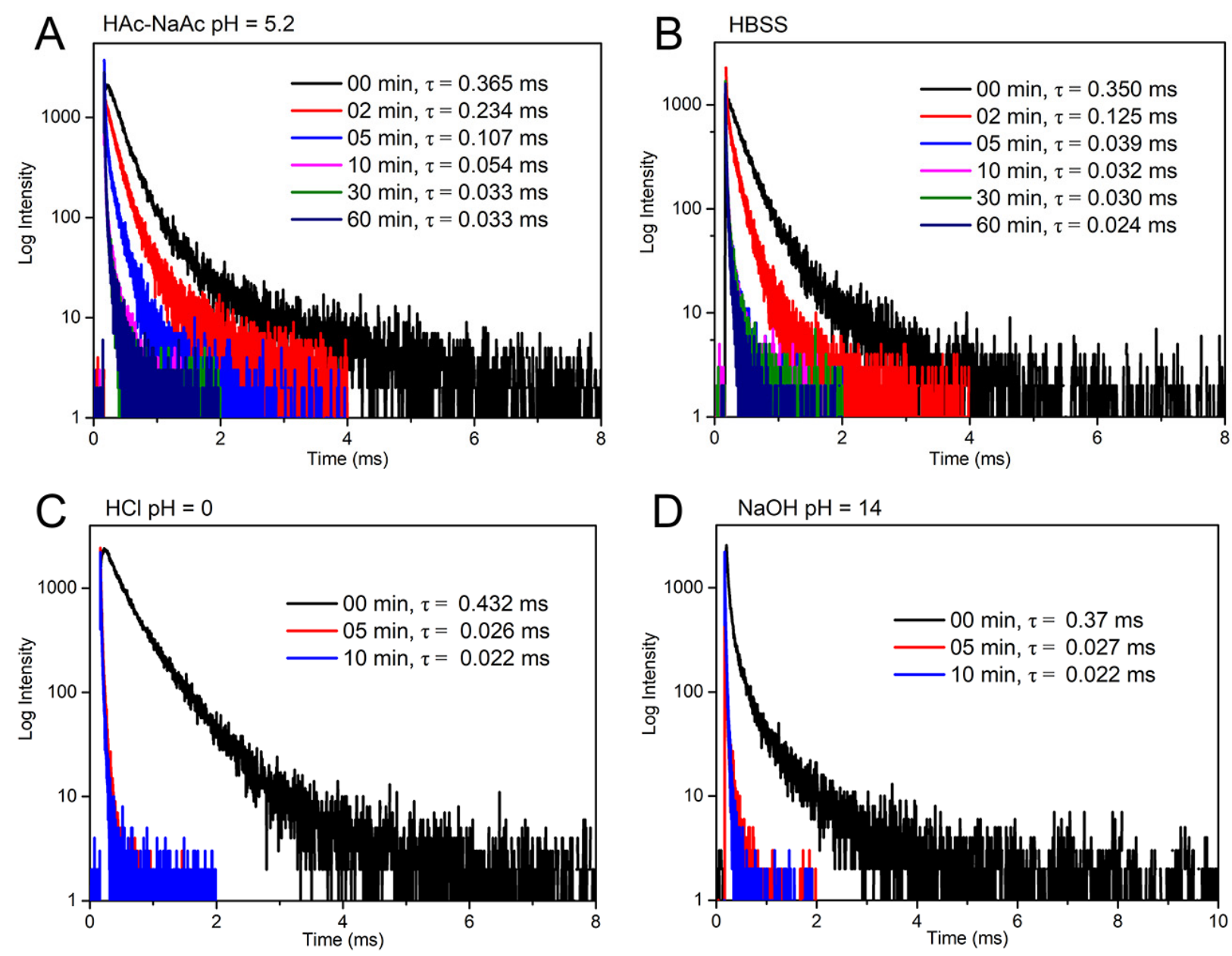

Figure S24. Red UCL decays of $\mathrm{Er}^{3+}$ as a function of time for the as-synthesized $\mathrm{K}_{3} \mathrm{ZrF}_{7}: \mathrm{Yb} / \mathrm{Er}$ UCNCs when directly immersed them into (A) NaAc-HAc buffer (pH 5.2), (B) Hank's balanced salt solution (HBSS, pH 7.4), (C) hydrochloric acid solution (pH 0.0), and (D) sodium hydroxide solution (pH 14). All the UCL decays were measured by monitoring red UCL of $\mathrm{Er}^{3+}$ centered at $656 \mathrm{~nm}$ upon excitation by a $980-\mathrm{nm}$ pulsed laser and fitted by using a double exponential function to deliver an average UCL lifetime $(\tau)$. As compared in Figure S24, the red UCL lifetime of $\mathrm{Er}^{3+}$ for the redemitting $\mathrm{K}_{3} \mathrm{ZrF}_{7}: \mathrm{Yb} / \mathrm{Er} \mathrm{UCNCs}$ in the NaAc-HAc buffer is observed to gradually decrease and then keep almost unchanged during water degradation, which differs markedly from the other scenarios with rapidly reduced lifetime from $\sim 0.4$ to $\sim 0.02 \mathrm{~ms}$ within 10 min particularly in strongly acidic and alkalinous buffer solutions. These UCL decay results further confirm that the degradation rate of $\mathrm{K}_{3} \mathrm{ZrF}_{7}: \mathrm{Yb} / \mathrm{Er} \mathrm{UCNCs}$ is indeed slowed down in the NaAc-HAc buffer relative to the other scenarios. 


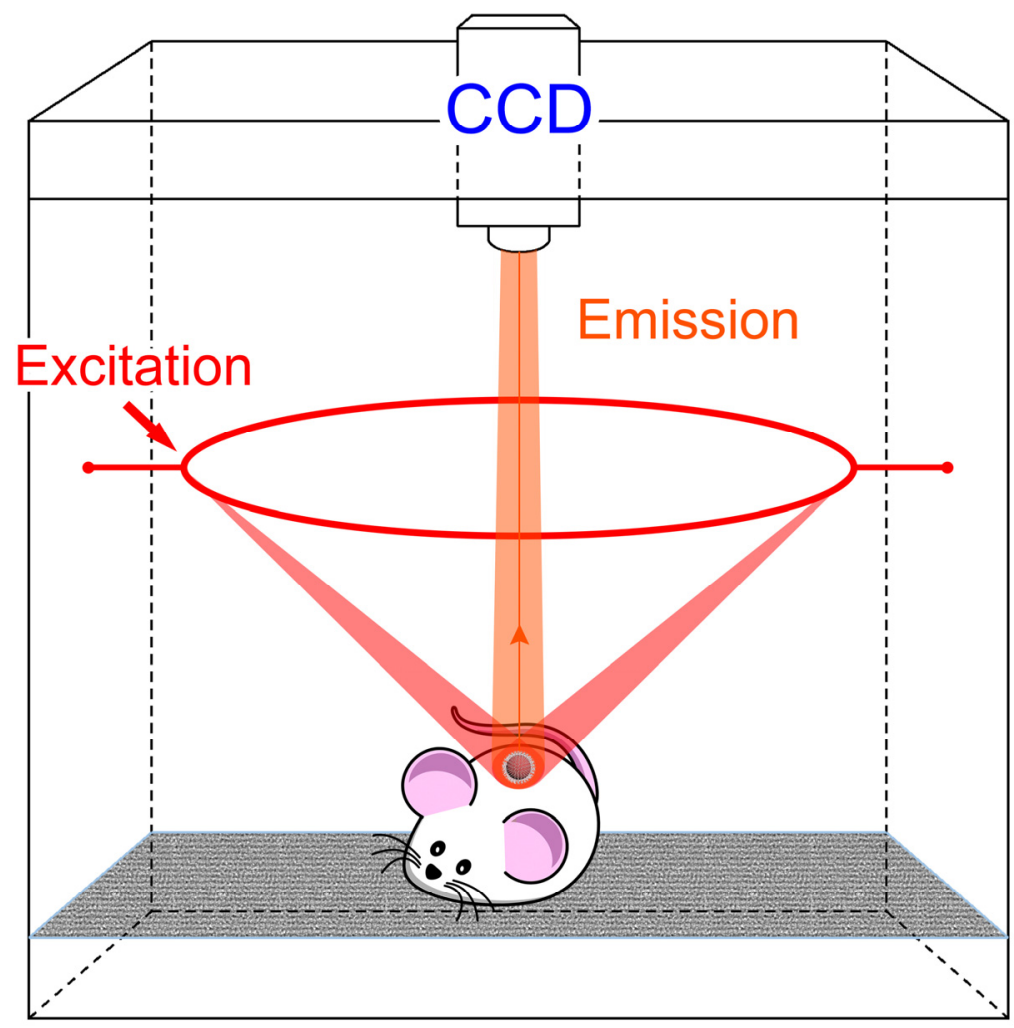

Figure S25. Schematic illustration of in vivo UCL imaging by using the red-emitting $\mathrm{K}_{3} \mathrm{ZrF}_{7}: \mathrm{Yb} / \mathrm{Er}$ UCNCs as fluorescent contrast agents in our home-made UCL imaging system. An external 0-3 W adjustable CW semiconductor laser at $980 \mathrm{~nm}$ was used to excite the samples. The UCL image was recorded by an imaging system equipped with an Andor CCD camera. 


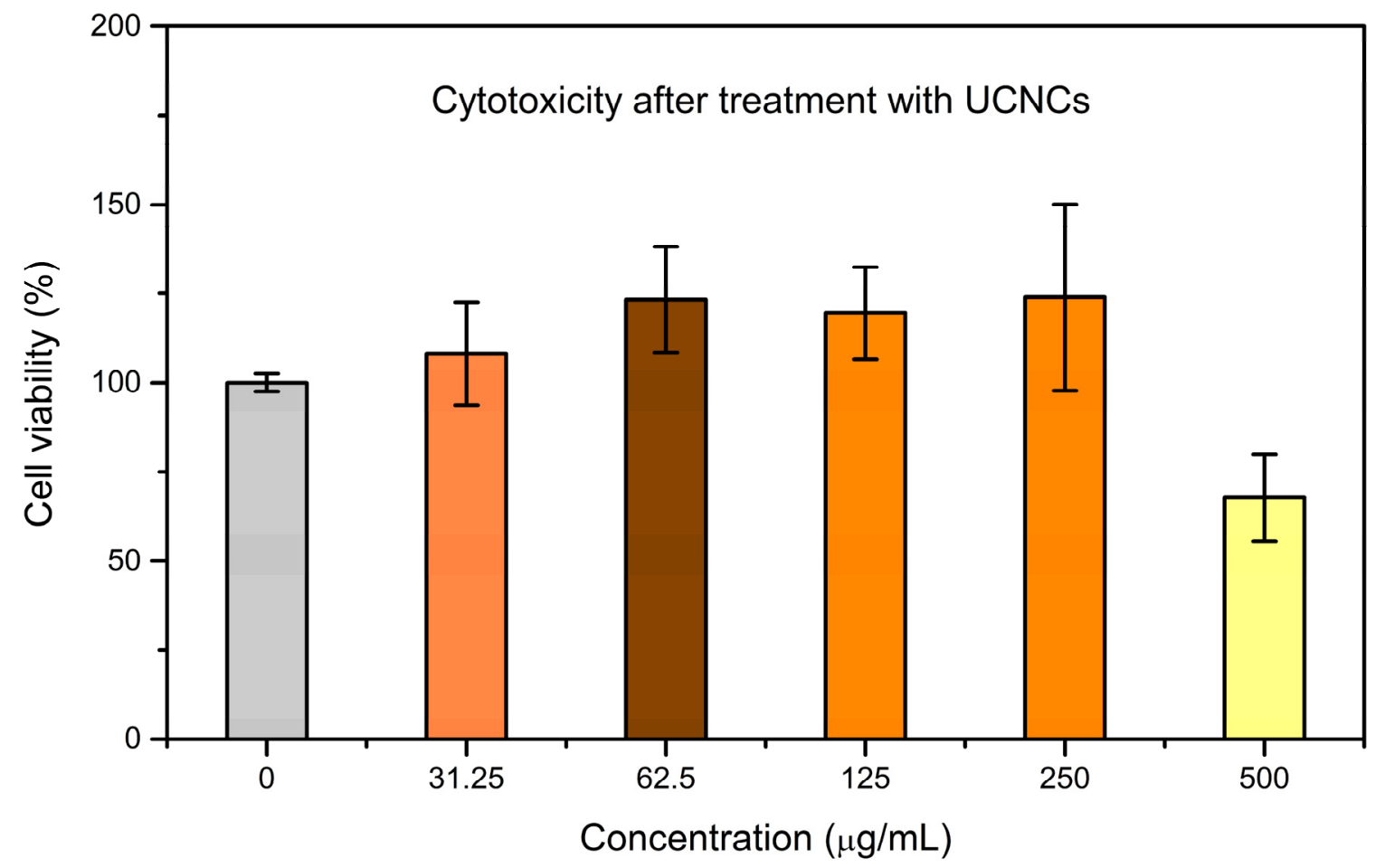

Figure S26. In vitro cytotoxicity for the as-synthesized $\mathrm{K}_{3} \mathrm{ZrF}_{7}: \mathrm{Yb} / \mathrm{Er} \mathrm{UCNCs}$ towards human embryonic lung fibroblasts (HELF) cells, determined by using a MTT assay. The $\mathrm{K}_{3} \mathrm{ZrF}_{7}: \mathrm{Yb} / \mathrm{Er}$ UCNCs dispersed in DMSO at the indicated concentrations $(\mu \mathrm{g} / \mathrm{mL})$ were incubated with cells for 24 h. As shown in Figure S26, the cell viability was determined to be about $100 \%$ in the concentration range from $0-250 \mu \mathrm{g} / \mathrm{mL}$, which suggest that the as-synthesized $\mathrm{K}_{3} \mathrm{ZrF}_{7}: \mathrm{Yb} / \mathrm{Er}$ UCNCs even in their hydrophobic nature are biocompatible and relatively non-toxic to HELF cells in vitro. 


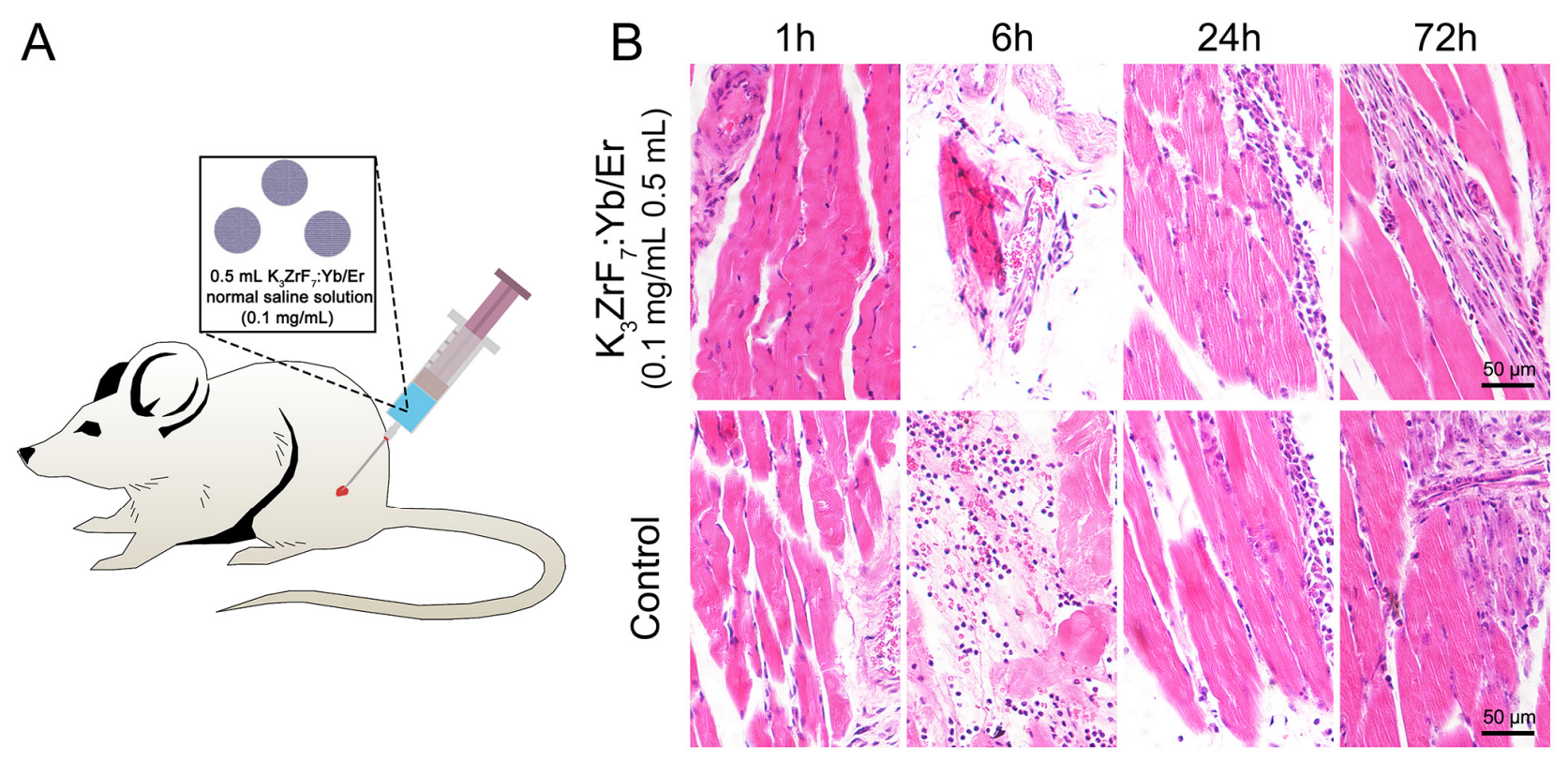

Figure S27. (A) Acute toxicity (or local stimulation) test on the quadriceps femoris of some SPF SD rats after intramuscularly injected with the dispersion of $\mathrm{K}_{3} \mathrm{ZrF}_{7}: \mathrm{Yb} / \mathrm{Er} \mathrm{UCNCs}$ in $0.9 \mathrm{wt} \%$ sodium chloride injection $(0.5 \mathrm{~mL}, 100 \mu \mathrm{g} / \mathrm{mL})$. Histopathological examinations of the quadriceps femoris on $(\mathbf{B})$ the control rat and the experimental rats after intramuscular injection with $\mathrm{K}_{3} \mathrm{ZrF}_{7}: \mathrm{Yb} / \mathrm{Er}$ UCNCs for 1, 6, 24 and 72 h, respectively. As compared in Figure S27, all the quadriceps muscle tissues have no obvious histopathological abnormities relative to their controls, implying that the quadriceps muscle tissues for all the experimental rats can rapidly recover to their normal morphology after intramuscular injection, confirming the high biosafety of $\mathrm{K}_{3} \mathrm{ZrF}_{7}: \mathrm{Yb} / \mathrm{Er} \mathrm{UCNCs}$ to muscles in vivo. 

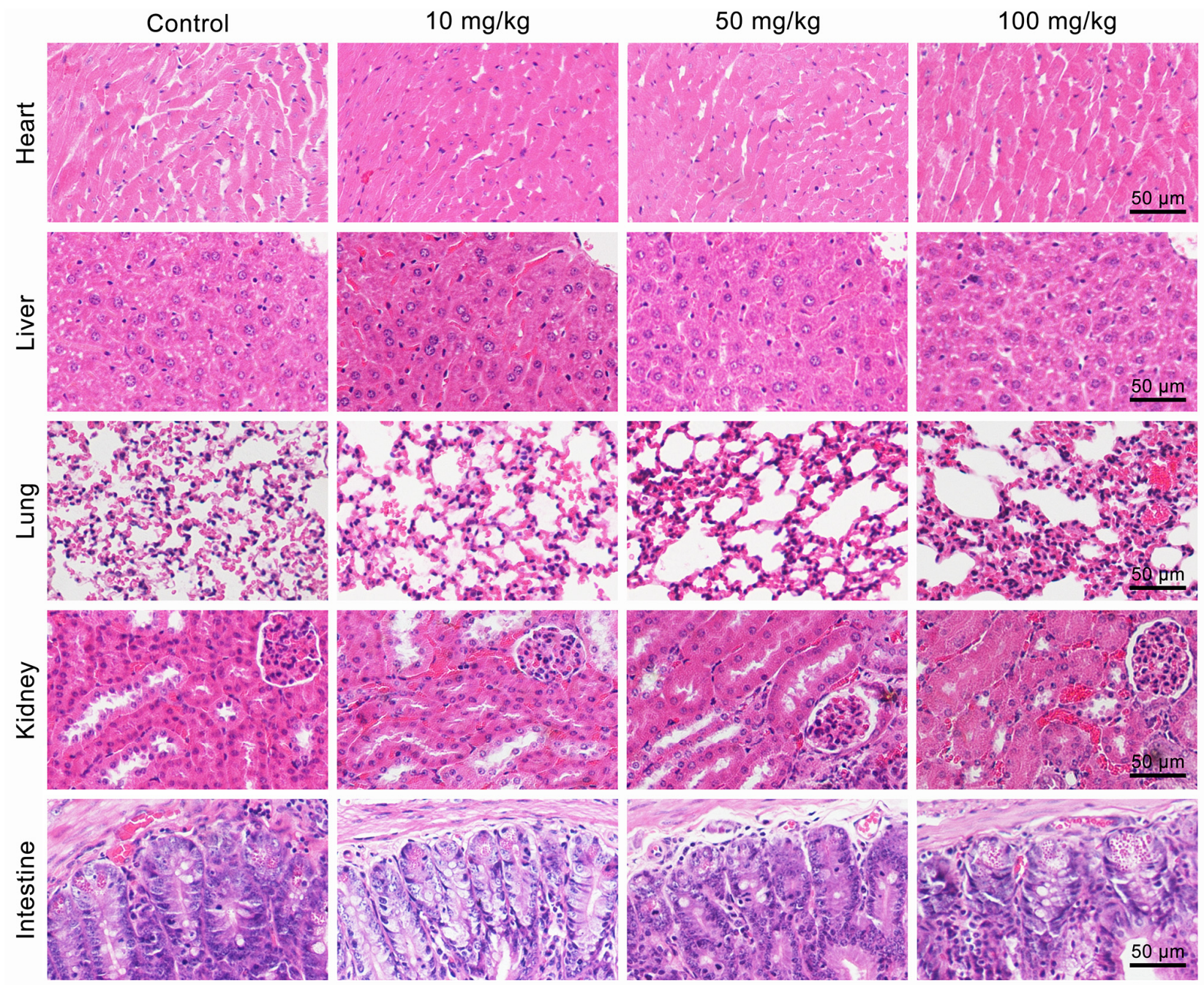

Figure S28. Histological assessments for the major organs of some randomly selected SPF SD rats after intravenously injected with the sodium chloride injection $(0.9 \mathrm{wt} \%)$ suspension of $\mathrm{K}_{3} \mathrm{ZrF} 7: \mathrm{Yb} / \mathrm{Er}$ UCNCs at different dosages of 0 (control), 10, 50 and $100 \mathrm{mg} \mathrm{kg}^{-1}$ and then subjected to 15-day feeding. Organs were stained with haematoxylin and eosin, and the scale bar is $50 \mu \mathrm{m}$ for all images. As compared in Figure S28, the main organs including heart, liver, lung, kidney and intestines for all the rats show no significant change in histology even at the highest injection dosage of $100 \mathrm{mg} \mathrm{kg}^{-1}$, which thereby provide solid evidences to prove that the as-synthesized $\mathrm{K}_{3} \mathrm{ZrF}_{7}: \mathrm{Yb} / \mathrm{Er} \mathrm{UCNCs}$ have no toxic side effects to the major organs of rats relative to the controls and shows promise as nontoxic biodegradable inorganic upconverting nanomaterials. 


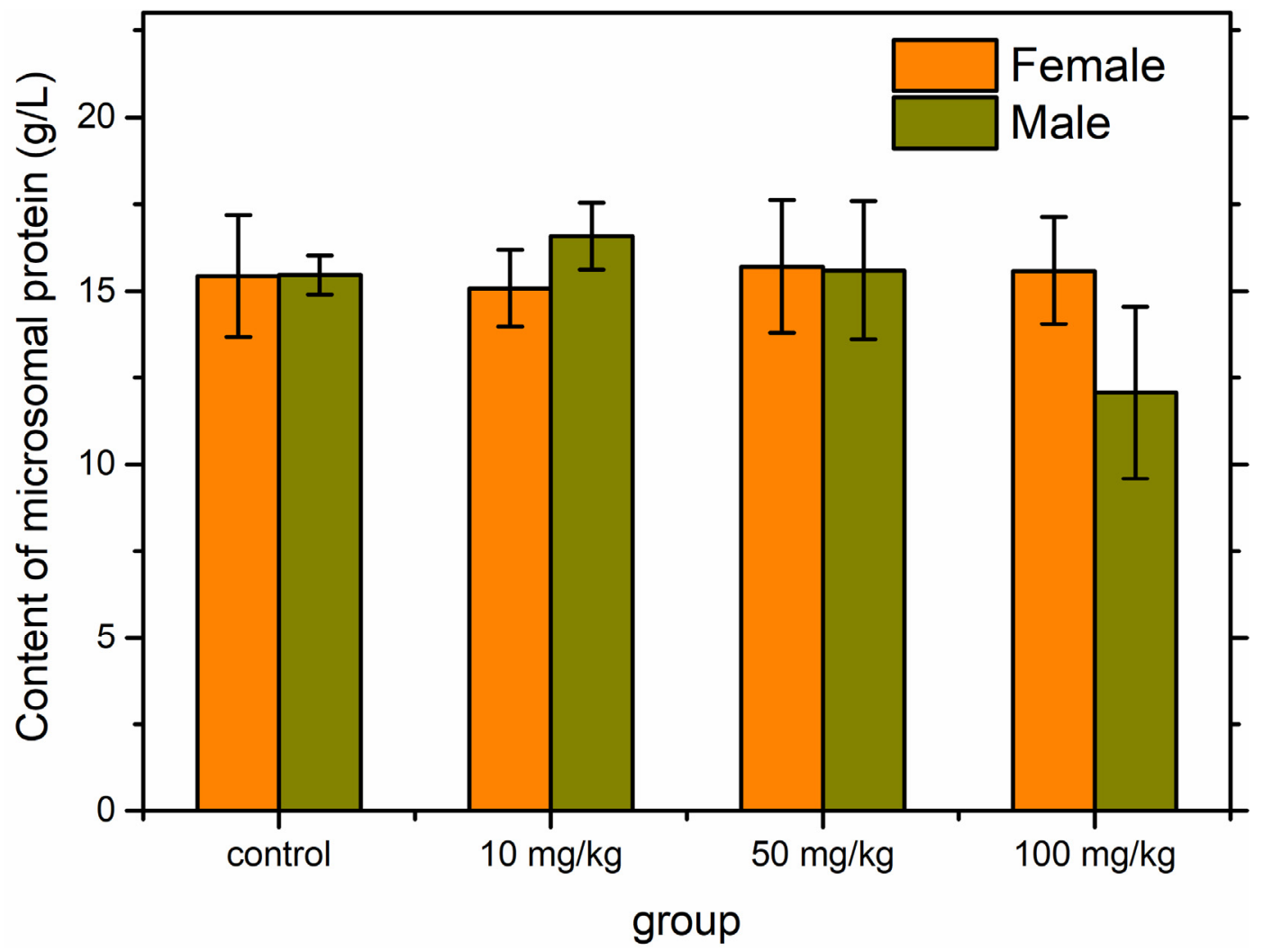

Figure S29. Comparison of the contents of liver microsomal proteins in the livers of SPF rats (10 rats per group containing 5 males and 5 females) after intravenous injections with sodium chloride injection (control, $0.9 \mathrm{wt} \%, 0.5 \mathrm{~mL}$ ) and the dispersant of the red-emitting $\mathrm{K}_{3} \mathrm{ZrF}_{7}: \mathrm{Yb} / \mathrm{Er} \mathrm{UCNCs}$ in sodium chloride injection with low dose of $10 \mathrm{mg} \mathrm{kg}^{-1}$, middle dose of $50 \mathrm{mg} \mathrm{kg}^{-1}$, and maximum dose of $100 \mathrm{mg} \mathrm{kg}^{-1}$. As compared in Figure S29, there was no appreciable difference in the content of liver microsomal proteins (or hepatic enzymes) in the livers of these intravenously injected rats despite their different injection dosages less than $100 \mathrm{mg} \mathrm{kg}^{-1}$, which unambiguously provides another solid proof to turn out the high biosafety of the red-emitting $\mathrm{K}_{3} \mathrm{ZrF}_{7}: \mathrm{Yb} / \mathrm{Er}$ UCNCs we prepared in vivo. 

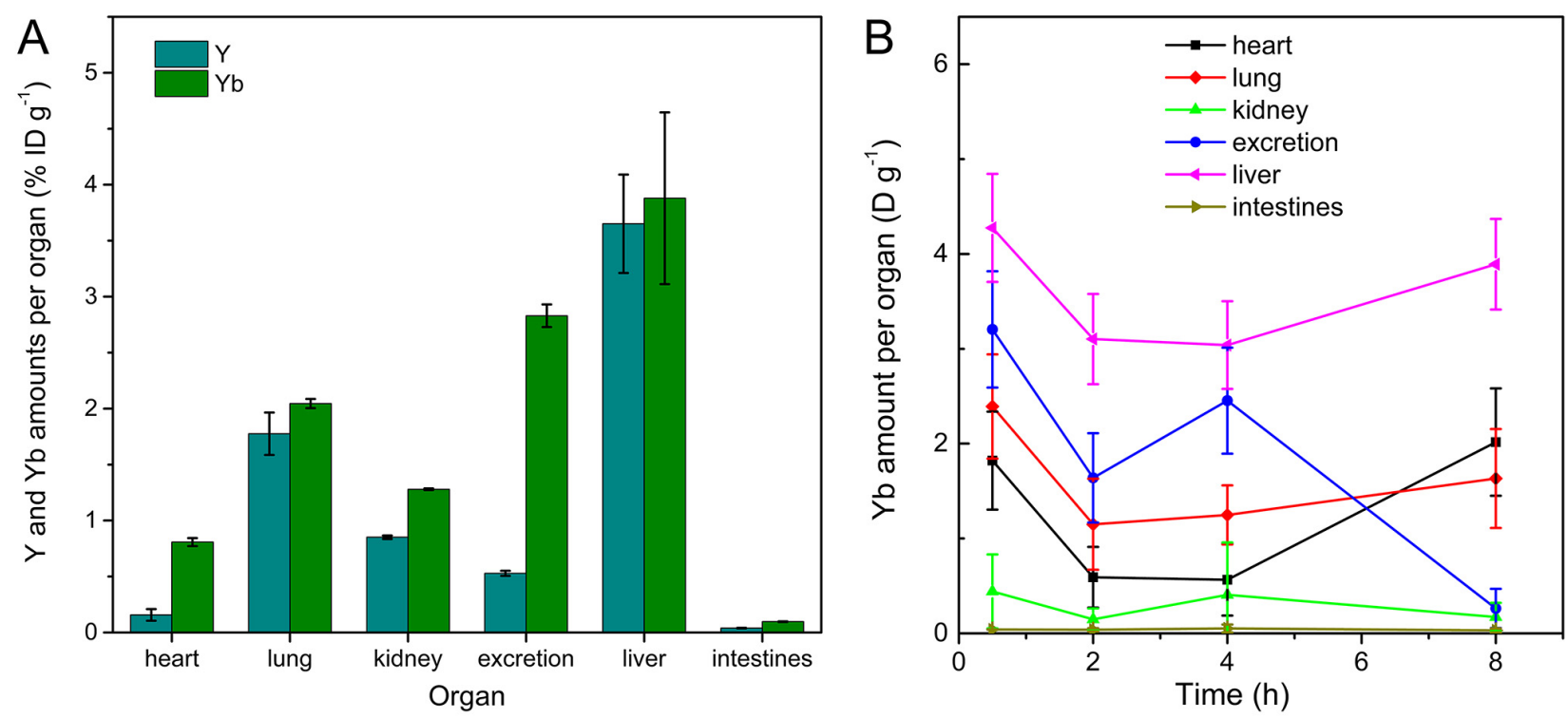

Figure S30. (A) In vivo biodistribution of $\mathrm{Y}$ and $\mathrm{Yb}$ in the main organs of SPF SD rats $(\mathrm{n}=5)$ after intravenously injected with $\sim 200 \mu \mathrm{L}$ sodium chloride injection of $\beta-\mathrm{NaYF}_{4}$ :Yb,Er UCNCs $(0.5$ $\mathrm{mg} / \mathrm{mL}$ ) over a period of $8 \mathrm{~h}$. (B) In vivo biodistribution of $\mathrm{Yb}$ from the degradation product of smallsized $(\sim 5 \mathrm{~nm}) \mathrm{KYb}_{3} \mathrm{~F}_{10}$ :Er in SPF SD rats $(\mathrm{n}=5)$ as a function of time after intravenously injected with $\sim 200 \mu \mathrm{L}$ sodium chloride injection of $\mathrm{K}_{3} \mathrm{ZrF}_{7}: \mathrm{Yb} / \mathrm{Er} \mathrm{UCNCs}(0.9 \mathrm{wt} \%, 0.5 \mathrm{mg} / \mathrm{mL})$. It should be noted that all the $\mathrm{Zr}, \mathrm{Yb}$ and $\mathrm{Y}$ concentrations in the main organs and excretions were determined at different time points after intravenous injection by using ICP-MS. Similar to the case of the $\beta$ $\mathrm{NaYF}_{4}: \mathrm{Yb}$,Er UCNCs, the small-sized $\mathrm{KYb}_{3} \mathrm{~F}_{10}$ :Er residues after the degradation of $\mathrm{K}_{3} \mathrm{ZrF}_{7}: \mathrm{Yb} / \mathrm{Er}$ UCNCs accumulate mainly in the organs of mice such as the liver and lung instead of excretion, which is totally different from the degradation product of $\mathrm{Zr}$ component from $\mathrm{K}_{3} \mathrm{ZrF}_{7}: \mathrm{Yb} / \mathrm{Er} \mathrm{UCNCs}$ that can be rapidly eliminated from the bodies of rats via excretion. These results strongly support that the clearance mechanism of $\mathrm{K}_{3} \mathrm{ZrF}_{7}: \mathrm{Yb} / \mathrm{Er} \mathrm{UCNCs}$ in vivo is primarily ascribed to the degradation of them into water-soluble $\left[\mathrm{ZrF}_{7}\right]^{3-}$ cluster in the bodies of mice followed by excretion. 


\section{Supplementary Tables}

Table S1. $\mathrm{pH}$ values for the aqueous solution of hydrolysates after the degradation of pure $\mathrm{K}_{3} \mathrm{ZrF}_{7}$ and $\mathrm{K}_{3} \mathrm{ZrF}_{7}: \mathrm{Yb} / \mathrm{Er}$ nanocrystals in pure water, determined from three parallel experiments.

\begin{tabular}{lcccc}
\hline & $\mathrm{pH}-1$ & $\mathrm{pH}-2$ & $\mathrm{pH}-3$ & $\mathrm{pH}$-average. \\
\hline $\mathrm{K}_{3} \mathrm{ZrF}_{7}: \mathrm{Yb} / \mathrm{Er}$ & 5.54 & 5.57 & 5.58 & $5.56 \pm 0.02$ \\
$\mathrm{~K}_{3} \mathrm{ZrF}_{7}$ & 5.69 & 5.75 & 5.76 & $5.73 \pm 0.04$ \\
\hline
\end{tabular}

Table S2. Summary table for the pathological changes of quadriceps femoris from 6-8-week-old SPF $\mathrm{SD}$ rats after intramuscular injection with the dispersant of $\mathrm{K}_{3} \mathrm{ZrF}_{7}: \mathrm{Yb} / \mathrm{Er} \mathrm{UCNCs}$ in $0.9 \mathrm{wt} \%$ sodium chloride injection $(0.5 \mathrm{~mL}, 100 \mu \mathrm{g} / \mathrm{mL})$ and $0.9 \mathrm{wt} \%$ sodium chloride injection $(0.5 \mathrm{~mL}$, as a control), through general and histopathological examinations. Sodium chloride injection $(0.9 \mathrm{wt} \%, 0.5 \mathrm{~mL})$ and the dispersant of $\mathrm{K}_{3} \mathrm{ZrF}_{7}: \mathrm{Yb} / \mathrm{Er} \mathrm{UCNCs}$ were intramuscularly injected to the left and right quadriceps femoris of the same rat via a self-contrast method, and the observation periods were set as $1,6,24$ and $72 \mathrm{~h}$, respectively, after intramuscular injection.

\begin{tabular}{|c|c|c|c|c|c|c|c|c|}
\hline & & \multicolumn{6}{|c|}{ Inflammatory cell infiltration } & \multirow{3}{*}{ Total } \\
\hline \multirow{2}{*}{\multicolumn{2}{|c|}{ Pathological changes }} & \multicolumn{3}{|c|}{ Muscle fiber } & \multicolumn{3}{|c|}{ Interstitial muscle } & \\
\hline & & $\pm^{\mathrm{a}}$ & + & ++ & \pm & + & ++ & \\
\hline \multirow{5}{*}{$\begin{array}{l}\text { Left quadriceps } \\
\text { femoris }^{\mathrm{b}}\end{array}$} & $1 \mathrm{~h}$ & 0 & 0 & 0 & 0 & 0 & 0 & 0 \\
\hline & $6 \mathrm{~h}$ & 0 & 0 & 0 & 1 & 0 & 1 & 2 \\
\hline & $24 \mathrm{~h}$ & 0 & 0 & 0 & 1 & 1 & 1 & 3 \\
\hline & $72 \mathrm{~h}$ & 2 & 1 & 0 & 1 & 1 & 0 & 5 \\
\hline & Total & 2 & 1 & 0 & 3 & 3 & 1 & l \\
\hline \multirow{5}{*}{$\begin{array}{l}\text { Right quadriceps } \\
\text { femoris }^{\mathrm{b}}\end{array}$} & $1 \mathrm{~h}$ & 0 & 0 & 0 & 0 & 0 & 0 & 0 \\
\hline & $6 \mathrm{~h}$ & 0 & 0 & 0 & 1 & 2 & 0 & 3 \\
\hline & $24 \mathrm{~h}$ & 0 & 0 & 0 & 1 & 2 & 0 & 3 \\
\hline & $72 \mathrm{~h}$ & 1 & 1 & 0 & 3 & 0 & 0 & 5 \\
\hline & Total & 1 & 1 & 0 & 5 & 4 & 0 & I \\
\hline
\end{tabular}

a Degree of lesion: \pm very slight, + slight, ++ mild; ${ }^{b}$ Number of experimental rats per group is 3 , namely, $\mathrm{n}=3$. As compared in Table S2, analogous to the controls only injected with normal saline $(0.5 \mathrm{~mL})$, ocular local stimulus and general side effects like swollen and red speckles were not observed at the injection sites of rats during the test period of $72 \mathrm{~h}$. Moreover, all the quadriceps femoris tissues have no obvious histopathological abnormities relative to their controls, implying that the quadriceps muscle tissues for all the experimental rats can rapidly recover to their normal morphology after injection, confirming the high biosafety of $\mathrm{K}_{3} \mathrm{ZrF} \mathrm{F}_{7}: \mathrm{Yb} / \mathrm{Er}$ UCNCs to muscles in vivo. 
Table S3. Clinical observations of individual SPF rat including poisoning symptom, poisoning time and duration from poisoning to recovery after intravenous injection with the dispersant of $\mathrm{K}_{3} \mathrm{ZrF}_{7}: \mathrm{Yb} / \mathrm{Er} \mathrm{UCNCs}$ in $0.9 \mathrm{wt} \%$ sodium chloride injection $(0.5 \mathrm{~mL}, 100 \mu \mathrm{g} / \mathrm{mL})$ at safe dosages of 0 (as a control), 10, 50 and $100 \mathrm{mg} \mathrm{kg}^{-1}$, during the first four hours of inspection.

\begin{tabular}{|c|c|c|c|c|c|c|c|c|}
\hline Group & No. & Gender & $\begin{array}{l}\text { Injection } \\
\text { time }\end{array}$ & $0 \sim 1 \mathrm{~h}$ & $2 \mathrm{~h}$ & $3 \mathrm{~h}$ & & $4 \mathrm{~h}$ \\
\hline \multirow{10}{*}{ Control group } & 1 & female & $11: 08$ & $\sqrt{\mathrm{a}}$ & $\sqrt{ }$ & $\sqrt{ }$ & & $\sqrt{ }$ \\
\hline & 2 & female & 11:09 & $\sqrt{ }$ & $\sqrt{ }$ & $\sqrt{ }$ & & $\sqrt{ }$ \\
\hline & 3 & female & $11: 10$ & $\sqrt{ }$ & $\sqrt{ }$ & $\sqrt{ }$ & & $\sqrt{ }$ \\
\hline & 4 & female & $11: 11$ & $\sqrt{ }$ & $\sqrt{ }$ & $\sqrt{ }$ & & $\sqrt{ }$ \\
\hline & 5 & female & $11: 11$ & $\sqrt{ }$ & $\sqrt{ }$ & $\sqrt{ }$ & & $\sqrt{ }$ \\
\hline & 6 & male & $11: 12$ & $\sqrt{ }$ & $\sqrt{ }$ & $\sqrt{ }$ & & $\sqrt{ }$ \\
\hline & 7 & male & $11: 13$ & $\sqrt{ }$ & $\sqrt{ }$ & $\sqrt{ }$ & & $\sqrt{ }$ \\
\hline & 8 & male & $11: 13$ & $\sqrt{ }$ & $\sqrt{ }$ & $\sqrt{ }$ & & $\sqrt{ }$ \\
\hline & 9 & male & $11: 14$ & $\sqrt{ }$ & $\sqrt{ }$ & $\sqrt{ }$ & & $\sqrt{ }$ \\
\hline & 10 & male & $11: 14$ & $\sqrt{ }$ & $\sqrt{ }$ & $\sqrt{ }$ & & $\sqrt{ }$ \\
\hline \multirow{10}{*}{$\begin{array}{l}\text { Maximum } \\
\text { dose group } \\
(100 \mathrm{mg} / \mathrm{kg})\end{array}$} & 11 & female & $11: 15$ & $\begin{array}{l}\text { 11:44 shiver } \\
\text { 11:52 hyperspasmia }\end{array}$ & & $\begin{array}{c}\text { less } \\
\text { activities }\end{array}$ & $\sqrt{ }$ & $\sqrt{ }$ \\
\hline & 12 & female & $11: 18$ & $\begin{array}{l}\text { 11:39 shiver } \\
11: 43 \text { shake }\end{array}$ & & $\begin{array}{c}\text { less } \\
\text { activities }\end{array}$ & $\sqrt{ }$ & $\sqrt{ }$ \\
\hline & 13 & female & $11: 19$ & 11:38-11:48 shiver & & $\begin{array}{c}\text { less } \\
\text { activities }\end{array}$ & $\sqrt{ }$ & $\sqrt{ }$ \\
\hline & 14 & female & $11: 21$ & 11:35-12:05 shiver & & $\begin{array}{c}\text { less } \\
\text { activities }\end{array}$ & $\sqrt{ }$ & $\sqrt{ }$ \\
\hline & 15 & female & $11: 23$ & 11:42 shiver & & $\begin{array}{c}\text { less } \\
\text { activities }\end{array}$ & $\sqrt{ }$ & $\sqrt{ }$ \\
\hline & 16 & male & $11: 25$ & $\begin{array}{l}\text { 11:39 shiver } \\
\text { 11:52 hyperspasmia }\end{array}$ & & $\begin{array}{c}\text { less } \\
\text { activities }\end{array}$ & $\sqrt{ }$ & $\sqrt{ }$ \\
\hline & 17 & male & $11: 26$ & $\begin{array}{l}\text { 11:39 shake } \\
\text { 11:48 shiver }\end{array}$ & & $\begin{array}{c}\text { less } \\
\text { activities }\end{array}$ & $\sqrt{ }$ & $\sqrt{ }$ \\
\hline & 18 & male & $11: 27$ & $\begin{array}{l}\text { 11:39 shiver } \\
\text { 11:50 hyperspasmia }\end{array}$ & & $\begin{array}{c}\text { less } \\
\text { activities }\end{array}$ & $\sqrt{ }$ & $\sqrt{ }$ \\
\hline & 19 & male & $11: 28$ & sedation & & $\sqrt{ }$ & $\sqrt{ }$ & $\sqrt{ }$ \\
\hline & 20 & male & $11: 29$ & sedation & & $\sqrt{ }$ & $\sqrt{ }$ & $\sqrt{ }$ \\
\hline
\end{tabular}

${ }^{\mathrm{a}}$ The check mark $(\sqrt{ })$ represents that the behavior of experimental rat is in normal condition after intravenous injection. 
Table S3 (continued).

\begin{tabular}{|c|c|c|c|c|c|c|c|}
\hline Group & No. & Gender & $\begin{array}{l}\text { Injection } \\
\text { time }\end{array}$ & $0 \sim 1 \mathrm{~h}$ & $2 \mathrm{~h}$ & $3 \mathrm{~h}$ & $4 \mathrm{~h}$ \\
\hline \multirow{10}{*}{$\begin{array}{l}\text { Middle dose } \\
\text { group } \\
(50 \mathrm{mg} / \mathrm{kg})\end{array}$} & 21 & female & $11: 30$ & $\sqrt{ } a^{a}$ & $\sqrt{ }$ & $\sqrt{ }$ & $\sqrt{ }$ \\
\hline & 22 & female & $11: 31$ & $\sqrt{ }$ & $\sqrt{ }$ & $\sqrt{ }$ & $\sqrt{ }$ \\
\hline & 23 & female & $11: 32$ & 11:46 shiver & less activities & $\sqrt{ }$ & $\sqrt{ }$ \\
\hline & 24 & female & $11: 32$ & $\sqrt{ }$ & $\sqrt{ }$ & $\sqrt{ }$ & $\sqrt{ }$ \\
\hline & 25 & female & $11: 33$ & $\sqrt{ }$ & $\sqrt{ }$ & $\sqrt{ }$ & $\sqrt{ }$ \\
\hline & 26 & male & $11: 34$ & $\begin{array}{l}\text { 12:04 hyperspasmia } \\
12: 08 \text { death } * \mathrm{~b}\end{array}$ & $*$ & $*$ & $*$ \\
\hline & 27 & male & $11: 35$ & $\sqrt{ }$ & $\sqrt{ }$ & $\sqrt{ }$ & $\sqrt{ }$ \\
\hline & 28 & male & 1136: & $\sqrt{ }$ & $\sqrt{ }$ & $\sqrt{ }$ & $\sqrt{ }$ \\
\hline & 29 & male & $11: 37$ & $\sqrt{ }$ & $\sqrt{ }$ & $\sqrt{ }$ & $\sqrt{ }$ \\
\hline & 30 & male & $11: 38$ & $\sqrt{ }$ & $\sqrt{ }$ & $\sqrt{ }$ & $\sqrt{ }$ \\
\hline \multirow{10}{*}{$\begin{array}{l}\text { Low dose } \\
\text { group } \\
(10 \mathrm{mg} / \mathrm{kg})\end{array}$} & 31 & female & 11:40 & $\sqrt{ }$ & $\sqrt{ }$ & $\sqrt{ }$ & $\sqrt{ }$ \\
\hline & 32 & female & $11: 40$ & $\sqrt{ }$ & $\sqrt{ }$ & $\sqrt{ }$ & $\sqrt{ }$ \\
\hline & 33 & female & $11: 41$ & $\sqrt{ }$ & $\sqrt{ }$ & $\sqrt{ }$ & $\sqrt{ }$ \\
\hline & 34 & female & $11: 41$ & $\sqrt{ }$ & $\sqrt{ }$ & $\sqrt{ }$ & $\sqrt{ }$ \\
\hline & 35 & female & $11: 42$ & $\sqrt{ }$ & $\sqrt{ }$ & $\sqrt{ }$ & $\sqrt{ }$ \\
\hline & 36 & male & $11: 43$ & $\sqrt{ }$ & $\sqrt{ }$ & $\sqrt{ }$ & $\sqrt{ }$ \\
\hline & 37 & male & $11: 44$ & $\sqrt{ }$ & $\sqrt{ }$ & $\sqrt{ }$ & $\sqrt{ }$ \\
\hline & 38 & male & $11: 45$ & $\sqrt{ }$ & $\sqrt{ }$ & $\sqrt{ }$ & $\sqrt{ }$ \\
\hline & 39 & male & $11: 45$ & $\sqrt{ }$ & $\sqrt{ }$ & $\sqrt{ }$ & $\sqrt{ }$ \\
\hline & 40 & male & $11: 46$ & $\sqrt{ }$ & $\sqrt{ }$ & $\sqrt{ }$ & $\sqrt{ }$ \\
\hline
\end{tabular}

${ }^{\mathrm{b}}$ The asterisk $(*)$ represents that the experimental rat is dead at the indicated time after intravenous injection.

Table S4. Clinical observations of individual SPF rat after intravenous injection with the dispersant of $\mathrm{K}_{3} \mathrm{ZrF}_{7}: \mathrm{Yb} / \mathrm{Er} \mathrm{UCNCs}$ in $0.9 \mathrm{wt} \%$ sodium chloride injection $(0.5 \mathrm{~mL}, 100 \mu \mathrm{g} / \mathrm{mL})$ at safe dosages of 0 (as a control), 10, 50 and $100 \mathrm{mg} \mathrm{kg}^{-1}$, during a 15-day period under observation.

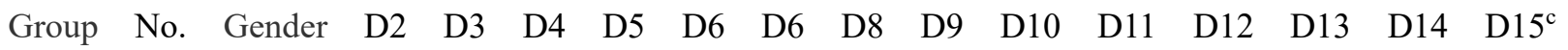

\begin{tabular}{|c|c|c|c|c|c|c|c|c|c|c|c|c|c|c|c|c|}
\hline \multirow{4}{*}{$\begin{array}{l}\tilde{F} \\
0 \\
\text { b. } \\
0 \\
0 \\
0 \\
0 \\
0\end{array}$} & 1 & female & $\sqrt{\mathrm{a}}$ & $\sqrt{ }$ & $\sqrt{ }$ & $\sqrt{ }$ & $\sqrt{ }$ & $\sqrt{ }$ & $\sqrt{ }$ & $\sqrt{ }$ & $\sqrt{ }$ & $\sqrt{ }$ & $\sqrt{ }$ & $\sqrt{ }$ & $\sqrt{ }$ & $\sqrt{ }$ \\
\hline & 2 & female & $\sqrt{ }$ & $\sqrt{ }$ & $\sqrt{ }$ & $\sqrt{ }$ & $\sqrt{ }$ & $\sqrt{ }$ & $\sqrt{ }$ & $\sqrt{ }$ & $\sqrt{ }$ & $\sqrt{ }$ & $\sqrt{ }$ & $\sqrt{ }$ & $\sqrt{ }$ & $\sqrt{ }$ \\
\hline & 3 & female & $\sqrt{ }$ & $\sqrt{ }$ & $\sqrt{ }$ & $\sqrt{ }$ & $\sqrt{ }$ & $\sqrt{ }$ & $\sqrt{ }$ & $\sqrt{ }$ & $\sqrt{ }$ & $\sqrt{ }$ & $\sqrt{ }$ & $\sqrt{ }$ & $\sqrt{ }$ & $\sqrt{ }$ \\
\hline & 4 & female & $\sqrt{ }$ & $\sqrt{ }$ & $\sqrt{ }$ & $\sqrt{ }$ & $\sqrt{ }$ & $\sqrt{ }$ & $\sqrt{ }$ & $\sqrt{ }$ & $\sqrt{ }$ & $\sqrt{ }$ & $\sqrt{ }$ & $\sqrt{ }$ & $\sqrt{ }$ & $\sqrt{ }$ \\
\hline
\end{tabular}




\begin{tabular}{|c|c|c|c|c|c|c|c|c|c|c|c|c|c|c|c|c|}
\hline & 5 & female & $\sqrt{ }$ & $\sqrt{ }$ & $\sqrt{ }$ & $\sqrt{ }$ & $\sqrt{ }$ & $\sqrt{ }$ & $\sqrt{ }$ & $\sqrt{ }$ & $\sqrt{ }$ & $\sqrt{ }$ & $\sqrt{ }$ & $\sqrt{ }$ & $\sqrt{ }$ & $\sqrt{ }$ \\
\hline & 6 & male & $\sqrt{ }$ & $\sqrt{ }$ & $\sqrt{ }$ & $\sqrt{ }$ & $\sqrt{ }$ & $\sqrt{ }$ & $\sqrt{ }$ & $\sqrt{ }$ & $\sqrt{ }$ & $\sqrt{ }$ & $\sqrt{ }$ & $\sqrt{ }$ & $\sqrt{ }$ & $\sqrt{ }$ \\
\hline & 7 & male & $\sqrt{ }$ & $\sqrt{ }$ & $\sqrt{ }$ & $\sqrt{ }$ & $\sqrt{ }$ & $\sqrt{ }$ & $\sqrt{ }$ & $\sqrt{ }$ & $\sqrt{ }$ & $\sqrt{ }$ & $\sqrt{ }$ & $\sqrt{ }$ & $\sqrt{ }$ & $\sqrt{ }$ \\
\hline & 8 & male & $\sqrt{ }$ & $\sqrt{ }$ & $\sqrt{ }$ & $\sqrt{ }$ & $\sqrt{ }$ & $\sqrt{ }$ & $\sqrt{ }$ & $\sqrt{ }$ & $\sqrt{ }$ & $\sqrt{ }$ & $\sqrt{ }$ & $\sqrt{ }$ & $\sqrt{ }$ & $\sqrt{ }$ \\
\hline & 9 & male & $\sqrt{ }$ & $\sqrt{ }$ & $\sqrt{ }$ & $\sqrt{ }$ & $\sqrt{ }$ & $\sqrt{ }$ & $\sqrt{ }$ & $\sqrt{ }$ & $\sqrt{ }$ & $\sqrt{ }$ & $\sqrt{ }$ & $\sqrt{ }$ & $\sqrt{ }$ & $\sqrt{ }$ \\
\hline & 10 & male & $\sqrt{ }$ & $\sqrt{ }$ & $\sqrt{ }$ & $\sqrt{ }$ & $\sqrt{ }$ & $\sqrt{ }$ & $\sqrt{ }$ & $\sqrt{ }$ & $\sqrt{ }$ & $\sqrt{ }$ & $\sqrt{ }$ & $\sqrt{ }$ & $\sqrt{ }$ & $\sqrt{ }$ \\
\hline \multirow{10}{*}{ 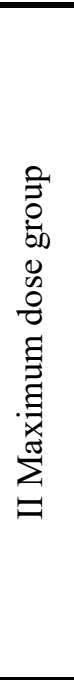 } & 11 & female & $\sqrt{ }$ & $\sqrt{ }$ & $\sqrt{ }$ & $\sqrt{ }$ & $\sqrt{ }$ & $\sqrt{ }$ & $\sqrt{ }$ & $\sqrt{ }$ & $\sqrt{ }$ & $\sqrt{ }$ & $\sqrt{ }$ & $\sqrt{ }$ & $\sqrt{ }$ & $\sqrt{ }$ \\
\hline & 12 & female & $\sqrt{ }$ & $\sqrt{ }$ & $\sqrt{ }$ & $\sqrt{ }$ & $\sqrt{ }$ & $\sqrt{ }$ & $\sqrt{ }$ & $\sqrt{ }$ & $\sqrt{ }$ & $\sqrt{ }$ & $\sqrt{ }$ & $\sqrt{ }$ & $\sqrt{ }$ & $\sqrt{ }$ \\
\hline & 13 & female & $\sqrt{ }$ & $\sqrt{ }$ & $\sqrt{ }$ & $\sqrt{ }$ & $\sqrt{ }$ & $\sqrt{ }$ & $\sqrt{ }$ & $\sqrt{ }$ & $\sqrt{ }$ & $\sqrt{ }$ & $\sqrt{ }$ & $\sqrt{ }$ & $\sqrt{ }$ & $\sqrt{ }$ \\
\hline & 14 & female & $\sqrt{ }$ & $\sqrt{ }$ & $\sqrt{ }$ & $\sqrt{ }$ & $\sqrt{ }$ & $\sqrt{ }$ & $\sqrt{ }$ & $\sqrt{ }$ & $\sqrt{ }$ & $\sqrt{ }$ & $\sqrt{ }$ & $\sqrt{ }$ & $\sqrt{ }$ & $\sqrt{ }$ \\
\hline & 15 & female & $\sqrt{ }$ & $\sqrt{ }$ & $\sqrt{ }$ & $\sqrt{ }$ & $\sqrt{ }$ & $\sqrt{ }$ & $\sqrt{ }$ & $\sqrt{ }$ & $\sqrt{ }$ & $\sqrt{ }$ & $\sqrt{ }$ & $\sqrt{ }$ & $\sqrt{ }$ & $\sqrt{ }$ \\
\hline & 16 & male & $\sqrt{ }$ & $\sqrt{ }$ & $\sqrt{ }$ & $\sqrt{ }$ & $\sqrt{ }$ & $\sqrt{ }$ & $\sqrt{ }$ & $\sqrt{ }$ & $\sqrt{ }$ & $\sqrt{ }$ & $\sqrt{ }$ & $\sqrt{ }$ & $\sqrt{ }$ & $\sqrt{ }$ \\
\hline & 17 & male & $\sqrt{ }$ & $\sqrt{ }$ & $\sqrt{ }$ & $\sqrt{ }$ & $\sqrt{ }$ & $\sqrt{ }$ & $\sqrt{ }$ & $\sqrt{ }$ & $\sqrt{ }$ & $\sqrt{ }$ & $\sqrt{ }$ & $\sqrt{ }$ & $\sqrt{ }$ & $\sqrt{ }$ \\
\hline & 18 & male & $\sqrt{ }$ & $\sqrt{ }$ & $\sqrt{ }$ & $\sqrt{ }$ & $\sqrt{ }$ & $\sqrt{ }$ & $\sqrt{ }$ & $\sqrt{ }$ & $\sqrt{ }$ & $\sqrt{ }$ & $\sqrt{ }$ & $\sqrt{ }$ & $\sqrt{ }$ & $\sqrt{ }$ \\
\hline & 19 & male & $\sqrt{ }$ & $\sqrt{ }$ & $\sqrt{ }$ & $\sqrt{ }$ & $\sqrt{ }$ & $\sqrt{ }$ & $\sqrt{ }$ & $\sqrt{ }$ & $\sqrt{ }$ & $\sqrt{ }$ & $\sqrt{ }$ & $\sqrt{ }$ & $\sqrt{ }$ & $\sqrt{ }$ \\
\hline & 20 & male & $\sqrt{ }$ & $\sqrt{ }$ & $\sqrt{ }$ & $\sqrt{ }$ & $\sqrt{ }$ & $\sqrt{ }$ & $\sqrt{ }$ & $\sqrt{ }$ & $\sqrt{ }$ & $\sqrt{ }$ & $\sqrt{ }$ & $\sqrt{ }$ & $\sqrt{ }$ & $\sqrt{ }$ \\
\hline \multirow{10}{*}{ 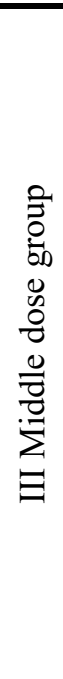 } & 21 & female & $\sqrt{ }$ & $\sqrt{ }$ & $\sqrt{ }$ & $\sqrt{ }$ & $\sqrt{ }$ & $\sqrt{ }$ & $\sqrt{ }$ & $\sqrt{ }$ & $\sqrt{ }$ & $\sqrt{ }$ & $\sqrt{ }$ & $\sqrt{ }$ & $\sqrt{ }$ & $\sqrt{ }$ \\
\hline & 22 & female & $\sqrt{ }$ & $\sqrt{ }$ & $\sqrt{ }$ & $\sqrt{ }$ & $\sqrt{ }$ & $\sqrt{ }$ & $\sqrt{ }$ & $\sqrt{ }$ & $\sqrt{ }$ & $\sqrt{ }$ & $\sqrt{ }$ & $\sqrt{ }$ & $\sqrt{ }$ & $\sqrt{ }$ \\
\hline & 23 & female & $\sqrt{ }$ & $\sqrt{ }$ & $\sqrt{ }$ & $\sqrt{ }$ & $\sqrt{ }$ & $\sqrt{ }$ & $\sqrt{ }$ & $\sqrt{ }$ & $\sqrt{ }$ & $\sqrt{ }$ & $\sqrt{ }$ & $\sqrt{ }$ & $\sqrt{ }$ & $\sqrt{ }$ \\
\hline & 24 & female & $\sqrt{ }$ & $\sqrt{ }$ & $\sqrt{ }$ & $\sqrt{ }$ & $\sqrt{ }$ & $\sqrt{ }$ & $\sqrt{ }$ & $\sqrt{ }$ & $\sqrt{ }$ & $\sqrt{ }$ & $\sqrt{ }$ & $\sqrt{ }$ & $\sqrt{ }$ & $\sqrt{ }$ \\
\hline & 25 & female & $\sqrt{ }$ & $\sqrt{ }$ & $\sqrt{ }$ & $\sqrt{ }$ & $\sqrt{ }$ & $\sqrt{ }$ & $\sqrt{ }$ & $\sqrt{ }$ & $\sqrt{ }$ & $\sqrt{ }$ & $\sqrt{ }$ & $\sqrt{ }$ & $\sqrt{ }$ & $\sqrt{ }$ \\
\hline & 26 & male & $* \mathrm{~b}$ & $*$ & $*$ & $*$ & $*$ & $*$ & $*$ & * & $*$ & $*$ & * & $*$ & $*$ & * \\
\hline & 27 & male & $\sqrt{ }$ & $\sqrt{ }$ & $\sqrt{ }$ & $\sqrt{ }$ & $\sqrt{ }$ & $\sqrt{ }$ & $\sqrt{ }$ & $\sqrt{ }$ & $\sqrt{ }$ & $\sqrt{ }$ & $\sqrt{ }$ & $\sqrt{ }$ & $\sqrt{ }$ & $\sqrt{ }$ \\
\hline & 28 & male & $\sqrt{ }$ & $\sqrt{ }$ & $\sqrt{ }$ & $\sqrt{ }$ & $\sqrt{ }$ & $\sqrt{ }$ & $\sqrt{ }$ & $\sqrt{ }$ & $\sqrt{ }$ & $\sqrt{ }$ & $\sqrt{ }$ & $\sqrt{ }$ & $\sqrt{ }$ & $\sqrt{ }$ \\
\hline & 29 & male & $\sqrt{ }$ & $\sqrt{ }$ & $\sqrt{ }$ & $\sqrt{ }$ & $\sqrt{ }$ & $\sqrt{ }$ & $\sqrt{ }$ & $\sqrt{ }$ & $\sqrt{ }$ & $\sqrt{ }$ & $\sqrt{ }$ & $\sqrt{ }$ & $\sqrt{ }$ & $\sqrt{ }$ \\
\hline & 30 & male & $\sqrt{ }$ & $\sqrt{ }$ & $\sqrt{ }$ & $\sqrt{ }$ & $\sqrt{ }$ & $\sqrt{ }$ & $\sqrt{ }$ & $\sqrt{ }$ & $\sqrt{ }$ & $\sqrt{ }$ & $\sqrt{ }$ & $\sqrt{ }$ & $\sqrt{ }$ & $\sqrt{ }$ \\
\hline \multirow{10}{*}{ 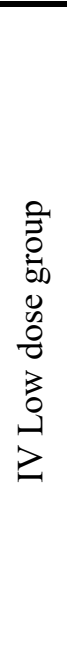 } & 31 & female & $\sqrt{ }$ & $\sqrt{ }$ & $\sqrt{ }$ & $\sqrt{ }$ & $\sqrt{ }$ & $\sqrt{ }$ & $\sqrt{ }$ & $\sqrt{ }$ & $\sqrt{ }$ & $\sqrt{ }$ & $\sqrt{ }$ & $\sqrt{ }$ & $\sqrt{ }$ & $\sqrt{ }$ \\
\hline & 32 & female & $\sqrt{ }$ & $\sqrt{ }$ & $\sqrt{ }$ & $\sqrt{ }$ & $\sqrt{ }$ & $\sqrt{ }$ & $\sqrt{ }$ & $\sqrt{ }$ & $\sqrt{ }$ & $\sqrt{ }$ & $\sqrt{ }$ & $\sqrt{ }$ & $\sqrt{ }$ & $\sqrt{ }$ \\
\hline & 33 & female & $\sqrt{ }$ & $\sqrt{ }$ & $\sqrt{ }$ & $\sqrt{ }$ & $\sqrt{ }$ & $\sqrt{ }$ & $\sqrt{ }$ & $\sqrt{ }$ & $\sqrt{ }$ & $\sqrt{ }$ & $\sqrt{ }$ & $\sqrt{ }$ & $\sqrt{ }$ & $\sqrt{ }$ \\
\hline & 34 & female & $\sqrt{ }$ & $\sqrt{ }$ & $\sqrt{ }$ & $\sqrt{ }$ & $\sqrt{ }$ & $\sqrt{ }$ & $\sqrt{ }$ & $\sqrt{ }$ & $\sqrt{ }$ & $\sqrt{ }$ & $\sqrt{ }$ & $\sqrt{ }$ & $\sqrt{ }$ & $\sqrt{ }$ \\
\hline & 35 & female & $\sqrt{ }$ & $\sqrt{ }$ & $\sqrt{ }$ & $\sqrt{ }$ & $\sqrt{ }$ & $\sqrt{ }$ & $\sqrt{ }$ & $\sqrt{ }$ & $\sqrt{ }$ & $\sqrt{ }$ & $\sqrt{ }$ & $\sqrt{ }$ & $\sqrt{ }$ & $\sqrt{ }$ \\
\hline & 36 & male & $\sqrt{ }$ & $\sqrt{ }$ & $\sqrt{ }$ & $\sqrt{ }$ & $\sqrt{ }$ & $\sqrt{ }$ & $\sqrt{ }$ & $\sqrt{ }$ & $\sqrt{ }$ & $\sqrt{ }$ & $\sqrt{ }$ & $\sqrt{ }$ & $\sqrt{ }$ & $\sqrt{ }$ \\
\hline & 37 & male & $\sqrt{ }$ & $\sqrt{ }$ & $\sqrt{ }$ & $\sqrt{ }$ & $\sqrt{ }$ & $\sqrt{ }$ & $\sqrt{ }$ & $\sqrt{ }$ & $\sqrt{ }$ & $\sqrt{ }$ & $\sqrt{ }$ & $\sqrt{ }$ & $\sqrt{ }$ & $\sqrt{ }$ \\
\hline & 38 & male & $\sqrt{ }$ & $\sqrt{ }$ & $\sqrt{ }$ & $\sqrt{ }$ & $\sqrt{ }$ & $\sqrt{ }$ & $\sqrt{ }$ & $\sqrt{ }$ & $\sqrt{ }$ & $\sqrt{ }$ & $\sqrt{ }$ & $\sqrt{ }$ & $\sqrt{ }$ & $\sqrt{ }$ \\
\hline & 39 & male & $\sqrt{ }$ & $\sqrt{ }$ & $\sqrt{ }$ & $\sqrt{ }$ & $\sqrt{ }$ & $\sqrt{ }$ & $\sqrt{ }$ & $\sqrt{ }$ & $\sqrt{ }$ & $\sqrt{ }$ & $\sqrt{ }$ & $\sqrt{ }$ & $\sqrt{ }$ & $\sqrt{ }$ \\
\hline & 40 & male & $\sqrt{ }$ & $\sqrt{ }$ & $\sqrt{ }$ & $\sqrt{ }$ & $\sqrt{ }$ & $\sqrt{ }$ & $\sqrt{ }$ & $\sqrt{ }$ & $\sqrt{ }$ & $\sqrt{ }$ & $\sqrt{ }$ & $\sqrt{ }$ & $\sqrt{ }$ & $\sqrt{ }$ \\
\hline
\end{tabular}

$\sqrt{a} \sqrt{\text { normal; }}{ }^{\mathrm{b} *}$ dead; D2-D15 represent the number of days under observation. 
Table S5. Weight statistics of female mice at the first, eighth and fifteenth days after intravenous injection of the dispersant of $\mathrm{K}_{3} \mathrm{ZrF}_{7}: \mathrm{Yb} / \mathrm{Er} \mathrm{UCNCs}$ in $0.9 \mathrm{wt} \%$ sodium chloride injection at safe dosages of 0 (control), 10,50 and $100 \mathrm{mg} \mathrm{kg}^{-1}$, respectively $(\mathrm{g}, \bar{x} \pm \mathrm{s}, \mathrm{n}=5)$.

\begin{tabular}{lccc}
\hline \multicolumn{1}{c}{ Group } & D1 & D8 & D15 \\
\hline $\begin{array}{l}\text { Control group } \\
(0.9 \% \text { sodium chloride injection })\end{array}$ & $19.7 \pm 0.6$ & $22.8 \pm 1.4$ & $24.4 \pm 1.7$ \\
$\begin{array}{l}\text { Maximum dose group } \\
\left(100 \mathrm{mg} \mathrm{kg}^{-1}\right)\end{array}$ & $19.7 \pm 0.6$ & $23.6 \pm 0.9$ & $26.0 \pm 1.4$ \\
$\begin{array}{l}\text { Middle dose group } \\
\left(50 \mathrm{mg} \mathrm{kg}^{-1}\right)\end{array}$ & $19.6 \pm 0.6$ & $23.2 \pm 1.0$ & $24.8 \pm 1.3$ \\
$\begin{array}{l}\text { Low dose group } \\
\left(10 \mathrm{mg} \mathrm{kg}^{-1}\right)\end{array}$ & $19.6 \pm 0.5$ & $24.0 \pm 1.4$ & $25.6 \pm 1.7$ \\
\hline
\end{tabular}

Table S6. Weight statistics of male mice at the first, eighth and fifteenth days after intravenous injection of the dispersant of $\mathrm{K}_{3} \mathrm{ZrF}_{7}: \mathrm{Yb} / \mathrm{Er} \mathrm{UCNCs}$ in $0.9 \mathrm{wt} \%$ sodium chloride injection at safe dosages of 0 (control), 10, 50 and $100 \mathrm{mg} \mathrm{kg}^{-1}$, respectively $(\mathrm{g}, \bar{x} \pm \mathrm{s}, \mathrm{n}=5)$.

\begin{tabular}{lccc}
\hline \multicolumn{1}{c}{ Group } & D1 & D8 & D15 \\
\hline Control group & $21.3 \pm 0.7$ & $28.0 \pm 1.8$ & $32.0 \pm 2.3$ \\
$\begin{array}{l}\text { Maximum dose group } \\
\left(100 \mathrm{mg} \mathrm{kg}^{-1}\right)\end{array}$ & $21.4 \pm 0.6$ & $27.4 \pm 1.8$ & $32.8 \pm 2.3$ \\
$\begin{array}{l}\text { Middle dose group } \\
\left(50 \mathrm{mg} \mathrm{kg}^{-1}\right)\end{array}$ & $21.3 \pm 1.0$ & $29.0 \pm 2.1$ & $32.7 \pm 2.4$ \\
$\begin{array}{l}\text { Low dose group } \\
\left(10 \mathrm{mg} \mathrm{kg}^{-1}\right)\end{array}$ & $21.2 \pm 0.8$ & $28.0 \pm 2.1$ & $32.2 \pm 3.2$ \\
\hline
\end{tabular}

\section{IV.References}

(1) Fu, H. H.; Peng, P. F.; Li, R. F.; Liu, C. P.; Liu, Y. S.; Jiang, F. L.; Hong, M. C.; Chen, X. Y., A General Strategy for Tailoring Upconversion Luminescence in Lanthanide-Doped Inorganic Nanocrystals through Local Structure Engineering. Nanoscale 2018, 10, 9353-9359.

(2) Hampson, G. C.; Pauling, L., The Structure of Ammonium Heptafluozirconate and Potassium 
Heptafluozirconate and the Configuration of the Heptafluozirconate Group. J. Am. Chem. Soc. 1938, 60, 27022707.

(3) Misyul, S. V.; Mel'nikova, S. V.; Bovina, A. F.; Laptash, N. M., Optical and X-Ray Diffraction Studies of the Symmetry of Distorted Phases of the $\left(\mathrm{NH}_{4}\right)_{3} \mathrm{ZrF}_{7}$ Crystal. Phys. Solid State 2008, 50, 1951-1956.

(4) Reynhardt, E. C.; Pratt, J. C.; Watton, A.; Petch, H. E., NMR-Study of Molecular Motions and Disorder in $\mathrm{K}_{3} \mathrm{ZrF}_{7}$ and $\mathrm{K}_{2} \mathrm{TaF}_{7}$. J. Phys. C Solid State 1981, 14, 4701-4715.

(5) Voit, E. I.; Didenko, N. A.; Galkin, K. N., Vibrational Spectra of Zirconium Fluoride Complexes with Different Structures of Anionic Sublattice. Opt. Spectrosc. 2015, 118, 114-124.

(6) Liu, Y. S.; Tu, D. T.; Zhu, H. M.; Li, R. F.; Luo, W. Q.; Chen, X. Y., A Strategy to Achieve Efficient DualMode Luminescence of $\mathrm{Eu}^{3+}$ in Lanthanides Doped Multifunctional $\mathrm{NaGdF}_{4}$ Nanocrystals. Adv. Mater. 2010, 22, 3266-3271.

(7) Bogdan, N.; Vetrone, F.; Ozin, G. A.; Capobianco, J. A., Synthesis of Ligand-Free Colloidally Stable Water Dispersible Brightly Luminescent Lanthanide-Doped Upconverting Nanoparticles. Nano Lett. 2011, 11, 835840.

(8) Luo, W. Q.; Wu, H. Y.; Li, B., Localization Induced Intense Red Upconversion Luminescence in Monodispersed $\mathrm{K}_{3} \mathrm{ZrF}_{7}: \mathrm{Yb}^{3+} / \mathrm{Er}^{3+}$ Nanocrystals. Chem. Phys. Lett. 2016, 658, 215-219. 